\title{
Individual assessment of children with profound intellectual and multiple disabilities by means of event-related brain potentials
}

Citation for published version (APA):

Brinkman, M. J. R. (2009). Individual assessment of children with profound intellectual and multiple disabilities by means of event-related brain potentials. [Doctoral Thesis, Maastricht University]. Universitaire Pers Maastricht. https://doi.org/10.26481/dis.20090619mb

Document status and date:

Published: 01/01/2009

DOI:

10.26481/dis.20090619mb

Document Version:

Publisher's PDF, also known as Version of record

Please check the document version of this publication:

- A submitted manuscript is the version of the article upon submission and before peer-review. There can be important differences between the submitted version and the official published version of record. People interested in the research are advised to contact the author for the final version of the publication, or visit the DOI to the publisher's website.

- The final author version and the galley proof are versions of the publication after peer review.

- The final published version features the final layout of the paper including the volume, issue and page numbers.

Link to publication

\footnotetext{
General rights rights.

- You may freely distribute the URL identifying the publication in the public portal. please follow below link for the End User Agreement:

www.umlib.nl/taverne-license

Take down policy

If you believe that this document breaches copyright please contact us at:

repository@maastrichtuniversity.nl

providing details and we will investigate your claim.
}

Copyright and moral rights for the publications made accessible in the public portal are retained by the authors and/or other copyright owners and it is a condition of accessing publications that users recognise and abide by the legal requirements associated with these

- Users may download and print one copy of any publication from the public portal for the purpose of private study or research.

- You may not further distribute the material or use it for any profit-making activity or commercial gain

If the publication is distributed under the terms of Article $25 \mathrm{fa}$ of the Dutch Copyright Act, indicated by the "Taverne" license above, 
Individual Assessment of Children with Profound Intellectual and Multiple Disabilities by means of Event-related Brain Potentials 
(c) copyright M.J.R. Brinkman, ELSLOO 2009

Omslagontwerp: Wiesje Verkoeijen (7 jaar) en Datawyse Druk: Datawyse

Universitaire Pers $M$ aastricht

ISBN 978-90-5278-830-2 


\title{
Individual Assessment of Children with Profound Intellectual and Multiple Disabilities by means of Event-related Brain Potentials
}

\author{
PROEFSCHRIFT \\ ter verkrijging van de graad van doctor aan de Universiteit Maastricht, \\ op gezag van de Rector Magnificus, Prof. mr. G.P.M .F. Mols, \\ volgens het besluit van het College van Decanen, \\ in het openbaar te verdedigen \\ op vrijdag 19 juni 2009 om 12.00 uur
}

door

Maria Jozefina Rudolfina Brinkman

Geboren op 9 december 1965 te Heerlen 


\section{PROM OTORES}

Prof. dr. L.M.G. Curfs

Prof. dr. J.M.H. de M oor (Radboud Universiteit Nijmegen)

\section{COPROM OTOR}

Dr. J.E.A. Stauder

\section{BEOORDELINGSCOM M ISSIE}

Prof. dr. C. Kemner (voorzitter)

Dr. A. Sambeth

Prof. dr. C. Vlaskamp (Rijksuniversiteit Groningen)

Het in dit proefschrift beschreven onderzoek werd mede mogelijk gemaakt door SWZZonhove te Son. 
Voor Jan, W iesje en Léonce 



\section{Contents}

$\begin{array}{llr}\text { CHAPTER } 1 & \text { General Introduction } & 9\end{array}$

CHAPTER 2 Development and Gender in the P50 Paradigm 17

CHAPTER 3 The Development of Passive Auditory Novelty 37 Processing

CHAPTER 4 The Development of Passive Visual Novelty 57

Processing

CHAPTER $5 \quad$ Individual Assessment of Children with Profound 73 Intellectual and Multiple Disabilities (PIM D) by means of Event-related Brain Potentials

$\begin{array}{lll}\text { CHAPTER } 6 & \text { General Discussion } & 93\end{array}$

$\begin{array}{ll}\text { SUMMARY } & 105\end{array}$

$\begin{array}{ll}\text { SAM ENVATTING } & 109\end{array}$

$\begin{array}{ll}\text { REFERENCES } & 113\end{array}$

$\begin{array}{ll}\text { DANKWOORD } & 121\end{array}$

$\begin{array}{ll}\text { CURRICULUM VITAE } & 125\end{array}$ 

Chapter 1

General Introduction 
The current thesis aims to examine whether it is possible to assess individually the sensory and cognitive information processing in children with profound intellectual and multiple disabilities (PIMD) by means of event-related potentials (ERPS). In 1980 the World Health Organization (WHO) published the International Classification of Impairments, Disabilities, and Handicaps (ICIDH), according to which impairment was defined as an abnormality of structure or function, while disability was defined as the functional, and handicap as the social consequence of an impairment. In 2001 the International Classification of Functioning, Disability, and Health (ICF) was published (WHO, 2001), taking a health instead of a disease perspective. Level of functioning and disability are determined by multiple interrelated factors like health status (presence or absence of a disease or disorder), impairments in body functions and structures (including intellectual functioning), activity limitations, participation restrictions, environmental factors, and personal factors. The ICF definition of intellectual disability encompasses deficits in both intellectual functioning and adaptive behavior (the ability to adapt to the daily demands of the normal social environment), according to which people with profound intellectual disabilities have IQs below 20-25, and a very serious developmental delay in the acquisition of gross motor, fine sensorimotor, communication and adaptive behavioral skills. As such, these people need intensive support to maximize their quality of life and supervised accommodation (Carr \& O'Reilly, 2007). In addition to profound intellectual disabilities, people with PIM D have other disabilities. Severe motor disabilities are very common, and many of them are diagnosed with cerebral palsy (CP), a disorder of the development of movement and posture that is due to a non-progressive abnormality of the immature brain (Bax, Goldstein, Rosenbaum, Leviton, \& Paneth, 2005). Furthermore, many people with PIMD have visual and hearing impairments (e.g. Aerts-Neggers, Schoonbrood-Lenssen, \& Maaskant, 2003; Evenhuis, Theunissen, Denkers, Verschuure, \& Kemme, 2001; McCulloch, Sludden, McKeown, \& Kerr, 1996; M euwese-Jongejeugd, et al., 2006; Van den Broek, Janssen, van Ramshorst, \& Deen, 2006; Van Splunder, Stilma, Bernsen, \& Evenhuis, 2006; Woodhouse, Griffiths, \& Gedling, 2000).

As stated before, people with profound intellectual disability show a very severe maturational delay in acquiring communication skills. For children with PIMD communication is even more troublesome as they are unable to use gestures to express themselves, and often have a dysfunctional speech (e.g. Solot, 1998; Johnson, Wilhelm, Eisert, \& Halperin-Philips, 2001; De Moor, Mulders, \& Didden, 
2003). This means that the individual assessment of sensory and cognitive functioning in children with PIMD is not easy, as most standard psychological tests suited for their chronological age, require motor or verbal responses. Therefore, in practice assessment of children with PIMD is mostly limited to the observation and analysis of behavior. However, the "reading" of their behavior is very difficult, as the same expression, sound and/or movement is setting dependent (Vlaskamp, 2006). The latter thus increases the chance of subjectivity or misinterpretation (authors' interpretation). Also, clinical instruments suited for infant assessment are often used, like the Fagan Test of Infant Intelligence that assesses novelty preference by (dis-) habituating infants to the photographs of faces (Fagan \& Shepherd, 1985), the Kent Infant Development Scale, observationally assessing development in children of 15 months or younger (Katoff, Reuter, \& Dunn, 1980), and the Bayley Scales of Infant Development-II, assessing developmental progress in children of 42 months or younger (Bayley, 1993). However, the last test still requires overt motor or verbal responses, making it less suitable for children with PIMD.

An alternative to the assessment mentioned above is the measurement of brain activity time-locked to events or ERPs. An important advantage of the ERP method is the ability to assess sensory and cognitive information processing independent from behavior. In addition, this method requires no overt responses, and is evidence-based. Therefore, the main topic of this thesis is the question whether it is possible to assess the information processing of children with PIMD individually by means of ERPs.

This chapter will start by giving some background information on the EEG/ERP method. Next, the ERP tasks used in this research project will be described, where after an outline of this thesis will be given.

\section{EEG/ERP method}

In 1929 Berger was the first to demonstrate the possibility of recording electrical brain activity by placing electrodes on the skull, thus creating an electroencephalogram (EEG). Electrical brain activity is the summation of synchronous post-synaptic activity of large number of neurons oriented in the same direction. Although ERPs are part of this recorded electrical brain activity, and thus of the EEG, they are very small and therefore usually not visible in the raw EEG. By averaging pieces of the EEG that are time-locked to repeatedly occurring events 
(stimuli) an ERP is derived from an EEG. Thus, all parts of the EEG that are not timelocked to an event are assumed to be random and are removed from the potentials by this averaging procedure (Fabiani, Gratton, \& Coles, 2000).

An ERP consists of a number of positive and negative voltage peaks, that are named according to their polarity and time of appearance (latency) measured after stimulus onset. ERPs have an excellent time-resolution and changes in brain activity are recorded in the order of a few milliseconds from multiple scalp locations (Coles \& Rugg, 1995; Kutas \& Dale, 1997). Therefore, a positive peak occurring $300 \mathrm{~ms}$ after stimulus onset is called a P300. There are two types of ERP components. During the first $100 \mathrm{~ms}$ after stimulus presentation the so-called sensory or exogenous ERP components appear. These components are influenced by the physical characteristics of an external event (stimulus) and represent the obligatory response to the event. After $100 \mathrm{~ms}$ the endogenous or cognitive ERP components emerge. They reflect the interaction between participant and event and are sensitive to task manipulation (Fabiani, et al., 2000).

The ERP method is a brain imaging technique that allows researchers to examine the relation between brain development and cognitive development in young children and in non-responsive patient groups like people in coma (Kane, Curry, Butler, \& Cummins, 1993; Wijnen, van Boxtel, Eilander, \& de Gelder, 2007), and thus it can be expected that ERPs will also provide useful information regarding the individual information processing of people with PIM D. First, ERPs do not require an overt response. Second, ERPs are non-invasive and can be used across the entire life span, enabling comparisons between different ages (DeBoer, Scott, \& Nelson, 2005).

\section{ERP tasks}

In order to evaluate the information processing of children with PIM D by means of ERPs, the ERP task to be used had to fulfill a number of conditions. First of all, it had to be a passive task, requiring no overt response. Furthermore, as the ultimate goal was to make a sensory and cognitive profile for each child with PIMD individually, the ERP task to be used should preferably have not only an auditory version, but also a visual one. Also, the ERP task to be used had to produce ERP components that were clearly visible at an individual level, as the final goal was to 
individually assess the information processing in children with PIMD. Finally, the ERP components should not mature very early, so that the brain activity patterns between the several age groups (controls) would be different, enabling the individual comparison of the brain activity patterns of children with PIMD to control groups of different ages.

One of such tasks is the passive auditory P50 sensory gating task. Sensory gating implies the filtering of incoming stimuli in order to prevent the brain from being flooded with irrelevant information. The component of interest is the P50 that is usually evoked when two clicks are presented shortly one after the other. Although the P50 component is already present in infants (Kisley, Polk, Ross, Levisohn, \& Freedman, 2003), data concerning its development in children are scarce and different tasks and techniques were used (Freedman, Adler, \& Waldo, 1987; Kisley, et al., 2003; M arshall, Bar-Haim, \& Fox, 2004; M yles-Worsley, Coon, Byerley, Waldo, Young, \& Freedman, 1996; Rasco, Skinner, \& Garcia-Rill, 2000). A brain is assumed capable of inhibiting redundant information, when the P50 component to the second click is smaller compared to the P50 component to the first click. Brain structures involved in P50 sensory gating are the prefrontal cortex (Grunwald, et al., 2003; Knight, Staines, Swick, \& Chao, 1999; Weisser, Weisbrod, Roehrig, Rupp, Schroeder, \& Scherg, 2001) and temporal-parietal areas (Grunwald, et al., 2003; Weate, et al., 1995).

The passive novelty oddball task was the second task that was decided upon, as this task met all the demands mentioned before. The visual novelty oddball task was first used in a developmental study of Courchesne (1978). Hereafter, many studies used the novelty oddball task to examine both auditory and visual novelty processing. Although only a few studies addressed the development of visual novelty processing in children using the visual novelty oddball task (Courchesne, 1978; Thomas \& Nelson, 1996; van der Stelt, Geesken, Gunning, Snel, \& Kok, 1998), several studies described the development of auditory novelty processing in children using the auditory novelty oddball task (Čeponiene, Lepistö, Soininen, Aronen, Alku, \& Näätänen, 2004; Cycowicz, Friedmann, \& Rothstein, 1996; Gumenyuk, Korzyukov, Alho, Escera, \& Näätänen, 2004; Gumenyuk et al., 2001; Määttä, Saavalainen, Könönen, Pääkkönen, Muraja-Murro, \& Partanen, 2005; Wetzel \& Schröger, 2007). Unfortunately, the data of these reports could not be used as referential data for children with PIMD, as these studies required overt responses, used participants in different age ranges or employed different task setups. 


\section{Outline of the thesis}

For the individual assessment of children with PIM D referential data of children with a typical development are necessary. Therefore, the first part of this thesis (chapters 2, 3, and 4) will handle the sensory and cognitive information processing in control children, and the lay-out of these chapters will fit the lay-out of typical ERP papers. Hereafter the information processing in children with PIMD will be dealt with (chapter 5), and as this paper individually assesses the information processing in children with PIM D, its lay-out will be very different from chapters 2-4.

Chapter 2 describes a study concerning the development of auditory sensory gating. Sensory gating is the ability to inhibit irrelevant information in order to prevent the brain from being flooded. Although many studies used the P50 task to examine auditory sensory gating, most of them involved adult participants. Studies employing the P50 task to examine auditory sensory gating in children are scarce, using very broad age ranges and/or small numbers of children for participants (Freedman, et al., 1987; Kisley, et al., 2003; Marshall, et al., 2004; M yles-Worsley, et al., 1996; Rasco, et al., 2000). Therefore, the present study was committed to supply referential data for the assessment of auditory sensory gating in children with PIMD. For this purpose the development of auditory sensory gating was examined in normally developing children aged 5-12 years and in adults. In addition, the existence of possible gender differences was examined as, when due, this factor needed to be taken into account during assessment. The component of interest in auditory sensory gating is the P50 that is usually evoked in a task during which 2 clicks are presented shortly one after the other. Typically, the P50 amplitude to the second click is smaller compared to the first one. The difference in P50 amplitude between the first and second click and/or the ratio between these two amplitudes indicates the degree of P50 sensory gating, that is the inhibition of irrelevant information.

Chapter 3 describes a study concerning the development of passive auditory novelty processing in normally developing children aged 5-12 years and in adults. Although many studies examined the development of auditory novelty processing, most of them used active tasks, thus requiring an overt response from the participant, or different task set-ups (Čeponiene, et al., 2004; Cycowicz, et al., 1996; Gumenyuk, et al., 2004; Gumenyuk et al., 2001; Määttä, et al., 2005). Conversely, 
one recent study (Wetzel \& Schröger, 2007) presented a passive auditory novelty oddball task to children aged 6-12 and to adolescents. Although the results of this study could have served as referential data for children with PIMD, the novelty oddball task used in this study was very long, as it used short and long novels and deviants, each presented in separate blocks. Therefore, the purpose of the present study was to replicate this study, using a shorter and simplified task. As the other study also reported the processing of deviant sounds, the present study also examined the development of deviant sound processing. The component of interest is the novelty P3 representing the novelty or orienting response that is usually evoked in an auditory novelty oddball task. The novelty or orienting response is the involuntarily focusing of attention to new, unexpected or unpredictable events. In the auditory novelty oddball task three stimulus categories are presented to the participant. In the present study most trials consisted of a harmonic $750 \mathrm{~Hz}$ tone (standard). In $15 \%$ of the trials a harmonic $500 \mathrm{~Hz}$ tone (deviant) was used and in the other $15 \%$ unique environmental sounds (novel) were presented.

Chapter 4 describes a study concerning the development of passive visual novelty processing. Up to now, only a few studies described the development of visual novelty processing in children, and the few reports that did this, used active tasks, making their results unsuitable to serve as referential data for children with PIM D (Courchesne, 1978; Thomas \& Nelson, 1996; van der Stelt, et al., 1998). Therefore, the present study examined the development of visual novelty processing in normally developing children of 5-12 years of age and in adults using a passive novelty oddball task. For this purpose, this study employed the same novelty oddball task as used in the study on the development of passive auditory novelty processing. However, the standard and deviant stimuli consisted of black and white gratings with a low and high spatial frequency, respectively, while the novel stimuli were colored standardized photographs.

Chapter 5 describes a study into the auditory and visual stimuli detection, and the auditory and visual novelty processing of each child with PIMD individually, using referential auditory and visual novelty oddball data of age-matched control children. M ain components of interest were the exogenous, sensory component P1, sensitive to the physical characteristics of the presented stimulus, and the novelty P3 (cognitive), a response reflecting the ability to distinguish old from new information. First, it was established whether a child with PIMD was capable of detecting the presented stimulation, that is could hear and see. Next, the stimuli detection of each child with PIMD individually was compared to the stimuli 
detection of a group of age-matched control children. Then, the novelty processing of a child with PIMD was compared to the novelty processing of a group of agematched control children. When the stimuli detection and/or novelty processing of a child with PIMD was aberrant from the stimuli detection and/or novelty processing of its age-matched control group, this processing was compared to the stimuli detection and/or novelty processing of a younger control group, thus assessing the possibility of a maturational delay.

Chapter 6 consists of a summary of the results and conclusions of the previous chapters. In addition, this chapter encompasses a general discussion regarding the use of ERPs in children with PIMD, the used ERP tasks and the applicability of the ERP method in practice. Finally, future lines of ERP research are proposed regarding information processing of children with PIMD. 


\section{Chapter 2}

\section{Development and Gender in the P50 Paradigm}

This chapter is based on: Brinkman, M.J.R., Stauder, J.E.A., 2007. Development and gender in the P50 paradigm. Clinical Neurophysiology 118, 1517-1524. 


\section{CHAPTER 2}

\section{Abstract}

The relative change in amplitude of the P50 component in response to the second click compared to the first one is commonly thought to index sensory gating. Despite numerous P50 gating studies, reports about its development are scarce. The present study examined the development and gender differences of P50 sensory gating in adults $(\mathrm{N}=31)$ and in children aged $10-12$ years $(\mathrm{N}=29), 8-9$ years $(\mathrm{N}=26)$ and 5-7 years $(\mathrm{N}=26)$, using a standard P50 paradigm. It appeared that the speed of processing and the frontocentral scalp distribution in P50 sensory gating were already mature at the age of 5 years. However, children of 5-7 years of age had smaller amplitudes to the first response and showed less sensory gating compared to the older age groups. No gender differences were found. Thus, it can be concluded that sensory gating matures around the age of 8 years. The current data help in evaluating whether abnormal P50 sensory gating is due to a maturational delay. There is no need to take into account gender differences. 


\section{Introduction}

Sensory gating is the ability of the central nervous system (CNS) to filter incoming stimuli and protect a person from being flooded with irrelevant information. A well-known electrophysiological measure of the degree to which someone is able to inhibit irrelevant stimulation is the decrease of the P50 auditory evoked potential to repeated stimulation. The P50 component is usually evoked in a conditioning-testing paradigm during which two clicks are presented shortly one after the other. Typically, the response to the second click is smaller than to the first one. Impaired suppression has been observed in several patient groups, especially schizophrenics (Adler, Pachtman, Franks, Pecevich, Waldo, \& Freedman, 1982; Boutros, Bonnet, Millana \& Liu, 1997; Freedman, Adler, \& Waldo, 1987; Freedman, Adler, Waldo, Pachtman, \& Franks, 1983; Judd, McAdams, Budnick, \& Braff, 1992). M ost studies used the ratio of the test amplitude to the conditioning amplitude (T/C ratio), with lower values indicative of increased auditory sensory gating (Freedman, Waldo, Bickford-Wimer, \& Nagamoto, 1991). Others reported the difference in P50 area (Judd, et al., 1992) or in amplitude (Smith, Boutros, \& Schwartzkopf, 1994) between the conditioning and testing clicks.

A number of brain structures has been mentioned to be involved in sensory gating. Grunwald et al. (2003) identified three structures in the human brain that contributed to sensory gating by using intracranial evoked potentials. According to them sensory gating may be a multistep process, with an early phase in which the temporo-parietal and prefrontal cortex are engaged and a later phase (250 ms) subserved by the hippocampus. Other studies also implicated the involvement of the prefrontal cortex (Knight, Staines, Swick, \& Chao, 1999; Weisser, Weisbrod, Roehrig, Rupp, Schroeder, \& Scherg, 2001), the temporal lobe (Weate, Moore, \& Drake, 1995) and the hippocampus (Adler, Rose, \& Freedman, 1986; BickfordWimer et al., 1990; Boutros, et al., 1997; Boutros \& Kwan, 1998; Flach, Adler, Gerhardt, Miller, Bickford, \& MacGregor, 1996; Moxon, Gerhardt, Gulinello, \& Adler, 2003) in P50 sensory gating.

Many studies have used the P50 paradigm to examine sensory gating, and most of them involved adult participants. However, there is increasing evidence suggesting that the frontal cortex is one of the key brain areas contributing to P50 sensory gating (Grunwald et al., 2003; Knight, et al., 1999; Weisser, et al., 2001) and 
that this function is still immature in preadolescence. Bunge, Dudukovic, Thomason, Vaidya, and Gabrieli (2002) reported that, compared to adults, children between 8 and 12 years failed to activate a region in right ventrolateral prefrontal cortex during interference suppression of irrelevant environmental stimuli. In a study of Freedman, Adler, and Waldo (1987) 163 participants were included, divided over 6 age groups (1-8; 9-11; 12-19; 20-29; 30-44; and 45-65 years). They found a significant negative correlation between P50 latency and age for the entire population and a rapid change in latency in the children aged 1-8 years, reaching adult levels in pre-adolescence. Furthermore, amplitudes of the conditioning response were negatively correlated with age. The two youngest groups had significantly larger amplitudes to the conditioning response compared to the other age groups. Maturation resulted not only in a decrease in mean conditioning-testing ratio, but also in a decrease of its variance. An adult level of suppression was found in most subjects only by the late teens. In a study of Myles-Worsley, Coon, Byerley, Waldo, Young, and Freedman (1996) the P50 ratio remained stable over the entire age range (10-39 years). Only the conditioning latency declined with age until 20 years of age. Rasco, Skinner, and Garcia-Rill (2000) found no significant differences in P50 amplitudes, latencies or sensory gating in participants between 12 and 78 years of age. M arshall, Bar-Haim, and Fox (2004) examined the development of P50 suppression in 32 children (7-13 years). The P50 testing amplitude was significantly smaller than the P50 conditioning amplitude, although one third of the children showed augmentation of the P50 to the second tone, and thus had larger P50 testing amplitudes as compared to P50 conditioning amplitudes. In children with P50 suppression, the magnitude of P50 suppression increased with age and reached adult levels in the oldest children. Kisley, Polk, Ross, Levisohn, and Freedman (2003) measured P50 gating during REM sleep in infants of 1-4 months. A correlation between increasing age and stronger response suppression indicated that already at a very early age sensory gating was functional in children.

There are reports in the literature suggesting that gender is also a factor deserving serious consideration, but these reports are not univocal. Freedman, et al. (1987) reported that women had a higher mean amplitude response to the first stimulus than men. Also, in females the mean P50 amplitude to the conditioning stimulus showed a small rise to about age 12 and decreased sharply through adolescence. In contrast, in males the mean P50 amplitude to the first stimulus decreased steadily. However, they found no differences in suppression between males and females. White, Kanazawa and Lee (2005) also reported that women had 
larger P50 amplitudes in the first stimulus condition as compared to men. Hetrick, Sandman, Bunney, Jin, Potkin, and White (1996) found that women had significantly higher P50 mean amplitudes to the second stimulus, and significantly higher P50 conditioning/testing ratios compared to men, indicating less sensory gating. Finally, Rasco, et al. (2000) reported no differences between males and females in P50 amplitudes, latencies or sensory gating.

Developmental studies are especially of interest when working with patient groups, as their data can help establish whether aberrant findings in patients are the result of a maturational delay or constitute a specific ERP pattern for a certain patient group. Therefore, we performed a developmental study wherein each age group consisted of a relative large number of participants. Based upon the fact that the frontal cortex is still immature in preadolescence (Bunge, et al., 2002), we expected to find that children would show increasingly more P50 inhibition with increasing age, although still immature compared to adults. Since the reports regarding gender differences are not univocal, the factor gender was also included in this study.

\section{M ethods}

\section{Participants}

Initially 35 adults and 87 children participated in this study. Four adults and 6 children were excluded because of technical problems and finally a total of 31 adults and 81 children with self-reported normal hearing were included in the analysis. The adult group consisted of 16 men and 15 women with an average age of 21.5 years (SD 2.4 years; range 18.5-29.4 years). The children were split up into three different age groups. The eldest group (10-12 years of age) counted 29 children (12 male and 17 female) with an average age of 11.2 years (SD 0.8 years; range 10.1-12.4 years). The middle group (8-9 years of age) included 26 children (10 male, 16 female) and had an average age of 8.8 years (SD 0.5 years; range 8.0-9.7 years). The youngest group (5-7 years of age) also consisted of 26 children (7 male, 19 female) with an average age of 6.2 years (SD 0.7 years; range 5.4-7.9 years). The EEG recordings for the adults were performed at the Maastricht University, and for the children at primary schools in towns in the vicinity of Maastricht (Elsloo, Stein and Schinnen). In both cases the same NuAmps DC Portable amplifier (Neuroscan, 


\section{CHAPTER 2}

Inc., USA) was used. Participants were primarily of middle-class background. Parental consent was obtained for all children and the study was approved by the Maastricht University Ethical Committee of Psychology (01-05-2004). Parents that agreed to participate in the study completed the Child Behavior Checklist/4-18 (CBCL/4-18) for their respective child. Children scoring in a clinical range on the scales for anxiety/depression, attentional problems and school activities in accordance with the Dutch norms, were excluded from the study (Verhulst, van der Ende, \& Koot, 1996). The exclusion criteria for adults were self reported attentional or psychiatric problems. Finally, both adults and children completed Raven's Standard Progressive M atrices (SPM) in order to control for intelligence level. Adults filled in the SPM during electrode application, the children did this as a group in the classroom.

\section{Stimuli}

Two identical clicks of a $1000 \mathrm{~Hz}$ frequency were presented binaurally by a headphone with a 500-ms interstimulus interval (ISI). Each click lasted $4 \mathrm{~ms}$ and had a sound level of $67 \mathrm{~dB}(\mathrm{~A})$, measured at the headphone. In order to customize the participants to the clicks and to reduce stress three paired stimuli preceded the actual paradigm.. Two blocks consisting of 35 pairs of clicks each were presented with an interpair interval of $8 \mathrm{~s}$, as $8 \mathrm{sec}$ is the minimum time needed for the P50 component to recover fully (Zouridakis, \& Boutros, 1992). In total, the task lasted about 10 minutes.

\section{EEG recording}

Thirty tin electrodes in an electro-cap (Electro-cap, Inc., USA) were connected to a 40 channel NuAmps DC Portable amplifier (Neuroscan, Inc., USA). The EEG was recorded from the scalp sites $\mathrm{Fz}, \mathrm{Cz}, \mathrm{Pz}, \mathrm{Oz}, \mathrm{F7}$, F8, F3, F4, C3, C4, T7, T8, P3, P4, P7, P8, 01, 02, Fp1, Fp2, FT7, FT8, FC3, FC4, TP7, TP8, CP3, CP4, FCZ and CPz (American Electroencephalographic Society, 1991). The ground electrode was placed in the middle between the Fp1, Fp2 and Fz electrodes. The reference electrode was placed at the right mastoid (A2). The vertical electro-oculogram (EOG) was recorded from one electrode above and one below the right eye and the horizontal EOG from two electrodes at the outer canthi of the eyes. The impedance of all electrodes was 
measured by a hand held impedance meter (F-EZM 4, Grass Inc., USA) and did not exceed the $5 \mathrm{kOhm}$ for the EEG and $8 \mathrm{kOhm}$ for the EOG electrodes. Data were bandpass filtered between 0.1 and $100 \mathrm{~Hz}$. Stimulus presentation and timing was controlled by ERTS software (Version 3.18, BeriSoft Cooperation, Germany).

\section{Procedure}

Upon arrival the procedure of the session was explained to the participant. Two researchers were seated in the same room, facing or beside the subject. The participant was asked to stay silent and sit quietly. During task presentation the subject watched a silent cartoon on a portable DVD player. The participants also performed a visual and auditory oddball task. The report of these data goes beyond the scope of the present paper and will be published in a separate paper. The sequence of presenting the tasks was fixed, with the P50 paradigm always being first. The entire recording lasted about 90 minutes.

\section{Data analysis}

The recorded EEG and EOG signals were analyzed using Neuroscan 4.3 software. First, the four EOG channels were reduced to two EOG channels (one horizontal and one vertical). Then, the EEG signals were corrected for vertical eye movements by means of linear regression (Neuroscan 4.2). Next, the signals were epoched at an interval between $50 \mathrm{~ms}$ prestimulus and 400 ms poststimulus, bandpass filtered between 10 and $50 \mathrm{~Hz}$, and baseline corrected. The choice of the 10-50 Hz bandpass filter over the 1-100 Hz bandpass filter was based upon the fact that this filter removes slow wave activity and renders a more reliable estimation of the peak latency (Smulders, Kenemans, \& Kok, 1994). Then, individual EEG sweeps were rejected when the amplitude exceeded $\pm 75-100 \mu \vee$ in students and $\pm 100-125 \mu \vee$ in children. Finally, the first (conditioning) and second (testing) stimuli were averaged. All P50 latencies were established between stimulus onset and the peak of the P50 component. A wave was identified as a P50 component when the wave was the second major positive component between 30 and $80 \mathrm{~ms}$ and was preceded by a $\mathrm{Pa}$ wave in the 15 to $40 \mathrm{~ms}$ range. If no Pa wave could be determined within a window of $15-40 \mathrm{~ms}$, the largest positive peak within $40-80 \mathrm{~ms}$ was taken (Boutros, \& Belger, 1999). The peak amplitudes were assessed in reference to the baseline and, for 
illustrative reasons, in reference to the preceding negativity. The peak of the testing stimulus was established in the same way, although the peak latency had to occur within $10 \mathrm{~ms}$ of the latency of the conditioning stimulus. However, after visual inspection, in some children it was necessary to extend the time window to $12 \mathrm{~ms}$. Both the P50 latencies and amplitudes were statistically (SPSS 11.5) analyzed by means of General Linear M odels - repeated measures ANOVA. In case of significant $(p<0.05)$ interactions post-hoc tests were performed using one-way ANOVAs. If there was a violation of the assumption of sphericity a Huyn-Feldt correction was applied. In order to compare the results of this study with those of other studies, both the P50 difference (conditioning response minus testing response) and the P50 ratio scores (testing response divided by conditioning response and multiplied by 100) were reported. When the peak amplitudes were scored in reference to the baseline, the raw amplitude scores were transformed by adding two amplitude points, in order to obtain all positive values for calculating the ratio scores. In addition, linear regression was performed with age (in months) for both the P50 latency and the two inhibition measures.

\section{Results}

Since the standard P50 paradigm is a passive task, no behavioral data are available. To evaluate the gross topographic distribution the midline electrodes $\mathrm{Fz}$, $\mathrm{Cz}, \mathrm{Pz}$ and $\mathrm{Oz}$ for each age group are displayed. Fig. 1 shows the grand averages of the event related potentials to the conditioning and testing clicks per group at the electrodes $\mathrm{Fz}, \mathrm{Cz}, \mathrm{Pz}$ and $\mathrm{Oz}$. The arrows indicate the P50 component. Except for the youngest age group (5-7 years of age) the conditioning amplitude was typically larger than the testing one for all the other age groups and all electrodes. It can be observed that the P50 peak decreases from the electrodes $\mathrm{Fz}$ and $\mathrm{Cz}$ to Pz and $\mathrm{Oz}$.

All children that were included scored within the normal range on the scales for anxiety/depression, attentional problems and school activities in accordance with the Dutch norms for the CBCL/4-18 (Verhulst, et al., 1996). In addition, all participants scored within a normal intelligence range in conformity with the British norms for the Raven's Standard Progressive Matrices (SPM). The raw mean scores (and SD) were 29.4 (8.9), 38.0 (9.6), 44.7 (5.5) and 53.4 (4.4) for the 5-7, 8-9, 10-12, and 18-29 years olds, respectively (Raven, et al., 1983). 


\section{P50 Latencies}

For the benefit of clarity in most cases only significant results are discussed. In Table 1 the means and standard deviations of both the conditioning and testing latencies after stimulus onset of the four age groups (columns) and four electrodes (rows) are displayed. Each column displays the peak latency of stimulus condition 1 and 2 for each age group, and the rows show the peak latency of stimulus condition 1 and 2 for the respective electrode. Linear Regression revealed no significant

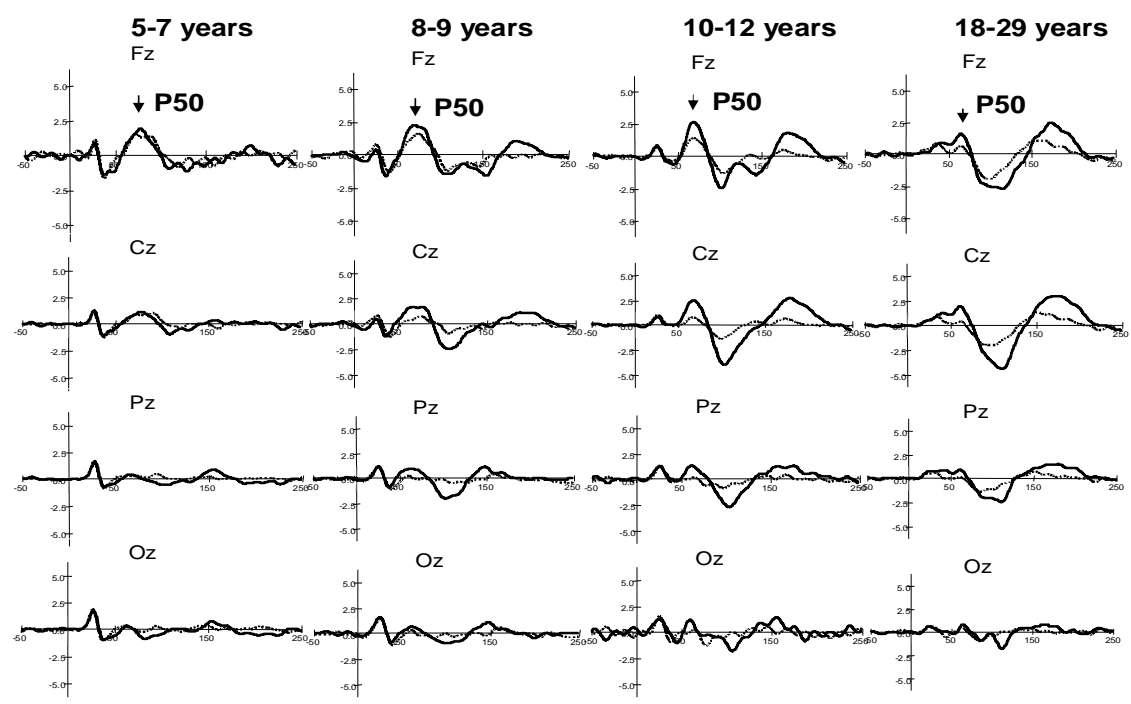

Figure 1. Grand averages of the event related potentials at Fz (row 1), Cz (row 2), Pz (row 3) and Oz (row 4) elicited by conditioning (solid line) and by testing stimuli (dotted line) in children aged 5-7 years (column 1), 8-9 years (column 2), 10-12 years (column 3) and in adults (column 4). The $x$ - axis displays the latency in ms after stimulus onset, the $y$-axis the amplitude in $\mu \mathrm{V}$ (positive is up, negative is down). Although the arrows indicating the P50 component are only visible at Fz, this component is also visible at the other electrodes. 


\section{CHAPTER 2}

correlations for age with the P50 latency of the conditioning or the testing response at $\mathrm{Fz}, \mathrm{Cz}, \mathrm{Pz}$ or $\mathrm{Oz}$. With regard to GLM repeated measures no significant gender differences in P50 latency were found. Therefore, the factor Gender was excluded from further analyses. GLM repeated measures with the within-subject factors condition (conditioning vs. testing) and electrodes ( $\mathrm{Fz}, \mathrm{Cz}, \mathrm{Pz}, \mathrm{Oz})$ and the betweensubjects factor group $(5-7 ; 8-9 ; 10-12 ; 18-29)$ showed a significant three-way interaction Group x Condition x Electrode $(F(8.0,288.6)=2.13, p=0.033)$ and a main effect of Electrode $(F(2.1,224.5)=20.99, p=0.0001)$. The significant three-way interaction was further explored by GLM repeated measures of Group x Electrode per condition, of Group x Condition per electrode and of Condition x Electrode per age group. However, none of these interactions revealed significant effects. The main effect of Electrode indicated decreasing latencies from anterior to posterior electrodes $(p \measuredangle 0.05)$.

Table 1. M eans and SD (between brackets) of P50 latencies (ms) of both the conditioning and testing response for each age group (columns) at electrodes $\mathrm{Fz}, \mathrm{Cz}, \mathrm{Pz}$, and $\mathrm{Oz}$ (rows).

\begin{tabular}{llllll}
\hline & & 8-9 years & $5-7$ years & 10-12 years & 18-29 years \\
\hline Fz & Click 1 & $65.6(7.8)$ & $65.9(9.6)$ & $64.0(8.3)$ & $62.1(8.3)$ \\
& Click 2 & $63.2(8.2)$ & $65.7(10.1)$ & $65.4(8.7)$ & $63.1(9.6)$ \\
Cz & Click 1 & $61.8(9.4)$ & $63.2(9.5)$ & $63.6(8.3)$ & $61.4(6.2)$ \\
& Click 2 & $60.3(10.0)$ & $65.3(11.3)$ & $63.4(8.4)$ & $61.2(7.7)$ \\
Pz & Click 1 & $61.2(8.6)$ & $60.1(6.8)$ & $60.3(7.7)$ & $59.4(7.8)$ \\
& Click 2 & $60.0(9.7)$ & $59.0(8.1)$ & $62.1(9.1)$ & $59.3(9.5)$ \\
& Click 1 & $60.3(8.9)$ & $60.6(7.0)$ & $59.9(7.3)$ & $60.0(9.2)$ \\
& Click 2 & $59.3(9.1)$ & $59.4(7.4)$ & $60.8(9.4)$ & $60.4(10.2)$ \\
\hline
\end{tabular}


P50 amplitudes (method: peak to peak)

When looking at the P50 amplitudes scored in reference to the preceding negativity, no significant gender differences in P50 amplitude were found. Therefore, the factor Gender was excluded from further analyses. GLM repeated measures with the within-subject factors condition (conditioning vs. testing) and electrodes ( $\mathrm{Fz}, \mathrm{Cz}, \mathrm{Pz}, \mathrm{Oz})$ and the between-subjects factor group (5-7; 8-9; 10-12; 18-29) revealed a significant Electrode $x$ Group interaction $(F(6.8,248.6)=2.88$, $p=0.007)$, a significant Condition $x$ Electrode interaction $(F(2.6,284.8)=7.24$, $p=0.0001)$ and main effects of Condition $(F(1.0,109.0)=47.85, p=0.0001)$, of Electrode $(F(2.3,248.6)=46.66, p=0.0001)$ and of $\operatorname{Group}(F(3.0,109.0)=4.12, p=0.008)$. Post hoc analyses indicated that all children groups had larger amplitudes at electrodes $\mathrm{Cz}$ and $\mathrm{Pz}$, and in addition the 5-7 and 8-9 years olds at electrode $\mathrm{Fz}$ compared to adults. Furthermore, all electrodes ( $\mathrm{Fz}, \mathrm{Cz}, \mathrm{Pz}$, and $\mathrm{Oz}$ ) showed larger amplitudes to the first click compared to the second one, indicating a successful task manipulation.

\section{P50 amplitudes (method: baseline to peak)}

Table 2 shows the means and standard deviations of the P50. Each column displays the peak amplitude of stimulus condition 1 and 2 for each age group, and the rows show the peak amplitude of stimulus condition 1 and 2 for the respective electrode. With regard to the baseline to peak analyses no significant gender differences in P50 amplitude were found. Therefore, the factor Gender was excluded from further analyses. GLM repeated measures with the within-subject factors condition (conditioning vs. testing) and electrodes $(\mathrm{Fz}, \mathrm{Cz}, \mathrm{Pz}, \mathrm{Oz}$ ) and the between-subjects factor group (5-7; 8-9; 10-12; 18-29) revealed a significant Group x Condition interaction $(F(3.0,108.0)=5.56, \quad p=0.001)$, a significant Condition $\times$ Electrode interaction $(F(2.5,270.6)=9.89, \quad p=0.0001)$ and main effects of Condition $(F(1.0,108.0)=60.17, p=0.0001)$, of Electrode $(F(2.0,217.6)=53.28, p=0.0001)$ and of Group $(F(3.0,108.0)=3.60, p=0.016)$. Post hoc analyses indicated that the youngest group had significant smaller amplitudes to the first click compared to the other age groups $(p \varangle 0.05)$. Furthermore, the group of $10-12$ years of age had significant larger amplitudes to the second click compared to the oldest group $(p=0.011)$. Finally, all 


\section{CHAPTER 2}

electrodes ( $\mathrm{Fz}, \mathrm{Cz}, \mathrm{Pz}$, and $\mathrm{Oz}$ ) showed larger amplitudes to the first click compared to the second one, indicating a successful task manipulation.

Table 2. Means and SD (between brackets) of P50 amplitudes $(\mu \mathrm{V})$ of both the conditioning and testing response for each age group (columns) at electrodes $\mathrm{Fz}, \mathrm{Cz}, \mathrm{Pz}$, and $\mathrm{Oz}$ (rows).

\begin{tabular}{|c|c|c|c|c|c|}
\hline & & 5-7 years & $8-9$ years & 10-12 years & $18-29$ years \\
\hline \multirow[t]{2}{*}{$\mathrm{Fz}$} & Click 1 & $2.2(1.6)$ & $2.7(1.7)$ & $3.3(1.8)$ & $2.6(1.5)$ \\
\hline & Click 2 & $1.8(1.3)$ & $2.0(1.6)$ & $2.3(1.1)$ & $1.4(1.1)$ \\
\hline \multirow[t]{2}{*}{$\mathrm{Cz}$} & Click 1 & $1.6(1.4)$ & $2.6(1.6)$ & $3.4(1.5)$ & $2.6(1.6)$ \\
\hline & Click 2 & $1.4(1.1)$ & $1.3(1.3)$ & $1.8(1.7)$ & $1.1(0.9)$ \\
\hline \multirow[t]{2}{*}{$\mathrm{Pz}$} & Click 1 & $0.9(1.1)$ & $1.9(1.1)$ & $2.1(1.3)$ & $1.5(1.3)$ \\
\hline & Click 2 & $1.0(1.0)$ & $0.8(1.1)$ & $1.2(1.0)$ & $0.7(0.8)$ \\
\hline \multirow[t]{2}{*}{$\mathrm{Oz}$} & Click 1 & $0.8(1.1)$ & $1.6(1.2)$ & $1.8(1.5)$ & $1.8(1.9)$ \\
\hline & Click 2 & $1.0(1.0)$ & $1.0(0.9)$ & $1.1(1.1)$ & $1.0(1.1)$ \\
\hline
\end{tabular}

P50 sensory gating (method: peak to peak)

In order to compare our results with other studies both the P50 difference scores (conditioning response minus testing response) and the P50 ratio scores (testing response divided by conditioning response and multiplied by 100) as inhibition measures were statistically analyzed. GLM repeated measures with the within-subject factor electrodes ( $\mathrm{Fz}, \mathrm{Cz}, \mathrm{Pz}, \mathrm{Oz})$ and the between-subjects factor group (5-7; 8-9; 10-12; 18-29) showed a significant main effect of Electrode for the difference score $(F(2.6,284.1)=7.37, p=0.001)$. Further analyses revealed that $F z$ and $\mathrm{Cz}$ showed more inhibition compared to $\mathrm{Pz}$ and $\mathrm{Oz}$. With regard to the ratio score GLM repeated measures showed a significant Electrode $x$ Group interaction and a significant main effect of Electrode, $(F(8.3,301.9)=2.05, p=0.039)$ and $(F(2.8$, $301.9)=2.82, p=0.043$ ), respectively. Post hoc analyses revealed that the youngest group showed significantly more inhibition at Cz compared to the 8-9 years olds, 
while children aged 8-9 and 10-12 years had more inhibition at Pz compared to adults $(p \varangle 0.05)$.

\section{P50 sensory gating (method: baseline to peak)}

In Table 3 the difference scores in $\mu \mathrm{V}$ are displayed for each age group at $\mathrm{Fz}, \mathrm{Cz}$, $\mathrm{Pz}$, and $\mathrm{Oz}$. Table 4 shows the ratio scores for all age groups also at the midline electrodes. When comparing the ratio score to the difference score the analysis did not reveal major differences between these two measures. Linear Regression revealed a significant positive correlation for Age with the differences score at $\mathrm{Cz}$ $(r=199, p=0.036)$ and positive correlations for Age that tended to be significant at $\mathrm{Fz}$ and $\mathrm{Oz}(r=171, p=0.071$ and $r=177, p=0.062$, respectively). With regard to the ratio score linear regression displayed significant negative correlations for Age at $\mathrm{Fz}(\mathrm{r}=\mathrm{r}$. $215, p=0.023)$ and $C z(r=.201, p=0.033)$. GLM repeated measures with the within-

Table 3. Sensory gating difference score $(\mu \mathrm{V})$ and SD (between brackets) for each age group (columns) and for each electrode (rows).

\begin{tabular}{lllll}
\hline & 5-7 years & 8-9 years & $10-12$ years & 18-29 years \\
\hline $\mathrm{Fz}$ & $0.3(1.6)$ & $0.8(1.4)$ & $1.0(1.5)$ & $1.2(1.3)$ \\
$\mathrm{Cz}$ & $0.2(1.6)$ & $1.3(1.6)$ & $1.6(1.4)$ & $1.5(1.3)$ \\
$\mathrm{Pz}$ & $-0.1(1.4)$ & $1.1(1.2)$ & $1.0(1.1)$ & $0.8(1.2)$ \\
$\mathrm{Oz}$ & $-0.1(1.0)$ & $0.7(1.0)$ & $0.7(1.3)$ & $0.8(1.7)$ \\
\hline
\end{tabular}

subject factor electrodes ( $\mathrm{Fz}, \mathrm{Cz}, \mathrm{Pz}, \mathrm{Oz}$ ) and the between-subjects factor group (5-7; 8-9; 10-12; 18-29) showed significant main effects of Group and Electrode for both the difference score $(F(3.0,108.0)=5.56, p=0.001)$ and $(F(2.5,270.6)=9.89$, $p=0.0001)$, respectively, and the ratio score $(F(3.0,108.0)=5.20, p=0.002)$ and $(F(2.4$, $260.1)=4.11, p=0.012$ ), respectively. Post hoc analyses revealed that with regard to both scores the youngest group showed significantly less inhibition compared to the other three age groups $(p \varangle 0.05)$. This difference is also visible in Figs. 2 and 3. Fig. 2 


\section{CHAPTER 2}

Table 4. Sensory gating ratio score and SD (between brackets) for each age group (columns) and for each electrode (rows).

\begin{tabular}{lllll}
\hline & $5-7$ years & 8-9 years & $10-12$ years & $18-29$ years \\
\hline Fz & $104.3(53.3)$ & $87.7(33.7)$ & $85.7(23.0)$ & $76.8(28.2)$ \\
Cz & $114.1(79.8)$ & $77.3(34.6)$ & $71.6(23.5)$ & $72.3(29.6)$ \\
Pz & $121.6(74.6)$ & $74.9(28.0)$ & $79.6(22.9)$ & $87.3(41.9)$ \\
Oz & $117.8(56.0)$ & $86.3(24.3)$ & $88.8(42.2)$ & $93.0(55.0)$ \\
\hline
\end{tabular}

\section{P50 difference scores per age group}

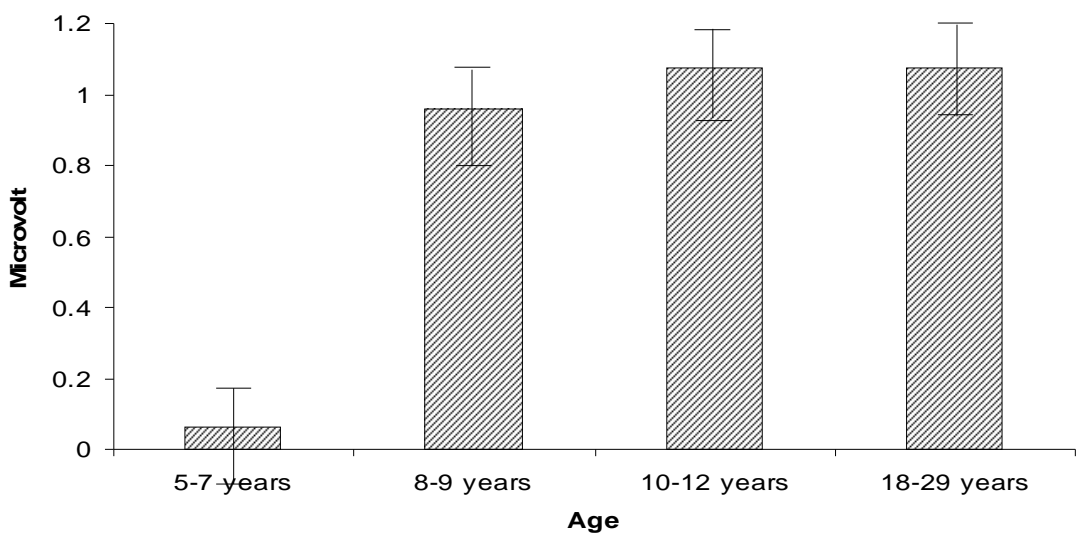

Figure 2. Mean difference scores $(\mu \mathrm{V})$ and error bars for each age group of all four electrodes combined. The youngest group showed significantly less inhibition compared to the other three groups.

displays the difference scores in bars for each age group. Fig. 3 shows the ratio scores in bars for each age group. Although both scores displayed a significant main effect of Electrode, their results are not totally comparable. With regard to the 
difference score electrode $\mathrm{Cz}$ showed significantly more inhibition compared to the other three electrodes $(p<0.05)$. In addition, Fz showed significantly more inhibition compared to $\mathrm{Oz}(\mathrm{p}=0.027)$. However, with regard to the ratio score $\mathrm{Cz}$ showed only significantly more inhibition compared to electrodes $\mathrm{Pz}$ and $\mathrm{Oz} \quad(\mathrm{p}<0.05)$. Furthermore, $\mathrm{Fz}$ displayed significantly more inhibition compared to $\mathrm{Oz}(\mathrm{p}=0.047)$.

\section{P50 ratio scores per age group}

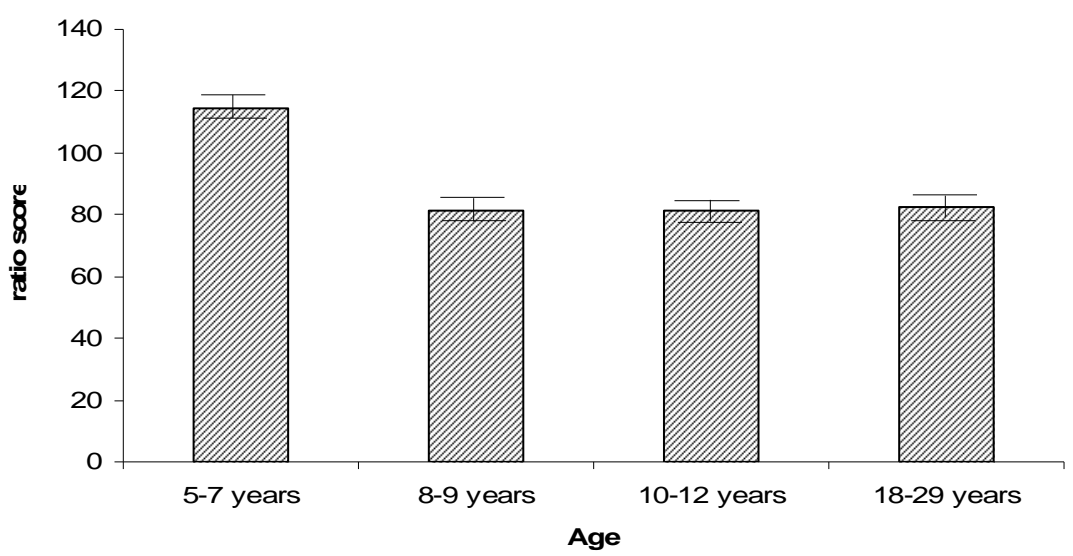

Figure 3. Mean ratio scores and error bars for each age group of all four electrodes combined. The youngest group showed significantly less inhibition compared to the other three groups.

\section{Discussion}

The P50 conditioning-testing paradigm was used in order to study the development of P50 sensory gating. As suggested by one of the reviewers we also present the analyses of the peak to peak method, next to the baseline to peak method. Overall did the peak to peak method reveal similar results as the baseline to peak method. However, we prefer the baseline to peak method over the peak to 
peak method because of the issue of replication. Baseline to peak scoring can be done automatically by the computer, and is thus more objective. The ERP averages of the P50 of some children contained two or more preceding negativities so that it was difficult to decide which preceding negativity to take when calculating the distance between the two peaks. Also did the baseline to peak method render developmental results for P50 amplitudes and for the two inhibition measures that were more readily interpretable. The only difference was that the peak to peak method produced an additional significant Electrode $x$ Group interaction that did not reach significance in the baseline to peak method. Therefore, it was decided to limit the discussion to the results obtained by the baseline to peak method.

Children aged 5-7 years had smaller conditioning amplitudes compared to the three other age groups (8-9; 10-12; 18-29 years). Furthermore, children of 10-12 years of age had larger testing amplitudes compared to adults. There were no differences in latency or gender in the age range between 5 years old to adulthood.

Although an increase in processing speed with increasing age is commonly found in developmental studies (Johnstone, Barry, Anderson, \& Coyle, 1996; Knight, Staines, Swick, \& Chao, 1999; Kurtzberg, Vaughan, Kreuzer, \& Fliegler, 1995; Oades, Dittmann-Balcar, \& Zerbin, 1997; Zenker \& Barajas, 1999) our study found no group differences in latency in the P50 sensory gating paradigm. This finding is comparable to the results of other P50 studies that also did not find P50 latency differences. Marshall, Bar-Haim, and Fox (2004) found no latency differences in the age range of 7-13 years, while Rasco, Skinner, and Garcia-Rill (2000) found no latency differences in persons of 12-78 years of age. However, Myles-Worsley, Coon, Byerley, Waldo, Young, and Freedman (1996) found significant longer latencies in 10-14 years old children as compared to two adult groups (20-39 years) for the conditioning stimulus only. This was not found in the present study. At this point it is not clear what may have caused this difference, although Myles-Worsley, et al. (1996) did not report that they controlled for intelligence. Freedman, Adler, and Waldo (1987) reported a significant correlation at $\mathrm{Cz}$ that reflected a rapid change in children aged 1-8. Overall, this study did not find a correlation for age at any of the four electrodes. However, when looking within the age range of 5 to 8 years old at electrode $\mathrm{Cz}$, there was a negative correlation that tended to be significant for the conditioning response and a significantly negative correlation for the testing response. In line with most P50 developmental studies the present study suggests that the speed of processing in P50 sensory gating has already reached maturity by the age of 5 years. 
Compared to the other three age groups, children of 5-7 years of age had smaller conditioning amplitudes and children aged 10-12 years had larger amplitudes to the testing response compared to adults. Freedman, et al. (1987) found a decrease in conditioning amplitude with increasing age within the two youngest age groups (1-11 years). However, our results are less readily comparable as they used a different age range. Contrary to the current study both MylesWorsley, et al. (1996) and Rasco, et al. (2000) found no age differences in amplitude. However, both these studies used older age groups, while Rasco, et al. (2000) used participants with an increased risk for schizophrenia. Marshall, et al. (2004) found only a significant negative age correlation for the testing amplitudes that is similar to our finding that 10-12 years old had larger testing amplitudes compared to adults. But, they included a smaller number of children in a different age range (7-13 years) and no adults. Apparently, P50 amplitude is not mature until the age of 8 years.

The youngest age group (5-7 years) showed significantly less P50 inhibition compared to the other age groups. Freedman, et al. (1987) reported a weak but significant negative correlation between $\mathrm{P} 50$ ratio score and age in the total group (1-55 years). When looking at the ratio score at $\mathrm{C} z$, this study also found a negative correlation within the age range of 5 to 29 years. Myles-Worsley, et al. (1996) and Rasco, et al. (2000) found no differences in sensory gating within the age ranges of 10-39 and 12-78 years, respectively. Finally, Marshall, et al. (2004) found that P50 suppression increased with age (7-13 years) and reached adult levels in the oldest participants, after removing the P50 augmenters. Overall, the reports mentioned above and the results in the current study suggest that the development of P50 sensory gating matures around the age of 8 years. To facilitate comparisons with other studies both difference scores (C-T) and ratio scores (T/Cx100) are reported in the Results section and in figures and tables. Both measures rendered similar results, except that the ratio score shows a very abrupt difference between the youngest age group and the other age groups (see Fig. 3), while the difference score displays a more gradual transition between 5 and 10 years old (see Fig. 2), although this difference is not significant. As the difference score seems more sensitive than the ratio score and because its results are easier to interpret, we prefer the use of the difference score.

There is increasing evidence that the frontal cortex is a major contributor to P50 sensory gating (Grunwald et al., 2003; Knight, Staines, Swick, \& Chao, 1999; Weisser, Weisbrod, Roehrig, Rupp, Schroeder, $\&$ Scherg, 2001), and that it reaches maturity 
past the age of 12 years (Bunge, Dudukovic, Thomason, Vaidya, \& Gabieli, 2002). In our data the anterior sites ( $\mathrm{Fz}$ and $\mathrm{CZ}$ ) produced indeed significant larger amplitudes than the posterior ones ( $\mathrm{Pz}$ and $\mathrm{Oz})$, but there were no differences in scalp distribution between the age groups. All children showed the same frontocentral distribution compared to adults. This study does not focus on the cerebral origin of the P50 phenomena. The brain activity that can be captured by electrodes at the skull cannot directly probe into hippocampal activity because it is situated to deep in the brain. But as far as cortical activity is concerned, the current data clearly show that P50 sensory gating matures before the age of 8 years.

The current study found no gender differences for P50 latency, P50 amplitude or P50 inhibition. With regard to P50 latency our data concerning gender are in agreement with the findings of other studies (Freedman, et al., 1987; Hetrick, Sandmann, Bunney, Jin, Potkin, \& White, 1996; Rasco, et al., 2000; White, Kanazawa, \& Yee, 2005) that also did not found gender differences for latency. Like the current study all the studies that included gender, did not find gender differences in P50 sensory gating. The current study points out that these gender differences cannot be found in adults, but also not in childhood development.

In conclusion, with regard to the development of sensory gating it can be stated that children as from the age of 5 years show the same frontocentral distribution and the same speed of processing in P50 sensory gating as adults. Up to 8 years of age P50 amplitudes to the first response appear to increase and sensory gating appears to improve. These developmental findings should be taken into account when interpreting the P50 data of patient groups as decreased amplitudes to the first response combined with less sensory gating can be due to a maturational lag. However, there seems to be no need to account for gender differences, both in adults and in children.

\section{Acknowledgements}

This research was supported by a grant of SWZ Zonhove, an institution for people with physical and multiple disabilities and by the Faculty of Psychology of M aastricht University. Special thanks goes to Mr. Chris Zaad, Head of the Division Treatment of SWZZonhove, for making this study possible. 
We also thank the primary schools St. Jozef in Elsloo, Don Bosco in Stein and Dionsius in Schinnen, the parents and the children for participating in our study. 



\section{Chapter 3}

The Development of Passive Auditory Novelty Processing

This chapter is based on: Brinkman, M.J.R., Stauder, J.E.A., 2008. The development of passive auditory novelty processing. International Journal of Psychophysiology 70, 33-39. 


\section{CHAPTER 3}

\section{Abstract}

In a passive auditory oddball study the development of novelty processing was examined in 5-7 $(\mathrm{N}=26), 8-9(\mathrm{~N}=31), 10-12(\mathrm{~N}=30)$, and 18-29 $(\mathrm{N}=35)$ years olds. Even though the main goal of this study was to replicate the findings of an earlier one, a shorter and simplified paradigm was used in order to gather developmental reference data for non-responsive patient groups that are unable to give an overt response. As expected, this adapted procedure replicated the findings regarding the development of passive novel sound processing. Firstly, the present data indicated two novelty components, each with a different topography and a different development. Secondly, both novelty components were still not mature in 10-12 years olds. The early novelty P3 had a central focus and its amplitude became more positive with increasing age. Also, its latency did not differ between the four age groups. The focus of the late novelty P3 shifted from frontocentral in 5-7 years olds to parietal in adults. In addition, the late novelty $\mathrm{P} 3$ amplitude at $\mathrm{Pz}$ became more positive with age, while the late novelty $\mathrm{P} 3$ latency was longer in 5-7 and 8-9 years olds compared to 10-12 years olds and adults. Thus, it appears that the adapted paradigm is a suitable tool for assessing auditory novelty processing in nonresponsive patients. 


\section{Introduction}

The ERP technique is a very suitable and common method to study cognitive development in children. In doing so, most studies require an overt response from their participants, using a so-called "active" paradigm. In addition, there are also ERP paradigms that require no response when studying cognitive development. A good example of such a paradigm is the passive auditory novelty oddball task, assessing the novelty or orienting response. Assets of this paradigm are the fact that the novelty response is easy to score individually, and that it shows strong developmental effects up to adolescence (Courchesne, 1978). However, up to now very few studies (Čeponiene, Lepistö, Soininen, Aronen, Alku, \& Näätänen, 2004; Wetzel \& Schröger, 2007) addressed the development of passive auditory novelty processing using the authentic passive auditory novelty oddball task and therefore developmental data regarding passive auditory novelty processing are scarce.

The orienting response, first studied by Sokolov (1963), is an essential mechanism for humans and higher animals for survival (Sokolov, 1963). This mechanism causes one to involuntarily focus one's attention to new, unexpected or unpredictable events like the scream of a child or the ringing of the door bell. Involuntarily focusing evokes a P3a, novelty P3 or no-go P3, variants of the same generation system that are dependent on type of distraction and task demands. The P3a has a central/parietal maximum and occurs when a deviant tone (distracter) is presented infrequently in a series of frequent tones (Polich, 2007). The novelty P3 appears when a unique sound (distracter) occurs in a series of repeating sounds, has a frontal/central focus and habituates rapidly (Courchesne, Hillyard, \& Galambos, 1975; Knight, 1984), whereas the no-go P3 with a central/parietal maximum is the result of a subject withholding his response to infrequent non-novel repeated stimuli used as distracters (Kok, 1986; Pfefferbaum, Ford, Weller, \& Kopell, 1985). According to Polich (2007) stimulus information is maintained in a frontal working memory and monitored by structures of the anterior cingulate. When a distracter (automatically) or target (purposefully) is detected, a P3a is generated by the activity pattern of the anterior cingulate and related structures (top-down attention switching). The attention-driven stimulus signal is then transmitted to temporalparietal areas, where context updating by memory-related storage operations takes place (bottom-up) and a P3b is generated (Polich, 2007). Friedman, Cycowicz, \& 
Gaeta (2001), on the other hand, indicated that the novelty P3 consists of a frontal and a parietal part. The frontal aspect, the $\mathrm{P} 3 \mathrm{a}$, reflects the orienting to the novel stimulus (Cycowicz \& Friedman, 1997; Friedman, Kazmerski, \& Cycowicz, 1998; Knight \& Nakada, 1998) and is hypothesized to decrease from the moment novels are being categorized (Friedman, et al., 2001). The posterior aspect is assumed to reflect the categorization of initially uncategorized sounds (Courchesne, et al.,1975; Knight, Grabowecky, \& Scabini, 1995) or the matching of sensory information to memory templates (Cycowicz \& Friedman, 1998; Knight, et al., 1995). Friedman, et al. (2001) acknowledges that the posterior aspect of the novelty P3 and the target P3b have features in common, but that the issue whether they are the same or not needs to be tested experimentally.

Recently, several studies (Čeponiene, Lepistö, Soininen, Aronen, Alku, \& Näätänen, 2004; Escera, Alho, Winkler, \& Näätänen, 1998; Gumenyuk, Korzyukov, Alho, Escera, \& Näätänen, 2004; Gumenyuk et al., 2001; Määttä, Saavalainen, Könönen, Pääkkkönen, M uraja-M urro, \& Partanen, 2005; Wetzel, \& Schröger, 2007) mentioned the existence of a novelty P3 component with a double peak. Although the functional significance of this double peak is not clear yet, it is suggested that the late novelty P3 is enhanced by attention and might represent the orienting response itself (Escera, et al., 1998), while the early novelty P3 might reflect a sensory-attention interface that based on the sensory output (from N1 or MMN mechanisms) governs the direction of the attentional move (Čeponiene, et al., 2004).

Although the prefrontal cortex is one of the key brain areas contributing to orienting (Knight, 1984) and this function is still immature in preadolescence (Bunge, Dudukovic, Thomason, Vaidya, \& Gabrieli, 2002) little is known about the development of orienting in children. Several studies mentioned age-related differences in the auditory novelty $\mathrm{P} 3$ scalp distribution between children and adults (Čeponiene, et al., 2004; Cycowicz, et al., 1996; Gumenyuk, et al., 2004; Gumenyuk et al., 2001; M äättä, et al., 2005; Wetzel, \& Schröger, 2007), but their results are not equivocal. Cycowicz, et al. (1996) found that the latency of the late novelty P3 decreased with increasing age, while Gumenuyk et al., $(2001,2004)$ mentioned no latency differences between different age groups. With regard to the early novelty P3 some studies reported that this component had a frontal focus in younger children (6-9) and a central one in older children (Määttä, et al., 2005; Wetzel, \& Schröger, 2007) and adults (Escera, et al., 1998; Määttä, et al., 2005; Wetzel, \& Schröger, 2007), while other studies (Čeponiene, et al., 2004; Gumenyuk, et al., 
2004; Gumenyuk et al., 2001) indicated that in both younger and older children and in adults the early novelty P3 had a frontocentral scalp distribution. The late novelty P3 had a central focus in 5-7 years olds (Cycowicz, et al., 1996) and a centroparietal one in older children and adults (Cycowicz, et al., 1996; Čeponiene, et al., 2004), while according to Määttä, et al. (2005) 8-9 years olds had a frontal scalp distribution and adults a parietal one. Gumenuyk et al. $(2001,2004)$ reported a central scalp distribution in 8-9 years olds and a frontal one in 12-13 years olds with the youngest group having larger amplitudes compared to the 12-13 years olds and Escera, et al. 1998) mentioned a right frontal maximum in adults. The use of different paradigms may be responsible for these differences. Čeponiene, et al. (2004), Cycowicz, et al. (1996), Escera, et al. (1998), and Wetzel and Schröger (2007) used an auditory novelty oddball task wherein environmental, complex and/or simple sounds acted as novel stimuli. Määttä, et al. (2005) presented 6 different artificial complex tone bursts as novel stimuli in a dichotic novelty oddball task, while Escera, et al. (1998) and Gumenuyk et al. (2001, 2004) exploited a visual discrimination task wherein environmental sounds as novel stimuli preceded visual stimuli. In addition, the study of Escera, et al. (1998) consisted of a passive auditoryalone condition. Furthermore, Cycowicz, et al. (1996), Escera, et al. (1998) and Gumenuyk et al. (2001 and 2004) had paradigms that required a response, while Čeponiene, et al. (2004), M äättä, et al. (2005), and Wetzel and Schröger (2007) used passive paradigms.

Wetzel and Schröger (2007) did not limit their study to the processing of unexpected novel sounds in children (6-8 and 10-12 years) and adolescents (17-18 years). They also looked at the P3a elicited by unexpected deviant sounds. For this purpose they used long $(500 \mathrm{~ms})$ and short $(100 \mathrm{~ms})$ novels and pitch deviants, each presented in separate blocks. The 6-8 years olds revealed a more anterior early novelty P3, whereas older children and adolescents had a clear maximum at Cz. Furthermore, adolescents showed larger late novelty P3 amplitudes at Pz compared to children. The mean amplitudes of the early P3a, elicited by deviant stimuli, were largest at $\mathrm{Cz}$, and those of the late P3a were largest at $\mathrm{Fz}$, while no duration or age effects were observed (Wetzel \& Schröger, 2007).

The main aim of the present study was to replicate the findings by Wetzel and Schröger (2007) regarding the development of auditory novelty and deviant processing as revealed by an early and late novelty P3 and a P3a, respectively. However, in order to use our data as reference for non-responsive patient groups like persons with profound intellectual and multiple disabilities (PIMD), low- 


\section{CHAPTER 3}

functioning people with autism and coma patients, we needed a much simpler and shorter paradigm. Therefore, we adapted our procedure by leaving out the duration manipulation and by presenting novel and deviant sounds together instead of in separate blocks. Thus, we wanted to examine whether the developmental data elicited by this shorter and simplified paradigm are comparable to the findings of Wetzel and Schröger (2007).

\section{Methods}

\section{Participants}

In total, 35 adults and 87 children with self-reported normal hearing were included in the analysis. The adult group consisted of 16 men and 19 women with an average age of 21.4 years (S.D. 2.3 years; range 18.5-29.4 years). The children were split up into three different age groups. The eldest group counted 30 children (12 male, 18 female) with an average age of 11.2 years (S.D. 0.8 years; range 10.112.4 years). The middle group consisted of 31 children ( 13 male, 18 female) with an average age of 8.8 years (S.D. 0.5 years; range 8.0-9.7). The youngest group included 26 children ( 8 male, 18 female) that had an average age of 6.8 years (S.D. 0.8 years; range 5.4-7.9 years). EEG recordings for adults were performed at the Faculty of Psychology of the Maastricht University, and for children at primary schools in Elsloo, Stein and Schinnen, towns in the vicinity of Maastricht, The Netherlands. Parental consent was obtained for all children and the study was approved by the Maastricht University Ethical Committee of Psychology (01-05-2004). Children agreeing to participate in the study were first administered the Child Behavior Checklist/4-18 (CBCL/4-18). Children scoring within a clinical range on the scales for anxiety/depression, attentional problems and school activities, were excluded from this study (Verhulst, van der Ende, \& Koot, 1996). The exclusion criteria for adults were attentional or psychiatric problems reported by themselves. Finally, both students and children completed Raven's Standard Progressive Matrices (SPM) in order to measure intelligence level (Raven, Court, \& Raven, 1983). Students filled in the SPM during electrode application, the children did this in a group in classrooms under supervision of the experimenters. 
Stimuli

The stimuli of the ERP task were harmonic tones and environmental sounds. The standard tone $(750 \mathrm{~Hz})$ was made up of the formants 750,1500 and $2250 \mathrm{~Hz}$. The deviant tone $(500 \mathrm{~Hz})$ included the formants 500,1000 , and $1500 \mathrm{~Hz}$. The second and third formants were presented with -3 and $-6 \mathrm{~dB}$, respectively, in order to compensate for differences in loudness. In addition to harmonic tones the participant also heard unique environmental sounds (Fabiani, Kazmerski, Cycowicz, \& Friedman, 1996) coming from six sound categories: animal, bird, human, music, noise and video-game noise. Novels and deviants were presented with a probability of $15 \%$, respectively. Both deviant and novel stimuli were always followed by a standard stimulus. All stimuli lasted $300 \mathrm{~ms}$, and had a sound level of about $75 \mathrm{~dB}$ SPL (A), measured at the headphones. The fixed ISI was 1000 ms. The task was divided into two blocks, each consisting of 205 stimuli. In order to get used to the stimuli 3 standards and 3 deviants preceded the actual paradigm. In total, the task lasted about 7.5 minutes.

\section{EEG recording}

Thirty tin electrodes in an electro-cap (Electro-cap, Inc., USA) were connected to a 40 channel NuAmps DC Portable amplifier (Neuroscan, Inc., USA). The ground electrode was placed equally distanced between the $\mathrm{Fp} 1, \mathrm{Fp} 2$ and $\mathrm{Fz}$ electrodes. The reference electrode was placed at the right mastoid (A2). The vertical electrooculogram (EOG) was recorded from one electrode above and one below the right eye and the horizontal EOG from two electrodes at the outer canthi of the eyes. The impedance of all electrodes was measured by a handheld impedance meter ( $F$ EZM 4, Grass Inc., USA) and did not exceed $5 \mathrm{kOhm}$ for the EEG and $8 \mathrm{kOhm}$ for the EOG electrodes. Data were continuously sampled with a gain of $250 \mathrm{~Hz}$. Stimulus presentation was controlled by ERTS software (Version 3.18, BeriSoft Cooperation, Germany).

\section{Procedure}

Upon arrival the procedure of the session was explained to the participant. Two researchers were seated in the same room, facing or beside the participant. During the task the participant watched a silent cartoon on a portable DVD player. The participants were instructed to concentrate on the DVD and ignore the sounds. The 


\section{CHAPTER 3}

participants also performed a visual oddball task and an auditory habituation task in addition to the task reported here. The entire experiment, including the application and removal of the facial electrodes and the electrocap, lasted 90 minutes.

\section{Data analysis}

The recorded EEG and EOG signals were analyzed using Neuroscan 4.3. The EOG signals consisted of horizontal and vertical EOG channels. The EEG signals were corrected by the EOG channels for vertical eye movements by means of linear regression. Next, the signals were epoched at an interval between $-200 \mathrm{~ms}$ prestimulus and 800 ms poststimulus, bandpass filtered between 0.1 and $30 \mathrm{~Hz}$, and baseline corrected (-200 to $0 \mathrm{~ms}$ ). After this, individual EEG sweeps were rejected when the amplitude exceeded $\pm 100 \mu \mathrm{V}$ in students and $\pm 150 \mu \mathrm{V}$ in children. When more than $20 \%$ of the sweeps had to be removed (this means that a minimum of 48 sweeps was averaged to produce an ERP deviant and novelty average), the participant was excluded from the analyses. Finally, the remaining standard, deviant and novel stimuli were averaged.

All early and late novelty P3 latencies at $\mathrm{Fz}, \mathrm{Cz}$, and Pz were established by measuring the maximum peaks of the raw ERPs in a window of 190-310 ms and of 290-410 ms, respectively. The mean amplitudes of the early and late novelty P3 were measured within windows of 200-300 ms and 300-400 ms after stimulus onset, respectively.

When looking at the scalp distribution, the mean amplitudes of the early and late novelty P3 were normalized using the vector scaling technique. This technique divides the amplitude at each electrode by the square root of the sum of the squared amplitudes at all electrodes (McCarthy \& Wood, 1985). The normalized data were statistically (SPSS 11.5) analyzed by means of General Linear M odels repeated measures ANOVA. In case of significant $(p<05)$ interactions post-hoc tests were performed using one-way ANOVAs and t-tests. If there was a violation of the assumption of sphericity a Huynh-Feldt correction was applied. 


\section{Results}

Fig. 1 displays grand-average ERPs of the standard (solid line) and novel (dotted line) stimuli and Fig. 2 those of the standard (solid line) and deviant (dotted line) stimuli. To show the differences between the stimuli more clearly, and to compare our data with other auditory novelty studies the novel minus standard difference waves (dashed line) are also displayed in Fig. 1, while the deviant minus standard

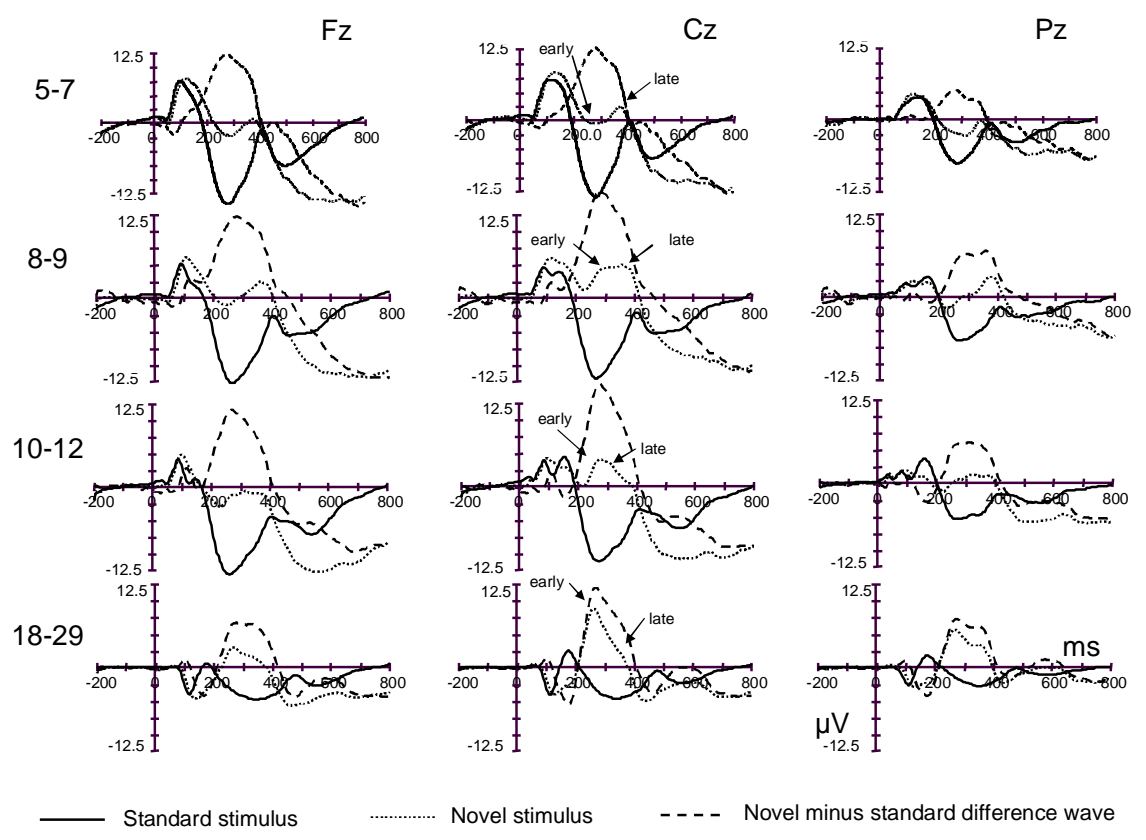

Figure 1. Grand-average ERPs of the standard and novel stimuli and the novel minus standard difference waves. The arrows indicate the early and late novelty P3, respectively. The novel sounds elicited biphasic negativity in the youngest children that developed towards biphasic positivity in older children (Cz and $\mathrm{Pz}$ ) and adults. 


\section{CHAPTER 3}

difference waves (dashed line) are shown in Fig. 2. The novel sounds elicited biphasic negativity in the youngest children that developed towards biphasic positivity in older children ( $\mathrm{Cz}$ and $\mathrm{Pz})$ and adults. Furthermore, the mean novel amplitudes in adults were more positive than in the ones in children. With regard to the deviant sounds it can be observed that the deviant amplitudes as compared to the standard ones are more negative in children and less negative in adults, and that the deviant amplitudes at Pz are less negative than the ones at $\mathrm{Fz}$ and $\mathrm{Cz}$ in both children and adults. Fig. 3 represents the mean amplitudes of the early novelty P3, Fig. 4 those of the late novelty P3.
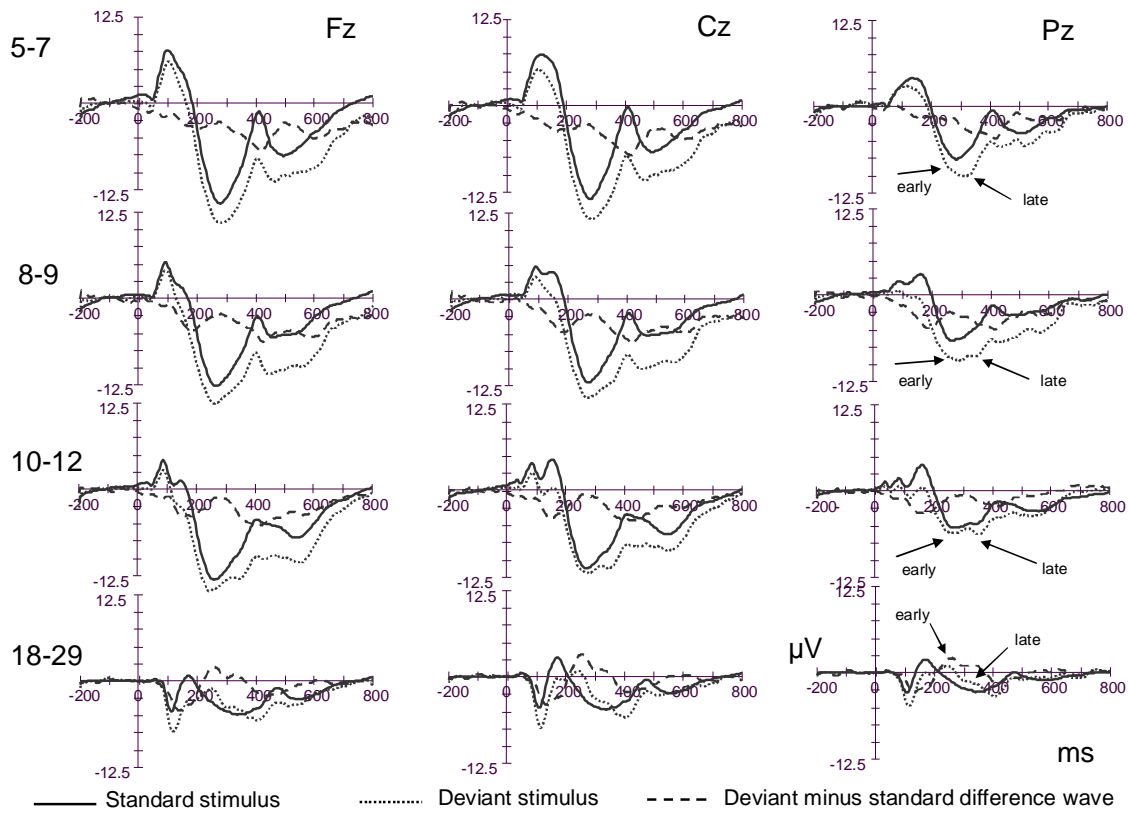

Deviant stimulus

Deviant minus standard difference wave

Figure 2. The grand-average ERPs of the standard and deviant stimuli and the deviant minus standard difference waves. The arrows indicate the early and late deviant component, respectively. The deviant amplitudes are more negative in children compared to adults. 
Novel stimuli

In order to confirm the existence of a biphasic novelty component in the present data they were checked for differences in topography. The normalized mean ERP amplitudes showed a three-way interaction of the factors Component (early, late), Stimulus (standard, deviant, novel), and Electrode ( $F z, C Z, P z)(F(2.6,315.3)=17.780$, $\mathrm{p}=0.0001$ ). Each stimulus category (standard, deviant, novel) displayed a significant Component $x$ Electrode interaction $(F(1.7,201.7)=33.350, \quad p=0.0001$, $F(1.8,217.4)=23.139, p=0.0001$ and $F(2.0,242.0)=29.030, p=0.0001)$, respectively. The early standard amplitudes at Pz and the early deviant amplitudes at $\mathrm{Cz}$ and $\mathrm{Pz}$ were less negative compared to the late ones. In contrast, the early standard amplitudes at $\mathrm{Cz}$ were more negative compared to the late ones. Also, the early novel amplitudes at $\mathrm{Cz}$ were more positive than the late ones, while at $\mathrm{Pz}$ the late novel amplitudes were more positive than the early ones $(p<0.005)$. Thus, based on the fact that each of the novelty components has a different topography the existence of a biphasic novelty component in the present data is supported.

Another argument for the existence of a biphasic novelty component is the finding of a different development. Therefore, it was examined whether the mean amplitudes of both components developed differently. The normalized mean amplitudes revealed a four-way interaction of the factors Component (early, late), Stimulus (standard, novel), Electrode ( $\mathrm{Fz}, \mathrm{Cz}, \mathrm{Pz}$ ) and Group (5-7, 8-9, 10-12, and 1829 years) $(F(5.8,229.9)=6.485, p=0.0001)$. For both the early and late component the normalized mean amplitudes displayed the three-way interaction Stimulus $x$ Electrode $x$ Group $(F(5.4,211.404)=3.214, p=0.007)$ and $(F(5.2,202.9)=5.185$, $\mathrm{p}=0.0001$ ), respectively.

\section{Early novelty P3}

In every age group the early mean amplitudes showed Stimulus $x$ Electrode interactions $(5-7$ years: $F(2.0,50.0)=62.795, p=0.0001 ; 8-9$ years: $F(1.8$, $54.2)=40.193, p=0.0001 ; 10-12$ years: $F(1.9,55.9)=35.370, p=0.0001$; adults: $F(1.6$, 53.7) $=48.260, p=0.0001$ ). In all age groups the standard amplitudes were more negative than the novel ones at $\mathrm{Fz}, \mathrm{Cz}$, and $\mathrm{Pz}(\mathrm{p} \varangle 0.05)$. Also, in all age groups the standard amplitudes at $\mathrm{Pz}$ were less negative compared to the ones at $\mathrm{Fz}$ and $\mathrm{Cz}$, and the $\mathrm{Cz}$ amplitudes were less negative compared to the ones at $\mathrm{Fz}$. The novel amplitudes of all age groups were most positive at electrode $\mathrm{Cz}$. Furthermore, the $\mathrm{Fz}$ amplitudes of the two youngest groups were less negative than the $\mathrm{Pz}$ 


\section{CHAPTER 3}

amplitudes, while in the 10-12 years olds the opposite was the case. The $\mathrm{Pz}$ amplitudes in adults were more positive than the $\mathrm{Fz}$ amplitudes $(p \varangle 0.05)$.

Both the standard and novel mean amplitudes revealed Electrode $x$ Group interactions $(F(5.1,199.3)=7.028, p=0.0001)$ and $(F(5.8,226.9)=7.822, p=0.0001)$, respectively. The standard $\mathrm{Fz}$ and $\mathrm{Pz}$ amplitudes of 5-7 years olds and the standard $\mathrm{Pz}$ amplitudes of 8-9 years olds were more negative compared to the adult ones. Furthermore, children aged 5-7 and 8-9 years had standard Pz amplitudes that were more negative than those of the 10-12 years olds. The adult novel amplitudes at $\mathrm{Cz}$

\section{Mean amplitudes of the early novelty P3}

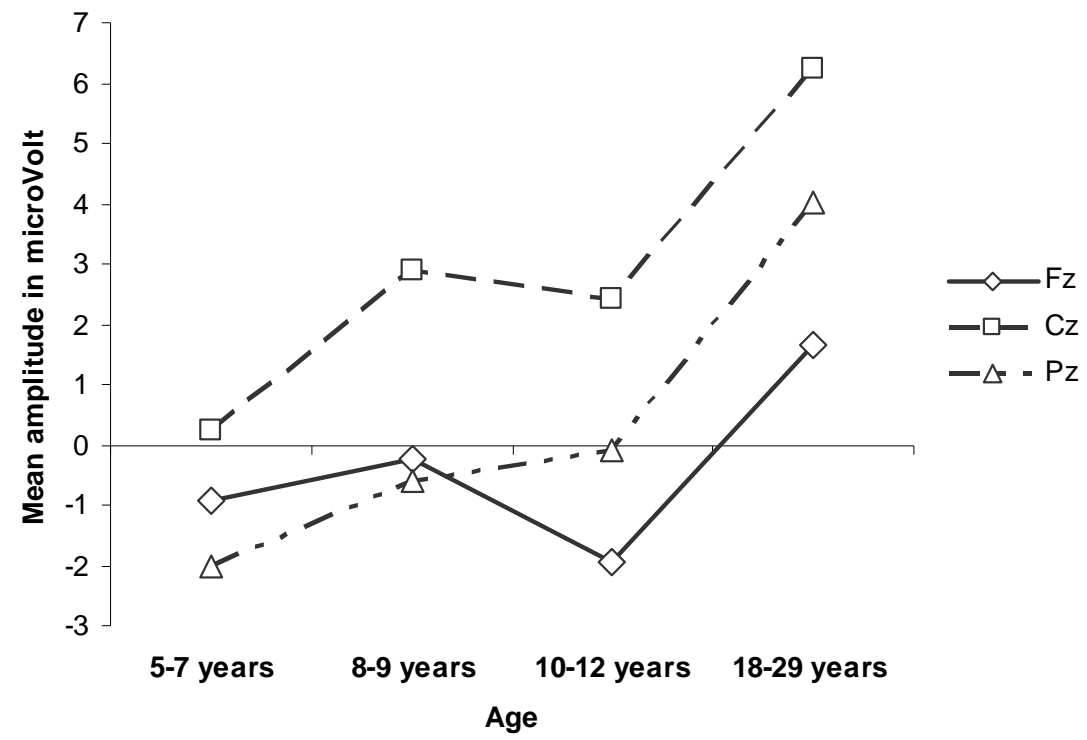

Figure 3. M ean amplitudes of the early novelty P3 at electrodes Fz (solid line, diamond), $\mathrm{Cz}$ (dashed line, square), and Pz.(dashed-dotted line, triangle). 
and Pz were more positive than those of the children. Also, 8-9 years olds had more positive novel $\mathrm{Cz}$ amplitudes than the 5-7 years olds, and adults had more positive novel $\mathrm{Fz}$ amplitudes than the $10-12$ years olds $(p \varangle 0.05)$.

In short, the focus of the early novelty P3 in children and adults was central and the novel amplitude became more positive with increasing age. The early novelty P3 latency did not differ between the four age groups.

\section{Mean amplitudes of the late novelty P3}

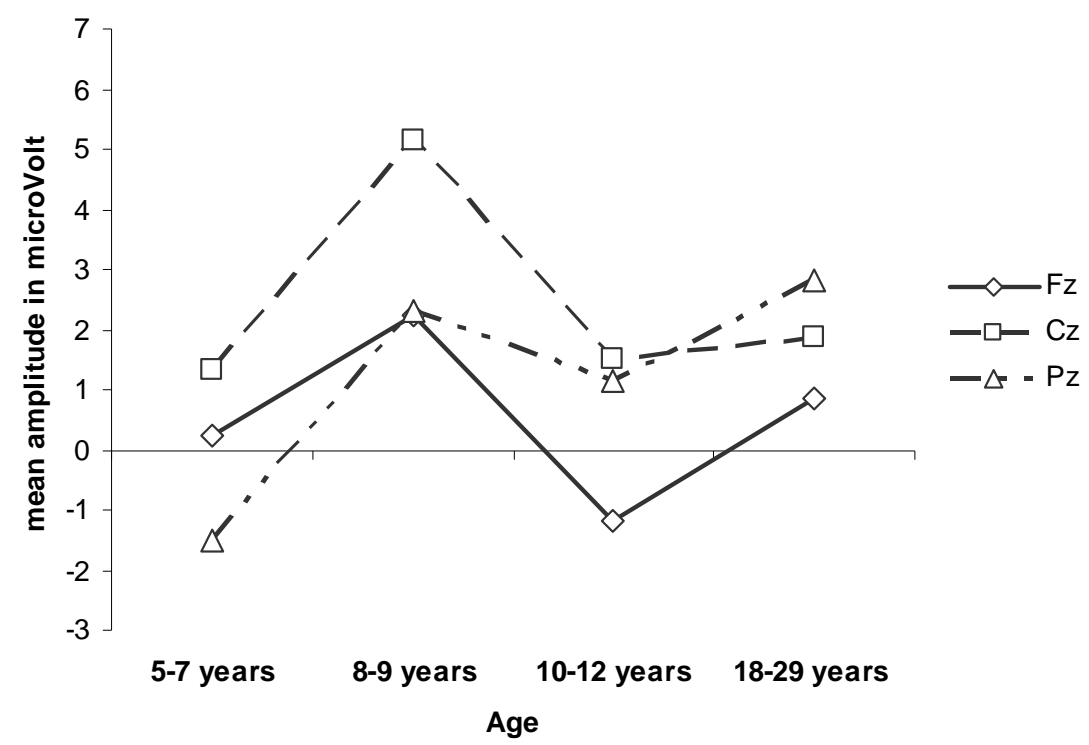

Figure 4. M ean amplitudes of the late novelty P3 at electrodes Fz (solid line, diamond), Cz (dashed line, square), and Pz.(dashed-dotted line, triangle).

Late novelty P3

In all children the late mean amplitudes showed Stimulus $x$ Electrode interactions (5-7 years: $F(1.6,40.7)=30.646, p=0.0001 ; 8-9$ years: $F(1.9$, 


\section{CHAPTER 3}

$57.8)=19.273, p=0.0001 ; 10-12$ years: $F(1.9,56.4)=14.991, p=0.0001)$. In adults there were significant main effects of Stimulus $(F(1.0,34.0)=140.356, p=0.0001)$ and of Electrode $(F(1.5,52.5)=52.202, p=0.0001)$. In children the standard amplitudes at electrodes $\mathrm{Fz}, \mathrm{Cz}$, and $\mathrm{Pz}$, and in adults the standard amplitudes overall were more negative than the novel amplitudes $(p \varangle 0.05)$. Also, in all age groups the standard amplitudes at Pz were less negative compared to the amplitudes at $\mathrm{Fz}$ and $\mathrm{Cz}$, and the $\mathrm{Cz}$ amplitudes were less negative compared to the ones at $\mathrm{Fz}$. The focus of the novel amplitudes shifted from more positive $\mathrm{Fz}$ and $\mathrm{Cz}$ amplitudes in 5-7 years olds via more positive $\mathrm{Cz}$ amplitudes in 8-9 years olds and more positive $\mathrm{Cz}$ and $\mathrm{Pz}$ amplitudes in 10-12 years olds to more positive $\mathrm{Pz}$ amplitudes than $\mathrm{Fz}$ and $\mathrm{Cz}$ amplitudes and more positive $\mathrm{Cz}$ amplitudes compared to $\mathrm{Fz}$ amplitudes in adults $(p \varangle 0.05)$.

The novel mean amplitudes revealed Electrode $x$ Group interactions, $(F(5.3$, 206.8) $=6.856, p=0.0001)$. The standard mean amplitudes displayed significant main effects of Electrode $(F(1.8,207.8)=278.240, p=0.0001)$ and of Group $(F(3$, 118) $=3.573, p=0.016$ ). Adults had less negative standard amplitudes than children aged 5-7 years and 8-9 years, and 10-12 years olds had less negative standard amplitudes compared to 5-7 years olds. Adults had more positive novel $\mathrm{Pz}$ amplitudes compared to the children, and 10-12 years olds had more positive $\mathrm{Pz}$ amplitudes compared to 5-7 years olds $(p<0.05)$.

An oneway Anova for the late novelty $\mathrm{P} 3$ latency showed significant main effects of Group at $\mathrm{Fz}(\mathrm{F}(3,118)=3.40, \mathrm{p}=0.02)$, at $\mathrm{Cz}(\mathrm{F}(3,118)=3.73, \mathrm{p}=0.013)$ and at $\mathrm{Pz}$ $(F(3,118)=9.35, p=0.0001)$. Post hoc $t$-tests revealed that the two youngest groups had significantly longer latencies at $\mathrm{Fz}, \mathrm{Cz}$, and Pz compared to the adults $(\mathrm{p} \varangle 0.05)$, and longer latencies at $\mathrm{Pz}$ compared to the $10-12$ years old $(\mathrm{p} \varangle .05)$.

In short, the focus of the late novelty $\mathrm{P} 3$ shifted from frontocentral in the youngest children to parietal in adults and amplitudes at $\mathrm{Pz}$ became more positive with increasing age. Finally, 5-7 and 8-9 years olds had longer latencies compared to older children and adults.

Deviant stimuli

The normalized mean amplitudes showed a four-way interaction of the factors Component (early, late), Stimulus (standard, deviant), Electrode $(F z, C z, P z)$ and Group (5-7, 8-9, 10-12, and 18-29 years) $(F(4.7,185.6)=8.446, p=0.0001)$. For both 
the early and late component the normalized mean amplitudes revealed Stimulus $x$ Electrode $x$ Group interactions $(F(4.9,190.6)=7.642, \quad p=0.0001)$ and $(F(4.0,157.3)=3.740, p=0.006)$, respectively.

\section{Early deviant}

Except for the 8-9 years olds the mean amplitudes of all groups showed Stimulus $x$ Electrode interactions (5-7 years: $F(1.4,34.1)=25.471, p=0.0001 ; 10-12$ years: $F(1.7,48.0)=28.001, p=0.0001 ;$ adults: $F(1.7,59.0)=27.566, p=0.0001)$. In the $5-7$ and 10-12 years olds the deviant amplitudes were more negative than the standard ones at the three electrodes, while in adults the opposite was the case $(p \varangle 0.05)$. Also, except for the 8-9 years olds the standard and deviant amplitudes at Pz were less negative compared to the ones at $\mathrm{Fz}$ and $\mathrm{Cz}$, and the standard and deviant $\mathrm{Cz}$ amplitudes were less negative compared to the ones at $\mathrm{Fz}(\mathrm{p} \varangle 0.05)$.

The mean deviant amplitudes displayed Electrode $x$ Group interactions $(F(5.2$, 202.5) $=9.753, p=0.0001$ ). The deviant $\mathrm{Cz}$ and $\mathrm{Pz}$ amplitudes in adults were less negative compared to these amplitudes in children and the deviant $\mathrm{Fz}$ amplitudes in adults were less negative compared to ones in the 10-12 years olds. In addition, the deviant $\mathrm{Fz}$ and $\mathrm{Cz}$ amplitude in 5-7 years olds and the deviant $\mathrm{Cz}$ and $\mathrm{Pz}$ amplitudes in 8-9 years olds were more negative compared to those amplitudes in the 10-12 years olds $(p \varangle 0.05)$.

Thus, the focus of the early mean deviant amplitude in all age groups was parietal. Also, the amplitudes became less negative with increasing age.

\section{Late deviant}

Except for the 8-9 years olds the mean amplitudes of all groups showed Stimulus $x$ Electrode interactions (5-7 years: $F(1.4,33.4)=10.357, p=0.001 ; 10-12$ years: $F(1.4$, 40.8 $=24.962, p=0.0001$; adults: $F(1.3,44.0)=27.940, p=0.0001)$. The deviant amplitudes in children were more negative compared to the standard ones at electrodes $\mathrm{Fz}, \mathrm{Cz}$, and $\mathrm{Pz}$. In adults, only the standard amplitude at Pz was more negative that the deviant one $(p<0.05)$. Also, in all age groups the standard and deviant amplitudes at $\mathrm{Pz}$ were less negative compared to the ones at $\mathrm{Fz}$ and $\mathrm{Cz}$. The standard amplitudes of all children groups at $\mathrm{Cz}$ were less negative compared to the 
ones at $\mathrm{Fz}$, while the deviant $\mathrm{Cz}$ amplitudes were only less negative than the deviant Fz amplitudes in the $5-7$ and $10-12$ years olds $(p<0.05)$.

The deviant mean amplitudes revealed Electrode $x$ Group interactions, ( $F(4.2$, 163.4) $=4.612, p=0.001$ ). The deviant $P z$ amplitudes in adults and in 10-12 years olds were less negative compared to these amplitudes in children aged 5-7 and 8-9 years. The deviant Fz amplitudes in 10-12 years olds were more negative compared to adults, while the deviant Fz amplitudes in 5-7 years olds were more negative compared to the $10-12$ years olds $(p<0.05)$.

Thus, the focus of the late mean deviant amplitudes in all age groups was parietal. In addition, the $\mathrm{Fz}$ and $\mathrm{Pz}$ amplitudes became less negative with increasing age.

\section{Discussion}

The main goal of the present study was to replicate the findings by Wetzel and Schröger (2007) regarding the development of auditory novelty and deviant processing using a shorter and simplified paradigm. The existence of two components in the present data was confirmed by both a different topography and a different development. Overall, for both the early and late component the standard mean amplitudes were more negative than the novel ones, while the deviant amplitudes were more negative compared to the standard ones. The standard and deviant sounds produced a large negativity in children and a smaller one in adults, whereas the novel sounds elicited a small negativity in the youngest children and a positivity in adults and in older children. The focus of the early novelty P3 in children and adults was central, and the early novelty amplitudes became more positive with increasing age. The focus of the late novelty P3 shifted from frontocentral in the youngest children to parietal in adults, and the novelty amplitudes at $\mathrm{Pz}$ became more positive with increasing age. Whereas the early novelty P3 latencies did not differ between the four age groups, the late novelty P3 latencies in 5-7 and 8-9 years olds were longer compared to older children and adults. Finally, the focus of both the early and late mean deviant amplitude in all age groups was parietal.

As in previous studies (Čeponiene, Lepistö, Soininen, Aronen, Alku, \& Näätänen, 2004; Escera, Alho, Winkler, \& Näätänen, 1998; Gumenyuk, Korzyukov, Alho, Escera, 
\& Näätänen, 2004; Gumenyuk et al., 2001; Määttä, Saavalainen, Könönen, Pääkkkönen, Muraja-Murro, \& Partanen, 2005; Wetzel, \& Schröger, 2007) novel sounds elicited a double-peaked novelty $\mathrm{P} 3$, both with a different distribution and a different development. Although all age groups showed an early novelty P3 that was maximal at $\mathrm{Cz}$, the scalp distribution was frontocentral in 5-7 and 8-9 years olds, and centroparietal in 10-12 years olds and in adults. Conform the present study others (Escera, et al., 1998; Määttä, et al., 2005; Wetzel, \& Schröger, 2007) also mentioned a frontal distribution in younger children and a central one in older children and adults, whereas Čeponiene, et al. (2004) and Gumenyuk et al. (2001, 2004) found a frontocentral distribution for both children and adults. This small discrepancy may be due to the fact that both Čeponiene, et al. (2004) and Gumenuyk et al. $(2001,2004)$ used paradigms in which the participant had to respond, while the present study and Escera, et al. (1998), Määttä, et al. (2005), and Wetzel and Schröger (2007) required no response. Furthermore, adults had more positive amplitudes at $\mathrm{Cz}$ then children. According to Čeponiene, et al. (2004) the early novelty $\mathrm{P} 3$ reflects a sensory-attention interface. Apparently, this interface is not fully mature yet by the age of 10-12 years. Finally, in line with Gumenyuk et al. $(2001,2004)$ the present study found no age-related latency differences.

According to Escera, et al. (1998) the late novelty P3 represents the orienting response itself. The amplitude focus of the late novelty P3 shifted from anterior to posterior sites, being frontocentral in 5-7, central in 8-9 and centroparietal in 10-12 years olds while adults had a parietal maximum. These results are in line with the reports of Cycowicz, et al. (1996), Čeponiene, et al. (2004), M äättä, et al. (2005), and Wetzel and Schröger (2007) who also reported a (fronto-) central scalp distribution in younger children, and a (centro-) parietal one in older children and adults. Furthermore, like the findings of M äättä, et al. (2005) and Wetzel and Schröger (2007) adults had more positive amplitudes than children at Pz. Finally, 5-7 and 8-9 years olds had longer late novelty $\mathrm{P} 3$ latencies at $\mathrm{Fz}, \mathrm{Cz}$, and $\mathrm{Pz}$ compared to adults, but only at Pz compared to 10-12 years olds. This is roughly comparable to Cycowicz, et al. (1996) who also indicated that the latency of the novelty P3 decreased with increasing age. In contrast, Gumenyuk et al. (2004 and 2001) indicated a central scalp distribution in the youngest group (8-9 years) and a frontal one in the oldest children (12-13 years) and Escera, et al. (1998) reported a right frontal maximum in adults. Also, Gumenyuk et al. $(2001,2004)$ found larger amplitudes in the 8-9 years olds compared to the 12-13 years olds and did not find age differences in latency. However, as both Escera, et al. (1998) and Gumenyuk et 
al. $(2004,2001)$ used a visual discrimination task instead of an auditory novelty oddball paradigm, the reported differences are probably the result of the different paradigms used. Also, in the study of Cycowicz, et al. (1996) even the 5-7 years olds showed a large novelty P3 while in the present study the novelty P3 in all age groups was relatively small. This discrepancy can be attributed to the fact that Cycowicz, et al. (1996) used a so-called active paradigm, while the present study employed a passive one. Passive tasks typically produce smaller amplitudes, as events like watching a DVD require attention (Polich, 2007). The findings of the present study concerning the late novelty P3 are compatible to Friedman, Cycowicz, and Gaeta (2001) who suggested a frontal and parietal aspect of the novelty P3. Our data indicate that the frontal aspect is far from mature by the age of 12 years. Evidently, as children display a more anterior activation pattern, they have more difficulty in categorizing novels compared to adults.

The main goal of this study was replicating the findings of Wetzel and Schröger (2007) by using a simplified and shorter paradigm. Like Wetzel and Schröger (2007) the present data showed a gradual ERP reduction of the positive and negative exogenous components with increasing age at the anterior electrodes. Both studies also found that adolescents had more positive late novelty P3 amplitudes at Pz compared to children. In addition, their and our study found a central early novelty P3 and a parietal focused late novelty P3. Although these two novelty P3 components are not clearly visible in figure 1 , they are manifest in the statistical analyses. Also, the novel positivity of our youngest children was smaller compared to the one of the youngest group of Wetzel and Schröger (2007). However, our youngest children were younger compared to theirs, namely 5-7 years versus 6-8 years. When comparing the short novel data of their 6-8 years olds with the data of our 8-9 years olds, there were no differences. Wetzel and Schröger (2007) indicated a polarity inversion of the novelty component at the mastoids. By using a right mastoid reference instead of a nose reference, novelty mastoid ERPs are lacking in the present study. In order to compare our study with Wetzel and Schröger (2007) the novelty data were re-referenced from the right mastoid to $\mathrm{Fz}$. This resulted in a polarity inversion of the novelty component at electrode $\mathrm{T} 3$, a site in close proximity of the left mastoid. Finally, the results regarding the deviant sounds were also roughly the same. The only difference concerned the focus. The present data found that both the early and late mean deviant amplitudes had a parietal focus in all age groups and that the amplitudes became less negative with increasing age. On the other hand, Wetzel and Schröger (2007) reported that the mean deviant amplitudes 
of the early P3a were largest at $\mathrm{Cz}$, and those of the late P3a were largest at $\mathrm{Fz}$, while no age effects were observed. However, a parietal P300 to deviant stimuli as found in our study is a very common finding in the literature (e.g. Polich, 1989; Oades, Dittman-Balcar, \& Zerbin, 1997; Zenker \& Barajas, 1999).

Admittedly, the standard stimuli in this paradigm evoked a huge negativity. The fact that they were also included in the ANOVAs might confound the novelty and deviance effects. Therefore, additional ANOVAs were run for both the novel and deviant stimuli separately. The novel and deviant ANOVAs revealed the same threeand two-way interactions as when the standard stimuli were included in the ANOVAs.

A disadvantage of using a passive paradigm is the fact that one cannot control the behavior of the participants. Especially in developmental studies it is conceivable that older children and adults use other strategies than younger children. Although one cannot rule out the possibility that the novel positivity that is found in adults and to a lesser extent in older children results from the use of different strategies, a passive auditory novelty paradigm does not readily evoke a specific strategy.

The developmental effects found in this study by analyzing only three midline electrodes are very robust. They were even significant when the data analyses included 30 electrodes.

In conclusion, the initial goal of the present study was an attempt to replicate the study of Wetzel and Schröger (2007) by using a simplified and shorter paradigm that was suitable for use in non-responsive patient groups. It appeared that this adapted procedure did not influence passive novel and deviant sound processing. The present data show that passive auditory novelty processing shows a very marked developmental change during childhood that is not yet mature in the 10-12 years olds. Based upon the reference data obtained in this study, one can compare the response to novel stimuli in non responsive people to the response of agematched groups. Furthermore, it will be possible to determine whether the pattern of auditory novelty processing assessed in these patients is the result of a maturational delay or due to abnormal development. 


\section{CHAPTER 3}

\section{Acknowledgements}

This research was supported by a grant of SWZ Zonhove, an institution for people with physical and multiple disabilities and by the Faculty of Psychology of the M aastricht University. Special thanks goes to Mr. Chris Zaad, Head of the Division Treatment of SWZZonhove, for making this study possible.

We thank the primary schools St. Jozef in Elsloo, Don Bosco in Stein and Dionysius in Schinnen, the parents and the children for participating in our study. 


\section{Chapter 4}

\section{The Development of Passive Visual Novelty Processing}

This chapter is based on: Brinkman, M.J.R., Stauder, J.E.A. The development of passive visual novelty processing (submitted). 


\section{Abstract}

In a passive visual novelty oddball study the development of novelty processing was examined in 5-7 ( $\mathrm{N}=27), 8-9(\mathrm{~N}=30), 10-12(\mathrm{~N}=29)$, and $18-29(\mathrm{~N}=34)$ years olds. It appeared that passive visual novelty processing is still not mature in children aged 10-12 years, as children differ from adults in both speed and intensity of this processing. Although earlier studies examined the development of visual novelty processing, they used active tasks. As active tasks require overt responses from its participants, they are unsuited for certain patient groups. To overcome this problem, the present study used a passive paradigm. Overall, the findings of earlier studies on the development of active visual novelty processing were replicated. 


\section{Introduction}

The ability to orient to novel events is not only an important survival mechanism, it is also vital for cognitive development and learning (Sokolov, 1963; Daffner et al., 2003). An ERP paradigm often used to study novelty processing is the novelty oddball task, first developed by Courchesne, Hillyard and Galambos (1975). The major component in this task is the novelty P3, peaking at 200-400 ms after stimulus onset (Escera, Alho, Winkler, \& Näätänen, 1998; Friedman, Cycowicz, \& Gaeta, 2001). The novelty P3 can be distinguished from the P3 to target stimuli, as the target P3 has a clear posterior focus, whereas the novelty P3 has both anterior and posterior foci (Fabiani \& Friedman, 1995) The frontal aspect of the novelty P3 reflects the orienting to the novel stimulus (Cycowicz \& Friedman, 1997; Friedman, Kazmerski, \& Cycowicz, 1998; Knight \& Nakada, 1998) and is hypothesized to decrease from the moment novels are being categorized (Friedman, et al., 2001). The posterior aspect is assumed to reflect the categorization of initially uncategorized sounds (Courchesne, et al., 1975; Knight, Grabowecky, \& Scabini, 1995) or the matching of sensory information to memory templates (Cycowicz \& Friedman, 1998; Knight, et al., 1995).

Most studies concerning visual novelty processing used so-called "active" oddball tasks, requiring an overt response from their participants, for example pushing a button or counting silently. However, the use of passive paradigms requiring no response can be advantageous in certain circumstances, for example when studying cognitive development in non-responsive patient groups like people with profound intellectual and motor disabilities (PIMD). The visual novelty oddball paradigm studying the novelty response is a good example of a paradigm that can be presented passively, as the novelty response is easy to score individually and displays strong developmental effects up to adolescence (Courchesne, 1978a). Jeon and Polich (2001) compared the activity of the adult novelty P3 in an active and a passive visual novelty oddball task. According to them the novelty P3 component in adults was similar in amplitude and scalp topography in both the active and passive task.

Up to now very few studies (Courchesne, 1977, 1978a; Thomas \& Nelson, 1996; Van der Stelt, Geesken, Gunning, Snel, \& Kok, 1998) addressed the development of visual novelty processing in children, and all these studies used active tasks. 
Therefore developmental data regarding passive visual novelty processing are nonexistent. According to these active studies visual novelty ERPs of children aged 6-13 years were characterized by a large negative component (Nc). In addition, a novelty P3 component was visible at electrode Pz. The visual novelty ERPs of older children (14-17) and of adults consisted of both N2 and novelty P3 components (Courchesne, 1977, 1978a; Thomas \& Nelson, 1996). According to Courchesne $(1977,1978 a)$ both the novelty P3 latency and the Nc amplitude decreased with age, while the $\mathrm{Nc}$ amplitude was maximal at electrode Fz. Furthermore, the scalp distribution of the novelty P3 changed, as it was parietal in children, and frontal in adults. Thomas and Nelson (1996) reported that the novelty P3 latency in 8-years-olds was longer than in adults, and that the $\mathrm{Nc}$ latency at $\mathrm{Fz}$ was longer compared to the Nc latencies at $\mathrm{Cz}$ and $\mathrm{Pz}$. In addition, the $\mathrm{Nc}$ amplitude was more negative at $\mathrm{Fz}$ and $\mathrm{Cz}$ that at Pz. Van der Stelt, et al. (1998) studied visual novelty processing in children of alcoholics and in control children aged 7-12 and 13-18 years. As the focus in this study was on children of alcoholics, data concerning the development of control children were very limited.

The present study aimed at replicating the findings of earlier studies (Courchesne 1977; 1978a; Thomas \& Nelson, 1996) concerning the development of visual novelty processing. However, as these data will be used to evaluate the visual novelty processing of children with PIMD, a passive visual novelty oddball paradigm that requires no overt response is employed.

\section{M ethods}

\section{Participants}

In total, 34 adults and 86 children were included in the analysis. The adult group consisted of 15 men and 19 women with an average age of 21.3 years (S.D. 2.3 years; range 18.5-29.4 years). The children were split up into three different age groups. The eldest group counted 29 children (11 male, 18 female) with an average age of 11.2 years (S.D. 0.7 years; range 10.1-12.4 years). The middle group consisted of 30 children ( 12 male, 18 female) with an average age of 8.8 years (S.D. 0.5 years; range 8.0-9.7). The youngest group included 27 children (8 male, 19 female) that had an average age of 6.8 years (S.D. 0.8 years; range $5.4-7.9$ years). EEG recordings 
were performed by a mobile measurement set-up, namely a NuAmps DC Portable amplifier, in classrooms at the Faculty of Psychology of the Maastricht University, and in class rooms at primary schools in towns in the vicinity of Maastricht, The Netherlands. Parental consent was obtained for all children and the study was approved by the Maastricht University Ethical Committee of Psychology (01-052004). Before the start of the EEG measurement al children were asked if they wanted to participate in the experiment. The parents of children agreeing to participate in the study first filled out the Child Behavior Checklist/4-18 (CBCL/4-18). All children that were included scored within the normal range on the scales for anxiety/depression, attentional problems and school activities in accordance with the Dutch norms for the CBCL/4-18 (Verhulst, van der Ende, \& Koot, 1996). The exclusion criteria for adults were attentional or psychiatric problems reported by themselves. In addition, all participants completed Raven's Standard Progressive Matrices (SPM) in order to control for intelligence level. Adults filled in the SPM during electrode application, the children did this in a group in the classroom under supervision of the experimenters. All participants scored within a normal intelligence range in conformity with the British norms for the Raven's Standard Progressive Matrices (SPM). The raw mean scores (and SD) were 29.4 (8.9), 38.0 (9.6), 44.7 (5.5) and 53.4 (4.4) for the 5-7, 8-9, 10-12, and 18-29 years olds, respectively (Raven, Court, \& Raven, 1983).

\section{Stimuli}

The stimuli of the ERP paradigm were two black and white horizontal (squarewave) gratings, which differed in spatial frequency (SF). The grating with the low SF consisted of 0.75 cycles per degree (c/d), the one with the high SF of $6 \mathrm{c} / \mathrm{d}$. In most cases (70\%) the grating with the low SF was presented (standards). Fifteen percent of the stimuli (deviants) consisted of the grating with the high SF $(n=60)$. The remaining $15 \%$ of novels $(n=60)$ were made up of colored photographs showing animals, people, nature, and food all of which were taken from the International Affective Picture System (IAPS, Lang, Bradley \& Cuthbert, 1999). All standard, deviant, and novel stimuli were of the same size. The stimuli were presented pseudo-randomly, meaning that randomly occurring deviant and novel stimuli were always followed by a standard stimulus. All stimuli lasted $300 \mathrm{~ms}$ and there was a fixed ISI of $1000 \mathrm{~ms}$. The size of both the gratings and the pictures was $640 \times 480$ 
$\mathrm{mm}$. The stimuli were presented at a portable 17-inch LCD-screen by ERTS software (Version 3.18, BeriSoft Cooperation, Germany). The distance between the screen and the participant was $0.5 \mathrm{~m}$. The paradigm was divided into two blocks, each consisting of 205 stimuli. In order to get used to the stimuli, 3 standards and 3 deviants preceded the actual paradigm. In total, the paradigm lasted about 7.5 minutes.

\section{EEG recording}

Thirty tin electrodes in an electro-cap (Electro-cap, Inc., USA) were connected to a 40 channel NuAmps DC Portable amplifier (Neuroscan, Inc., USA). The EEG was recorded from the scalp sites $\mathrm{Fz}, \mathrm{Cz}, \mathrm{Pz}, \mathrm{Oz}, \mathrm{F7}$, F8, F3, F4, C3, C4, T7, T8, P3, P4, P7, P8, 01, 02, Fp1, Fp2, FT7, FT8, FC3, FC4, TP7, TP8, CP3, CP4, FCZ and CPz (American Electroencephalographic Society, 1991). Although 30 electrode channels were recorded, only the electrodes $\mathrm{Fz}, \mathrm{Cz}$, and Pz were included in the analyses, as earlier developmental studies of visual novelty processing also limited their reports to the results of these electrodes. The ground electrode was at equal distance placed between the Fp1, Fp2 and Fz electrodes. The reference electrode was placed at the right mastoid (A2). The vertical electro-oculogram (EOG) was recorded from one electrode above and one below the right eye and the horizontal EOG from two electrodes at the outer canthi of the eyes. The impedance of all electrodes was measured by a handheld impedance meter (F-EZM 4, Grass Inc., USA) and did not exceed the $5 \mathrm{kOhm}$ for the EEG and $8 \mathrm{kOhm}$ for the EOG electrodes. The sampling rate was $250 \mathrm{~Hz}$ and data were bandpass filtered between 0.05 and $50 \mathrm{~Hz}$ by Neuroscan 4.3 software. Stimulus presentation was controlled by ERTS software (Version 3.18, BeriSoft Cooperation, Germany).

\section{Procedure}

Upon arrival the procedure of the session was explained to the participant. Two researchers were seated in the same room, in front of or beside the subject. The participant was asked to watch the stimuli. The researcher in front of the child observed whether the child was looking at the screen continuously. In the rare instance where a child turned away from the screen, the EEG recording was stopped and restarted when the child resumed watching. This procedure ensured that 
children were indeed looking at the screen during the total time of EEG recording. In addition to the paradigm reported here the participants also performed an auditory oddball paradigm and an auditory habituation paradigm. The entire experiment, including the application and removal of the facial electrodes and the electrocap, lasted 90 minutes.

\section{Data analysis}

The recorded EEG and EOG signals were analyzed using Neuroscan 4.3. The EOG signals consisted of horizontal and vertical EOG channels. The EEG signals were corrected by the EOG channels for vertical eye movements by means of linear regression. Next, the signals were epoched at an interval between $-200 \mathrm{~ms}$ prestimulus and 800 ms poststimulus, bandpass filtered between 0.1 and $30 \mathrm{~Hz}$, and baseline corrected (-200 and $0 \mathrm{~ms})$. After this, individual EEG sweeps were rejected when the amplitude exceeded $\pm 100 \mu \mathrm{V}$ in adults and $\pm 150 \mu \mathrm{V}$ in children. When more than $20 \%$ of the trials of a child or adult were rejected, the data of this person were removed from the analyses. Finally, the remaining standard, deviant and novel stimuli were averaged.

The novelty latencies at $\mathrm{Fz}, \mathrm{Cz}$, and $\mathrm{Pz}$ were established by measuring the most negative peak in windows of 200-600 ms in children, and of 200-400 ms in adults. The mean amplitudes of the novel and standard grand averages at $\mathrm{Fz}, \mathrm{Cz}$, and $\mathrm{Pz}$ were measured within the windows of 200-600 ms in children and of 200-400 ms in adults for the negative component.

The novelty latencies at $\mathrm{Fz}, \mathrm{Cz}$, and Pz were statistically (SPSS 11.5) analyzed by means of General Linear Models-repeated measures ANOVA. In case of significant $(p<05)$ interactions post-hoc tests were performed using one-way ANOVAs and ttests. If there was a violation of the assumption of sphericity a Greenhouse-Geisser correction was applied. In order to prevent the interpretation of amplitude differences between age groups as topographic differences, the mean amplitudes of the standard, and novel grand-averages were normalized using the vector scaling technique. This technique divides the value of each electrode amplitude within a subject by the square root of the sum of all the squared amplitude values of all electrodes within the same subject (McCarthy \& Wood, 1985). After the normalization the normalized amplitude data at $\mathrm{Fz}, \mathrm{Cz}$, and $\mathrm{Pz}$ were statistically analyzed similar to the novelty latencies. In case of significant effects the direction 
of these amplitude effects was determined by interpreting the raw, non-normalized data.

\section{Results}

Fig. 1 displays grand-average ERPs of the standard (solid line), and novel (dotted line) stimuli. It can be observed that the novel visual stimuli elicited a large negative component (NC) in children that was less negative in adults. In addition, the mean amplitudes at $\mathrm{Pz}$ were less negative compared to the ones at $\mathrm{Fz}$ and $\mathrm{Cz}$. It can also be observed that the $\mathrm{NC}$ latencies in children were increased compared to the latencies in adults.
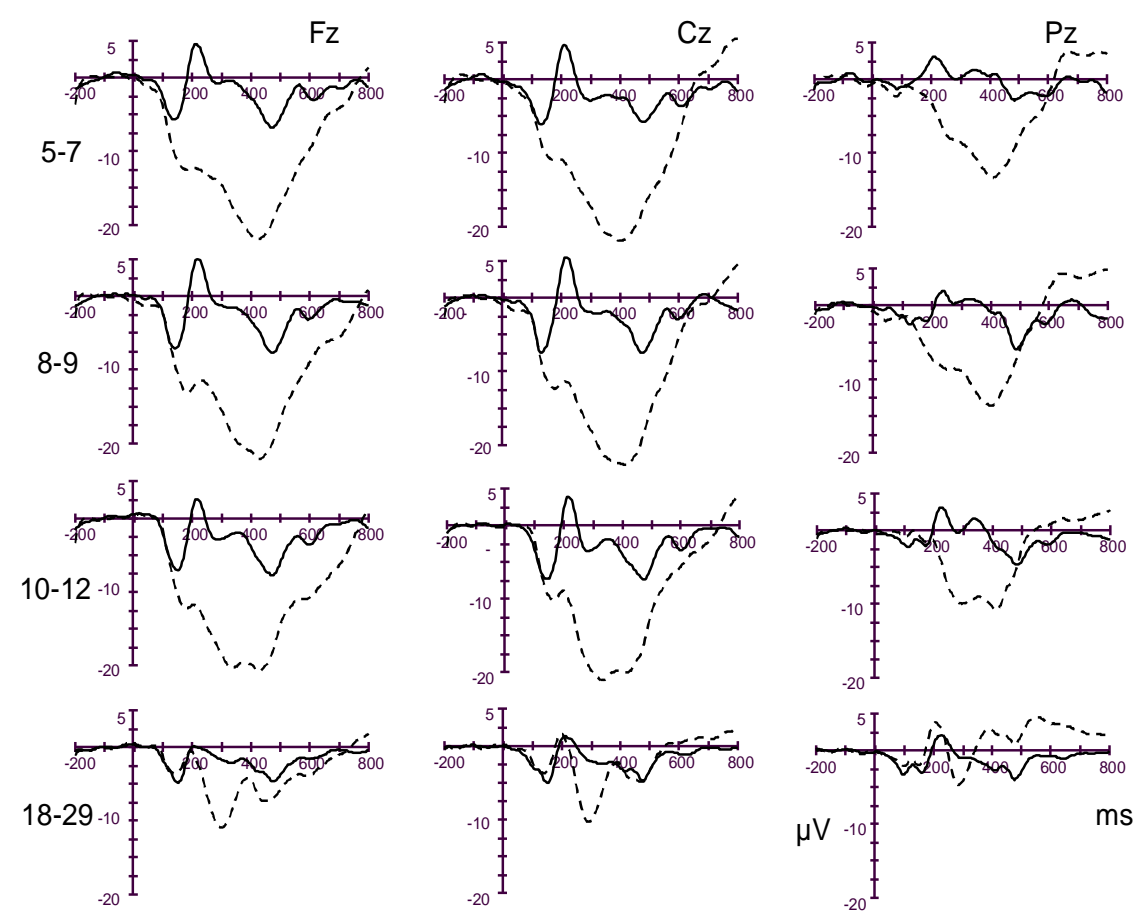

Fig. 1. The grand-average ERPs of the standard (solid line) and novel (dotted line) stimuli. 
NC latencies

GLM repeated measures with the within-subject factor Electrode ( $F z, C z, P z)$ and the between-subjects factor Group (5-7, 8-9, 10-12, 18-29 years) revealed significant main effects of Electrode $(F(1.8,211.5)=8.567, p=0.0001)$ and $G r o u p(F(3$, $116)=38.315, p=0.0001$ ). Post-hoc t-tests indicated that the Nc latency at $\mathrm{Fz}$ (see also Fig. 2) was longer compared to the Nc latencies at $\mathrm{Cz}(\mathrm{t}(119)=3.671, \mathrm{p}<0.01)$ and $\mathrm{Pz}(\mathrm{t}(119)=3.477, \mathrm{p} \varangle 0.01)$. The $\mathrm{t}$-tests also revealed that the children groups were slower.

\section{Nc latencies at electrodes $\mathrm{Fz}, \mathrm{Cz}$, and $\mathrm{Pz}$}

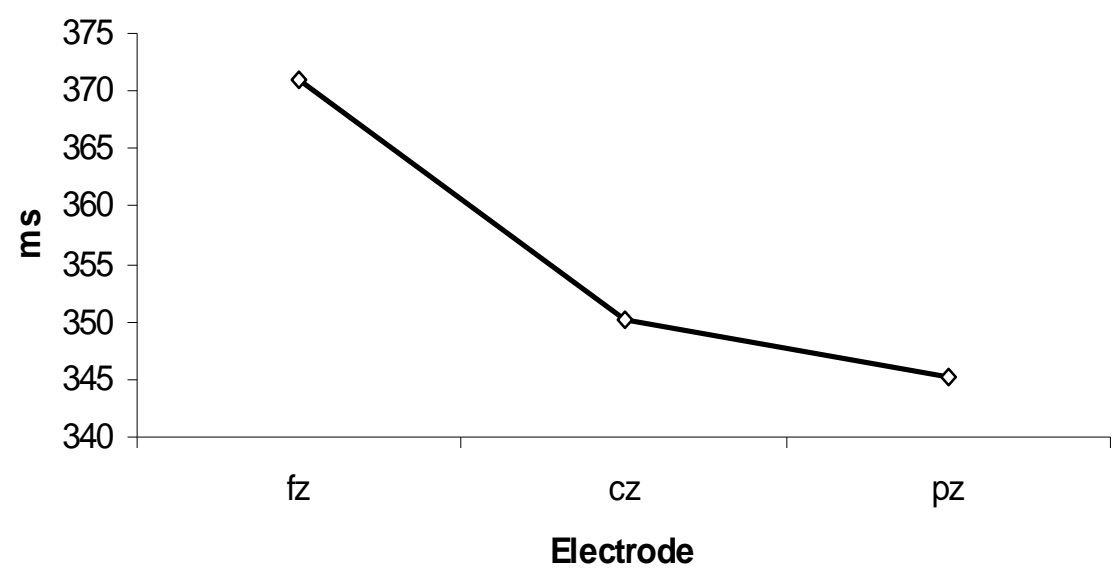

Fig. 2. The mean Nc latencies at electrodes $\mathrm{Fz}, \mathrm{Cz}$, and $\mathrm{Pz}$.

NC amplitudes

GLM repeated measures of the within-subject factors Stimulus (standard, novel), and Electrode $(F z, C z, P z)$, and the between-subjects factor Group (5-7, 8-9, 10-12 and 18-29 years) revealed significant main effects of Stimulus $(F(1.0,116.0)=41.783$, $p=0.0001)$, Electrode $(F(1.3,147.7)=87.476, p=0.0001)$, and Group $(F(3$, 
$116)=22.291, p=0.0001$ ). Furthermore, the statistical analysis showed a significant two-way interaction of Stimulus $x$ Group $(F(3.0,116.0)=4.596, p=0.004)$. As depicted in Fig. 4, post-hoc t-tests showed that the normalized mean standard and novel amplitudes were more negative in children compared to adults (5-7 years: $t(59)=$ 2.114, $\mathrm{p}<0.05$, and $\mathrm{t}(42.4)=8.881, \mathrm{p}<0.01$, respectively; $8-9$ years: $\mathrm{t}(62)=2.551$, $p \varangle 0.05$, and $t(49.1)=7.760, p \varangle 0.01$, respectively; $10-12$ years: $t(61)=3.886, p \varangle 0.01$, and $t(51.2)=7,856$, respectively).

\section{Nc latencies in children and adults}

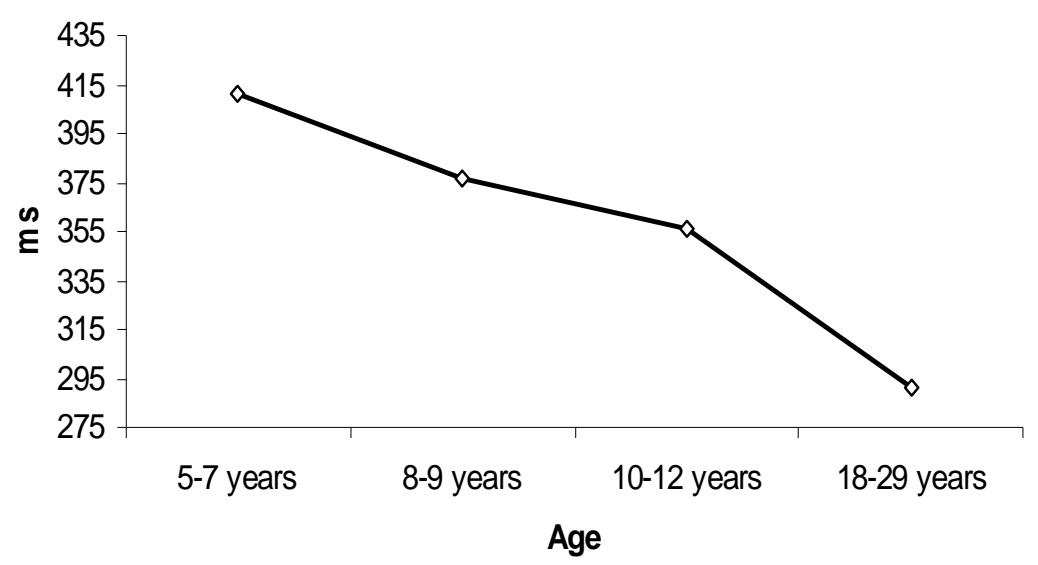

Fig. 3. The mean Nc latencies in children and adults.

GLM repeated measures also showed a significant two-way interaction of Stimulus $x$ Electrode $(F(1.4,160.8)=17.400, p=0.0001)$. Post-hoc $t$-tests revealed that the mean novel amplitudes were more negative compared to the mean standard amplitudes $(t(119)=5.931, p<0.01)$, indicating a successful task manipulation. As depicted in Fig. 5 , it also appeared that the mean Nc amplitudes at $\mathrm{Fz}$ and $\mathrm{Cz}$ were both more negative compared to the mean amplitudes at $\mathrm{Pz}(\mathrm{t}(119)=8.885, \mathrm{p} \varangle \mathrm{0} .01$, and $\mathrm{t}(119)=11.015, \mathrm{p}<0.01$, respectively). 


\section{Nc amplitudes in children and adults}

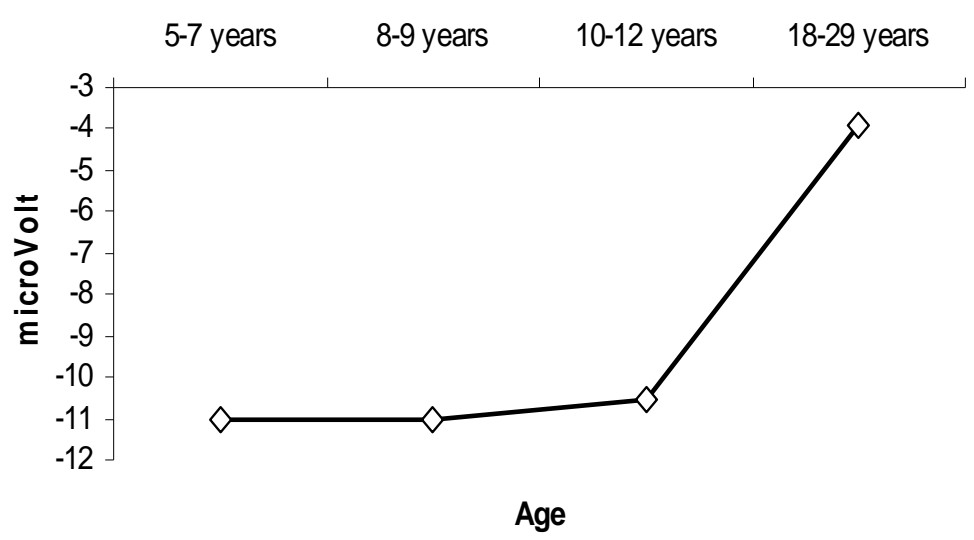

Fig. 4. The mean Nc amplitudes in children and adults.

Nc amplitudes at electrodes $\mathrm{Fz}, \mathrm{Cz}$, and $\mathrm{Pz}$

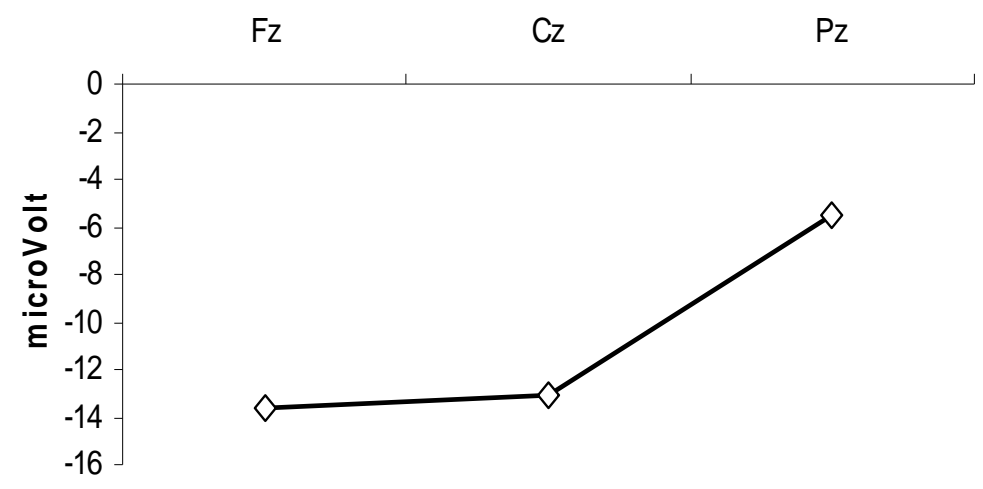

Electrode

Fig. 5. The mean Nc amplitudes at electrodes $\mathrm{Fz}, \mathrm{Cz}$, and Pz. 


\section{Discussion}

In this study the development of passive visual novelty processing was examined. For this purpose a passive visual novelty oddball paradigm was presented to children in the age of 5-12 years and in adults. It appeared that children were slower compared to adults when processing the visual novel stimuli. Likewise, 5-7 years olds were slower compared to 8-9 and 10-12 years olds. Also, the latency of the negative component (NC) at Fz was increased compared to these latencies at $\mathrm{Cz}$ and $\mathrm{Pz}$. In addition, the Nc amplitude in children was larger compared to the one in adults, and the mean Nc amplitudes at electrodes $\mathrm{Fz}$ and $\mathrm{Cz}$ were more negative compared to the mean Nc amplitudes at electrode $\mathrm{Pz}$.

As in previous studies (Courchesne, 1977,1978a; Thomas $\&$ Nelson, 1996), the visual novel stimuli caused a negative component (Nc) in children. Although both Courchesne (1977, 1978a) and Thomas and Nelson (1996) did not report an age effect with regard to the Nc latency, a decreasing latency with age is a very common finding in the literature (e.g. Brinkman \& Stauder, 2008; Cycowicz, Friedman, \& Rothstein, 1996). Courchesne $(1977,1978$ a) probably did not find an age effect with regard to the Nc latency, as his youngest group (6-8 years) was slightly older than the 5-7 years olds of the present study, and he only included the Nc latency data of children in the analyses. Thomas and Nelson (1996) described the Nc only in 8years-olds, and thus could not comment on the development of the Nc latency. In addition, the present study reported an increased Nc latency at Fz compared to the Nc latencies at Cz and Pz. Courchesne (1977, 1978a) only reported the Nc latency at Fz. Like the present study Thomas and Nelson (1996) also reported that the Nc latency at $\mathrm{Fz}$ was increased compared to the latencies at $\mathrm{Cz}$ and $\mathrm{Pz}$, although this effect did not reach significance.

Nc amplitudes in children were larger as compared to those in adults. Courchesne (1977, 1978a) also mentioned an age effect with regard to the Nc amplitude, but he did not include adults in the data analyses. A closer look at his results revealed that the largest age effect occurred between 6-13 and 14-17 years olds. Thus, there is probably a major change in the novel amplitude after 13 years of age. Also, the Nc amplitudes at electrodes Fz and Cz were more negative compared to the Nc amplitude at Pz. This anterior negativity was also found by Courchesne (1977, 1978a) and Thomas and Nelson (19960, although this difference did not reach significance in Courchesne's study. 
Although many of the present results regarding passive visual novelty processing were comparable to earlier findings, there were also some differences. First of all, in the studies of both Courchesne $(1977,1978 a)$ and Thomas and Nelson (1996) children displayed a novelty P3 component at electrode Pz. Although a novelty P3 component at $\mathrm{Pz}$ is also visible in the present data $(600-700 \mathrm{~ms})$ in children, its effects are very small, and therefore not included in the data analyses. This discrepancy can probably be explained by the use of a passive paradigm instead of an active one. Although Jeon and Polich (2001) indicated that an active or a passive novelty P3 did not differ in amplitude or scalp distribution, their study only included adults. It is therefore possible that the very small novelty P3 component, seen in children in the present study, is due to the use of a passive novelty oddball paradigm. A second difference relates to the inclusion of adult data in the $\mathrm{Nc}$ analyses. Unlike the present study both Courchesne $(1977,1978 a)$ and Thomas and Nelson (1996) ignored the small adult negativity $(<5 \mu \mathrm{V})$ evoked by novel stimuli. According to them this negativity was a N2. However, the negativity in the present study was much larger (about $10 \mu \mathrm{V}$ at $\mathrm{Fz}$ and $\mathrm{Cz}$ ) and not visible in standard and deviant ERPs. The presence of this large adult negativity at $\mathrm{Fz}$ and $\mathrm{Cz}$ can be explained by the use of easy recognizable pictures as novel stimuli. Several studies in adults on processing of easy recognizable pictures (e.g. Barrett \& Rugg, 1990; Hamm, Johnson, \& Kirk, 2002; Holcomb \& McPherson, 1994; Schendan \& Kutas, 2002; Sitnikova, West, Kuperberg, \& Holcomb, 2006) reported a frontal negativity peaking between 325 and 400 ms called N300 or N350. According to Schendan and Kutas (2002) this negativity reflects the activity of a neural system concerned with identification, namely the matching of the presented picture with a stored structural description. It is therefore very likely that the anterior adult negativity found in the present data reflects such a N300/N350.

Earlier reports on visual novelty processing used active tasks requiring overt responses from their participants. However, these tasks are unsuited for lowfunctioning participants, like people with profound intellectual and multiple disabilities (PIMD), as they are unable to produce an overt response. The present study employed a passive visual novelty oddball paradigm, and since its results are comparable to the findings of earlier active tasks, the present data can serve as referential data in clinical applications for the evaluation of visual novelty processing.

Many studies reported the existence of two novelty components in auditory novelty processing (Brinkman \& Stauder, 2008; Čeponiene, Lepistö, Soininen, 
Aronen, Alku, \& Näätänen, 2004; Escera, Alho, Winkler, \& Näätänen, 1998; Gumenyuk, Korzyukov, Alho, Escera, \& Näätänen, 2004; Gumenyuk et al., 2001; Määttä, Saavalainen, Könönen, Pääkönen, \& Muraja-Murro, 2005; Wetzel \& Schröger, 2007). When looking at the adult novelty ERPs in the present study (Fig. 1) two components are clearly visible within the first $600 \mathrm{~ms}$ after stimulus onset, thus hinting at the existence of a biphasic visual novelty component. Assuming that the mechanisms involved in novelty processing are the same for both visual and auditory modalities, one could hypothesize that the functional interpretation of the two auditory novelty components also applies to visual novelty processing. According to Čeponiene, et al. (2004) the first or early novelty component might be a receiver of the sensory output from either the $\mathrm{N} 1$ or the $\mathrm{MMN}$, calling for attention. Based upon this sensory output the early novelty component would then govern the direction of the attentional move, in turn reflected by the second or late novelty component. During an auditory novelty experiment Escera, et al. (1998) presented participants with pairs of stimuli consisting of an auditory stimulus followed by a visual one. The auditory stimulus was a standard tone, a deviant tone or a novel sound. Participants were required to give a response to each visual stimulus while ignoring the auditory stimulation. It was found that the late novelty component was enhanced by attention, while the early novelty component was not. Apparently, participants used auditory stimuli as warning signals to prepare for the visual ones. In addition, Courchesne (1978b) and Cycowicz and Friedman (1997) found that after repeating novel sounds the novelty component habituated, that is became increasingly less frontal and more parietal. Habituation is a characteristic of the orienting response (Sokolov, 1963). As the late novelty component was modulated by attention and habituated, Escera, et al. (1998) concluded that this late novelty component probably represents the orienting response itself. However, as this is the first time that a biphasic component in visual novelty processing is found, this notion warrants further research.

In conclusion, this is the first time that the development of passive visual novelty processing is examined. Like active visual novelty processing, passive visual novelty processing has a prolonged development. Both speed and intensity of novel sound processing is still not mature in 10-12 years olds. Overall, the present study replicates the findings of earlier, active studies on visual novelty processing. For the first time biphasic visual novelty processing is found in adults. In analogy of auditory novelty processing it is hypothesized that the early visual novelty component 
represents a sensory interface, while the late one concerns the orienting response itself.

\section{Acknowledgements}

This research was supported by a grant of SWZ Zonhove, an institution for people with physical and multiple disabilities and by the Faculty of Psychology of the M aastricht University. Special thanks goes to Mr. Chris Zaad, Head of the Division Treatment of SWZZonhove, for making this study possible.

We thank the primary schools St. Jozef in Elsloo, Don Bosco in Stein and Dionysius in Schinnen, the parents and the children for participating in our study. 



\section{Chapter 5}

\section{Individual Assessment of Children with Profound Intellectual and M ultiple Disabilities (PIM D) by means of Event-related Brain Potentials}

This chapter is based on: Brinkman, M.J.R., Stauder, J.E.A., Curfs, L.M.G., Zaad, C.P.M., de Moor, J.M.H. Individual assessment of children with Profound Intellectual and Multiple Disabilities (PIMD) by means of event-related brain potentials (submitted). 


\section{Abstract}

Individual auditory and visual information processing in children with profound intellectual and multiple disabilities (PIMD) was assessed by means of event-related brain potentials (ERPs). To this purpose a passive novelty oddball paradigm was used. All PIM D children could hear and see. The detection of auditory and visual stimuli was normal in 12 out of 15 , and in 3 out of 13 PIMD children, respectively. Auditory novelty processing was normal in 7 out of 15 children, as was the case for visual novelty processing in 6 out of 13 children. Also, auditory and visual novelty processing was maturational delayed in 2 out of 15 and in 1 out of 13 PIMD children, respectively. The results show that ERPs are pre-eminently suited to assess information processing in PIMD children. Assets of this non-invasive technique are its behavior-independency, and ability to gather a vast amount of useful information in a relatively short time. 


\section{Introduction}

This study addresses the evaluation of information processing in children with profound intellectual and multiple disabilities (PIMD) by means of event-related brain potentials. Although the term PIMD is not listed in international diagnostic classification systems like DSM-IV-TR or ICD-10/ICF, it is used in scientific literature (e.g. Zijlsta \& Vlaskamp, 2005; Hogg, Juhlberg, \& Lambe, 2007; M aes, Lambrechts, Hostyn, \& Petry, 2007) to indicate people who are cognitively very low-functioning. Profound intellectual disabilities, also called profound mental retardation (MR) imply an IQ level below 20, a mental age of less than 3 years in adults, and severe limitations in self-care, continence, communication, and mobility according to the definition of ICD-10/ICF (WHO, 1992; 1993; 1996; 2001). In addition, people with PIMD have severe motor disabilities, and many are diagnosed with cerebral palsy $(\mathrm{CP})$, a disorder of the development of movement and posture that is due to a nonprogressive abnormality of the immature brain (Bax, Goldstein, Rosenbaum, Leviton, \& Paneth, 2005).

People with PIMD are also at a high risk for visual and hearing impairments. In practice visual impairments are measured by techniques like preferential looking and the use of Stycar balls, hearing impairments by methods like oto-acoustic emission and impedance audiometry. At least $19 \%$ of them have hearing problems (e.g. Evenhuis, Theunissen, Denkers, Verschuure, \& Kemme, 2001; Aerts-Neggers, Schoonbrood-Lenssen, \& Maaskant, 2003; M euwese-Jongejeugd, et al., 2006) and at least $29 \%$ experience visual impairments (e.g. McCulloch, Sludden, McKeown, \& Kerr, 1996; Woodhouse, Griffiths, \& Gedling, 2000; Evenhuis, et al., 2001; Van den Broek, Janssen, van Ramshorst, \& Deen, 2006; Van Splunder, Stilma, Bernsen, \& Evenhuis, 2006), while the prevalence of blindness was at least 17\% (Van Splunder, et al., 2006). In addition, people with PIMD have difficulties communicating, due to an inability to use gestures or expressions to express themselves, to a dysfunctional speech organ, and/or to disturbed development of language (De M oor, Mulders, \& Didden, 2003).

In practice, it is very difficult to assess sensory and cognitive functioning in children with PIMD, for most standard psychological tests require motor or verbal responses. However, for the benefit of child and therapy, it is essential to have 
insight in its sensory and cognitive capabilities. Therefore, clinical instruments suited for infant assessment are often used. One of these instruments is the Fagan Test of Infant Intelligence (Fagan \& Shepherd, 1985), assessing novelty preference by (dis-) habituating infants to the photographs of faces. Other measures are the Kent Infant Development Scale (Katoff, Reuter, \& Dunn, 1980), the Denver Developmental Screening Test-II (Frankenburg \& Dodds, 1990), the Bayley Scales of Infant Development-II (Bayley, 1993) and the Bayley Infant Neurodevelopmental Screen (Aylward, 1992), assessing developmental progress in children in an age range from 0 months to 8 years.

A possible alternative method to assess sensory and cognitive processing in children with PIMD is the measurement of electrical brain activity. This non-invasive technique includes the recording of EEG during the presentation of stimuli (e.g. sounds or pictures). When the recording is finished, the EEG is cut into pieces, where after all pieces of EEG evoked by for example the novel stimuli, are averaged, and thus an ERP is generated. During the first 100-150 ms after stimulus presentation the ERP reflects the detection and processing of the physical characteristics of these stimuli, like loudness and pitch. This processing is called sensory information processing. After the first 100-150 ms the ERP shows the cognitive information processing of a stimulus, dependent on task manipulation (Fabiani, Gratton, \& Coles, 2000). Further details concerning the ERP-method can be found in the M ethods section, but are not essential for grasping the application of this method to evaluate the information processing of individual children.

With ERPs coming from passive tasks, meaning that no instruction and no overt response is required, it is possible to evaluate information processing without the help of behavioral data, making it pre-eminently suited for low-functioning patient groups, e.g. children with PIMD. The measurement of brain activity has already been widely used in for example normally developing children (e.g. Brinkman \& Stauder, 2007), in children with developmental disorders like autism (e.g. Kemner, Verbaten, Cuperus, Camfferman, \& van Engeland, 1995), and ADHD (e.g. Jonkman, Lansbergen, \& Stauder, 2003), in children with syndromes like Rett syndrome (Stauder, Smeets, van Mil, \& Curfs, 2006) and Prader-Willi syndrome (e.g. Stauder, Brinkman, \& Curfs, 2002) and in infants (e.g. Nelson, Thomas, de Haan, \& Wewerka, 1998). As all these ERP studies focused on group differences, reference data were necessary to evaluate the information processing of each child with PIMD individually. Therefore, the auditory and visual stimuli detection and novelty processing of normally developing children aged $5-7$ years $(n=26), 8-9$ years $(n=30)$, 
10-12 years $(n=29)$ and of adults $(n=34)$ were examined using a passive novelty oddball paradigm. In order to be certain that only normal children were part of these control groups, a CBCL score within the clinical range was used as an exclusion criterion (for more details, see Brinkman \& Stauder, 2008; Brinkman \& Stauder, chapter 4 of this thesis). During the presentation of this novelty oddball paradigm the same stimuli (standard) are repeatedly shown, while novel stimuli are presented infrequently and unexpectedly. At a psychological level novelty processing can only take place when attention and memory systems are functional.

The present study examines the brain activity related to sensory stimuli detection and novelty processing in individual PIM D children using a passive novelty oddball paradigm. First of all, it will be examined whether these children can detect auditory and visual stimuli that is if they can hear and see. Then, the auditory and visual stimuli detection and the processing of auditory and visual novel stimuli in each child with PIMD individually will be compared to age-matched reference data of normally developing children.

\section{Methods}

\section{Participants}

A total of 17 children with profound intellectual and multiple disabilities (PIMD) participated in this study. Fifteen of these children were recruited via SWZ/Zonhove and the Emilius School situated in Son, the Netherlands, an institution for students with multiple disabilities, and two of them via Mariëndael in Arnhem, the Netherlands, a school for children with intellectual, physical or multiple disabilities. The inclusion criteria for participation in this study were: aged between 5 and 12 years, profound mental retardation, an inability to speak, and a developmental age (DA) of 24 months or less. The DA was mainly determined by observation lists of professionals in the institutions. All children with PIMD were at a Gross Motor Function Classification System (GM FCS) Level of IV or V (Russell, et al., 1993). A medical diagnosis did not serve as selection criterion. Eventually, two of the seventeen children dropped out. One child had excessive movements, interfering with the application of facial electrodes and electrocap, the other one was temporarily disordered. The individual characteristics of the 15 children who did 


\section{CHAPTER 5}

participate are displayed in Table 1. Fifteen children with PIMD completed the auditory novelty oddball task (mean age: 10.0 years; S.D. 2.1 years), while 13 children with PIMD participated in the visual novelty oddball task (mean age: 10.2 years; S.D. 2.0 years), as two children dropped out because of not watching the screen. Parental consent was obtained for all children and the study was approved by the 'Moreel Beraad' (Ethical committee) of SWZIZonhove, and by the MedicalEthical Commission of the Academic Hospital of M aastricht (MEC 04-263).

Table 1. Individual characteristics of children with PIM D

\begin{tabular}{lllll}
\hline & Sex & CA (year; month) & DA (months) & Diagnosis \\
\hline 01 & F & $10 ; 9$ & 16 & CP, bilateral spastic \\
02 & F & $11 ; 7$ & 12 & $\begin{array}{l}\text { Psychomotor retardation, } \\
\text { epileptic } \\
\text { CP, bilateral spastic, impaired } \\
\text { vision }\end{array}$ \\
03 & M & $12 ; 6$ & 12 & CP, bilateral spastic, epileptic \\
04 & M & $10 ; 0$ & $9-10$ & CP, bilateral spastic, epileptic, \\
05 & F & $10 ; 9$ & 14 & impaired vision \\
06 & F & $8 ; 0$ & $3-4$ & CP, psychomotor retardation, \\
07 & M & $10 ; 3$ & 7 & epileptic, impaired vision \\
08 & M & $6 ; 10$ & $15-24$ & PDD-NOS (possible) \\
09 & F & $11 ; 0$ & $4-6$ & CP, epilateral spastic, epileptic \\
10 & M & $10 ; 3$ & Unavailable & CP \\
11 & M & $8 ; 10$ & 4 & Pallister-Killian syndrome \\
12 & M & $10 ; 9$ & $3-4$ & CP, bilateral spastic, epileptic, \\
13 & F & $12 ; 10$ & $18-24$ & impaired vision \\
14 & M & $6 ; 5$ & 6 & CP, bilateral spastic \\
15 & F & $6 ; 8$ & Unavaileptic, impaired vision & Epileptic \\
\hline
\end{tabular}

${ }^{1}$ CA: Chronological Age; ${ }^{2}$ DA: Developmental Age. 


\section{Stimuli}

The novelty oddball task consists of three stimuli types. The first one is the most common (70\%) and is called standard. In this study the standard stimulus was used to assess the sensory stimuli detection and processing. The second stimulus type is different from the standard, is presented in $15 \%$ of the trials and is called deviant. Both the standard and deviant stimuli are presented to the participant in advance. The third stimulus category is also presented in $15 \%$ of the cases and is called novel stimulus. However, the novel stimuli are not presented to the participant in advance, are very different from the other two stimulus types, and are all unique. In this study the novel stimuli were used to assess the novelty information processing.

The auditory stimuli consisted of harmonic tones and environmental sounds. The standard tone $(750 \mathrm{~Hz})$ was made up of the formants 750,1500 and $2250 \mathrm{~Hz}$. The deviant tone $(500 \mathrm{~Hz})$ included the formants 500,1000 , and $1500 \mathrm{~Hz}$. The second and third formants were presented with -3 and $-6 \mathrm{~dB}$, respectively, in order to compensate for differences in loudness. In addition to harmonic tones the participant also heard unique environmental sounds (Fabiani, Kazmerski, Cycowicz, \& Friedman, 1996) coming from six sound categories: animal, bird, human, music, noise and video-game noise. All stimuli had a sound level of about $75 \mathrm{~dB}$ SPL (A), measured at the headphones.

The visual stimuli consisted of two black and white horizontal (square-wave) gratings, which differed in spatial frequency (SF). The grating with the low SF consisted of 0.75 cycles per degree $(\mathrm{c} / \mathrm{d})$ and made up the standard stimuli, the one with the high SF consisted of $6 \mathrm{c} / \mathrm{d}$ and represented the deviant stimuli. The novel stimuli were made up of colored standardized photographs showing animals, people, nature, and food all of which were taken from the International Affective Picture System (IAPS, Lang, Bradley, \& Cuthbert, 1999). The size of both the gratings and the pictures was $640 \times 480 \mathrm{~mm}$. The stimuli were presented on a 17-inch LCDscreen. The distance between the screen and the participant was $0.5 \mathrm{~m}$.

The stimuli were presented pseudo-randomly by ERTS software (Version 3.18, BeriSoft Cooperation, Germany), meaning that randomly occurring deviant and novel stimuli were always followed by a standard stimulus. All stimuli lasted $300 \mathrm{~ms}$ and there was a fixed ISI (inter-stimulus-interval) of $1000 \mathrm{~ms}$. The tasks were divided into two blocks, each consisting of 205 stimuli. In order to get used to the stimuli 3 standards and 3 deviants preceded the actual paradigm. In total, all tasks lasted about 7.5 minutes. 


\section{Procedure}

First, the procedure of the session was explained to the participant. Then, the facial electrodes and electrocap were applied to the participant while watching a DVD. During the presentation of the tasks two researchers were seated in the same room, in front of or beside the participant. Between the several tasks and between the two blocks of stimuli within each task breaks were provided. In case of the auditory novelty oddball task the participants watched a silent cartoon on a portable DVD player. In case of the visual novelty oddball task the researcher in front of the participant observed whether the participant looked at the screen. This procedure was chosen, as it is very difficult to calibrate the EEG signals in order to extract eye movements when children cannot follow instructions. Periods of notlooking were registered so that these periods could be removed from the analyses afterwards. In addition the participants performed a tactile novelty oddball task and an auditory habituation task. These data will be presented in another paper. The entire measurement, including the application and removal of the facial electrodes and the electrocap, lasted 90 minutes.

\section{ERP measures for auditory and visual information processing}

In this study sensory stimuli detection and sensory stimuli processing was indicated by the P1 component, a component that is sensitive to the physical properties of a stimulus. The auditory and visual P1 is a positive peak occurring between 50 and $250 \mathrm{~ms}$ in children (e.g. Coch, Skendzel, \& Neville, 2005) after stimulus presentation. The P1 component embodying sensory stimuli detection and processing is already present in infants, and its amplitude increases as the infant matures. However, from early childhood until adolescence the P1 amplitude decreases significantly in size (e.g. Polich \& Starr, 1984; Stauder, van der Molen, \& M olenaar, 2003; Wetzel, Widmann, Berti, \& Schröger, 2006). The components of interest for novelty processing are the auditory novelty P3 and the visual novelty negativity (Nc). Although it is already present in infants of 3 months of age (e.g. Fagan, 1990), it is still not mature in 12 years olds (e.g. Courchesne, 1978; Cycowicz, Friedman, \& Rothstein, 1996). 


\section{EEG recording}

Thirty tin electrodes in an electro-cap (Electro-cap, Inc., USA) were connected to a 40 channel NuAmps DC Portable amplifier (Neuroscan, Inc., USA). The EEG electrodes were recorded from the 30 scalp sites $\mathrm{Fz}, \mathrm{CZ}, \mathrm{Pz}, \mathrm{Oz}, \mathrm{F7}, \mathrm{F} 8, \mathrm{~F} 3, \mathrm{~F} 4, \mathrm{C3}, \mathrm{C4}$, T7, T8, P3, P4, P7, P8, 01, 02, Fp1, Fp2, FT7, FT8, FC3, FC4, TP7, TP8, CP3, CP4, FCz and $\mathrm{CPz}$ (American Electroencephalographic Society, 1991). The ground electrode was placed equally distanced between the $\mathrm{Fp} 1, \mathrm{Fp} 2$ and $\mathrm{Fz}$ electrodes. The reference electrode was placed at the right mastoid (A2). The vertical electrooculogram (EOG) was recorded from one electrode above and one below the right eye and the horizontal EOG from two electrodes at the outer canthi of the eyes. The impedance of all electrodes was measured by a handheld impedance meter (FEZM 4, Grass Inc., USA) and did not exceed $5 \mathrm{kOhm}$ for the EEG and $8 \mathrm{kOhm}$ for the EOG electrodes. Data were continuously sampled with a gain of $250 \mathrm{~Hz}$. Stimulus presentation was controlled by ERTS software (Version 3.18, BeriSoft Cooperation, Germany).

\section{Data analysis}

The recorded EEG and EOG signals were analyzed using Neuroscan 4.3. The EOG signals consisted of horizontal and vertical EOG channels. The EEG signals were corrected by the EOG channels for vertical eye movements by means of linear regression. Next, the signals were epoched at an interval between $-200 \mathrm{~ms}$ prestimulus and 800 ms poststimulus, bandpass filtered between 0.1 and $30 \mathrm{~Hz}$, and baseline corrected (-200 to $0 \mathrm{~ms}$ ). Individual EEG sweeps were rejected when the amplitude exceeded $\pm 300 \mu \mathrm{V}$, where after the remaining standard and novel stimuli were averaged. Using the standard grand averages the mean areas for the auditory and visual P1 component were defined within windows of 70-170 ms and of 60-160 $\mathrm{ms}$, respectively. Based upon the novel grand averages windows of 200-430 ms and of 250-600 ms were used to determine the mean areas of auditory and visual novelty processing, respectively. Next, a novelty difference wave was defined by subtracting the standard from the novelty average. In this novelty difference wave the novelty effect can be seen. As it is common to normalize the data in developmental ERP studies and as the reference data of normally developing children were also normalized, the data regarding the $\mathrm{P} 1$ and the novelty difference 


\section{CHAPTER 5}

wave in children with PIMD were normalized (vector scaling technique, McCarthy $\&$ Wood, 1985).

\section{Statistical analysis}

The normalized data of the P1 and the novelty difference wave (novelty minus standard) were individually compared to the normalized referential data by means of Stat Map +3D version 1.0 (DigiMed Systems Inc 1998). This program compares the brain activity measures between groups and individuals (z-tests). First, the brain activity of each control child individually was compared to the averaged brain activity of its age-matched control group, thus calculating z-scores for all 30 electrodes. This cut-off z-score is comparable to a standard-deviation. Then, as only normal children were accepted in the control groups, the z-score was determined at a level according to which all these children passed as normal. It so happened that the cut-off point was always set at 4 , as all individual control children had z-scores at or below 4 for each modality and component. Finally, the z-scores of an individual child with PIMD were determined by comparing its brain activity over 30 electrodes to its age-matched control group. When the brain activity of all electrodes was equal to or below this z-score of 4 the information processing of a child with PIMD was called normal. If not, its brain activity was compared to younger groups of control children. In case that all z-scores were equal to or below 4 the child's brain activity was considered to be maturational delayed.

\section{Results}

Although the referential data of normally developing children and adults are not the scope of this paper, these data are nonetheless shown in figures 1-4, in order to illustrate normal brain activity regarding stimuli detection and novelty processing.

Detection of auditory and visual stimuli (sensory information processing)

Fig. 1 shows the detection of auditory standard stimuli, embodied by the P1 


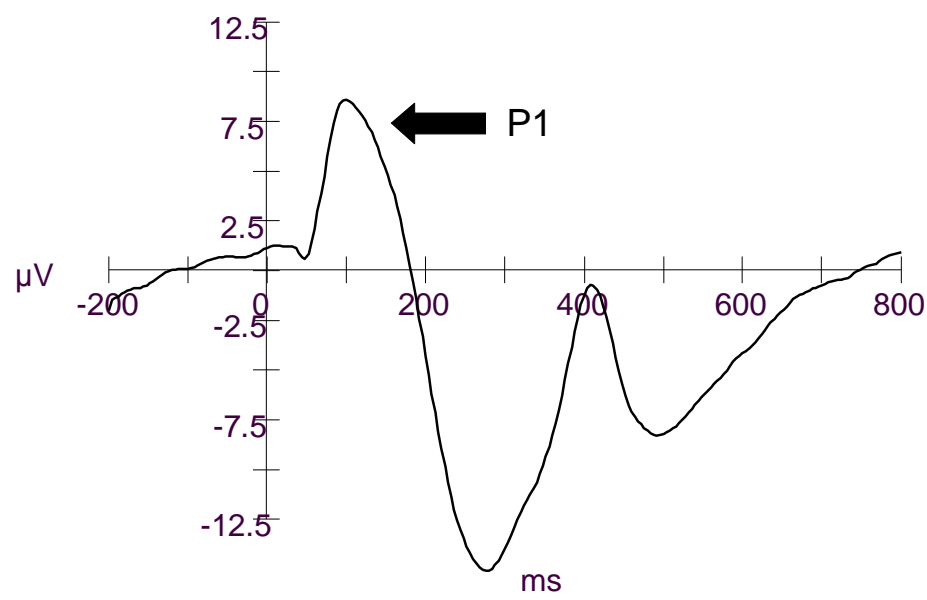

Fig. 1 displays the detection of auditory standard stimuli in 5-7 years olds at electrode FC4. The component of interest is the P1, indicated by an arrow.

component. In this case the P1 component of 5-7 years olds at electrode FC4 is displayed. As can be seen, the $\mathrm{P} 1$ is a positive component, peaking (about $8.5 \mu \mathrm{V}$ ) at about $100 \mathrm{~ms}$ after presenting the auditory standard stimuli. Figure 2 displays the visual P1 component in 5-7 years olds at electrode $0 z$ that indicates the ability to detect visual standard stimuli. As can be seen, the P1 has a peak of $21.5 \mu \mathrm{V}$ at about $140 \mathrm{~ms}$ after presentation of the standard visual stimuli.

When eyeballing the individual brain activity of children with PIMD, it appeared that all participating children were able to detect the auditory and visual standard stimuli. Two children could not be assessed as they had their eyes closed. This means that all children with PIMD in this group are able to hear and see (see Table 2). 


\section{CHAPTER 5}

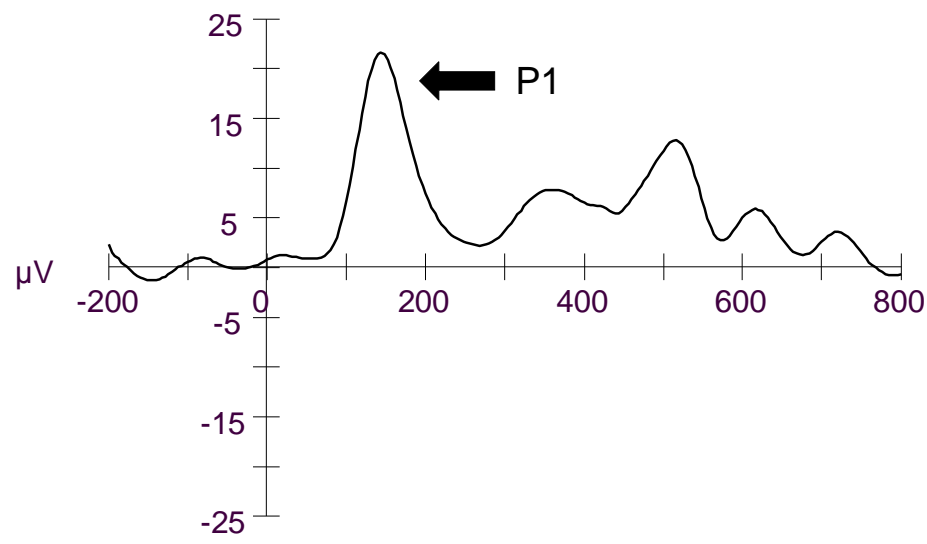

$\mathrm{ms}$

Fig. 2 displays the detection of visual standard stimuli in 5-7 years olds at electrode $0 z$. The component of interest is the $\mathrm{P} 1$, indicated by an arrow.

In addition, the z-scores regarding stimuli detection of each child with PIMD individually were calculated. This was done by comparing the individual brain activity of a PIMD child to the brain activity of its age-matched control group. Twelve out of 15 PIMD children had z-scores at or below the cut-off point of 4 , indicating normal auditory stimuli detection. Likewise, 3 out of 13 PIMD children had normal visual stimuli detection. None of these children displayed a maturational delay (Table 2). It can be seen in Table 1 that 6 children had visual impairments. Despite the fact that all of them were able to detect the visual stimuli, none of them did this in a way comparable to normally developing children (Table 2). 
Table 2. The sensory stimuli detection, sensory stimuli processing and novelty processing of each child with PIMD.

\begin{tabular}{|c|c|c|c|c|c|c|}
\hline & \multicolumn{2}{|c|}{ Hearing } & \multicolumn{4}{|c|}{ Vision } \\
\hline & Hearing $^{1}$ & $\begin{array}{l}\text { Stimuli } \\
\text { detection }^{2}\end{array}$ & $\begin{array}{l}\text { Novelty } \\
\text { Processing }\end{array}$ & Vision $^{1}$ & $\begin{array}{l}\text { Stimuli } \\
\text { detection } 2\end{array}$ & $\begin{array}{l}\text { Novelty } \\
\text { processing } 2\end{array}$ \\
\hline 01 & $X$ & $A$ & $\mathrm{~N}$ & $X$ & $\bar{A}$ & A \\
\hline 02 & $X$ & $\mathrm{~N}$ & $A$ & $X$ & A & $\mathrm{N}$ \\
\hline 03 & $X$ & $\mathrm{~N}$ & $A$ & $X$ & A & $\mathrm{N}$ \\
\hline 04 & $X$ & $\mathrm{~N}$ & $D$ & $x$ & $\mathrm{~N}$ & $\mathrm{~N}$ \\
\hline 05 & $X$ & $\mathrm{~N}$ & $\mathrm{~N}$ & $x$ & $A$ & D \\
\hline 06 & $X$ & A & $A$ & $X$ & A & A \\
\hline 07 & $X$ & $\mathrm{~N}$ & $\mathrm{~N}$ & $x$ & $\mathrm{~N}$ & $\mathrm{~N}$ \\
\hline 08 & $X$ & $\mathrm{~N}$ & $\mathrm{~N}$ & n.a. & n.a. & n.a. \\
\hline 09 & $X$ & $\mathrm{~N}$ & $A$ & $X$ & A & A \\
\hline 10 & $X$ & $\mathrm{~N}$ & $\mathrm{~N}$ & n.a. & n.a. & n.a. \\
\hline 11 & $X$ & $\mathrm{~N}$ & $D$ & $x$ & A & A \\
\hline 12 & $X$ & $\mathrm{~N}$ & $A$ & $X$ & A & A \\
\hline 13 & $X$ & $\mathrm{~N}$ & $\mathrm{~N}$ & $X$ & $\mathrm{~N}$ & $\mathrm{~N}$ \\
\hline 14 & $X$ & $\mathrm{~N}$ & $\mathrm{~N}$ & $X$ & A & A \\
\hline 15 & $x$ & A & A & $x$ & A & $\mathrm{N}$ \\
\hline
\end{tabular}

${ }^{1}$ x: ability is present; ${ }^{2} \mathrm{~A}$ : abnormal; D: delayed; $\mathrm{N}$ : normal; n.a.: not available.

Auditory and visual novelty processing

Fig. 3 displays the auditory novelty P3 in adults at electrode Cz. For the novelty P3 (novelty response) to appear the brain has to focus its attention to the novel stimulus and to recognize that the template of the novel stimulus is different from the template of the standard stimulus kept in working memory. The solid line represents the response to the standard stimulus, the dashed line the response to the novel stimulus, and the dotted line the novelty difference wave, in which the novelty effect is visible. It can be seen, that the auditory novelty effect is positive, with a maximum peak of $14 \mu \mathrm{V}$ at about $270 \mathrm{~ms}$ after stimulus presentation. Fig. 4 


\section{CHAPTER 5}

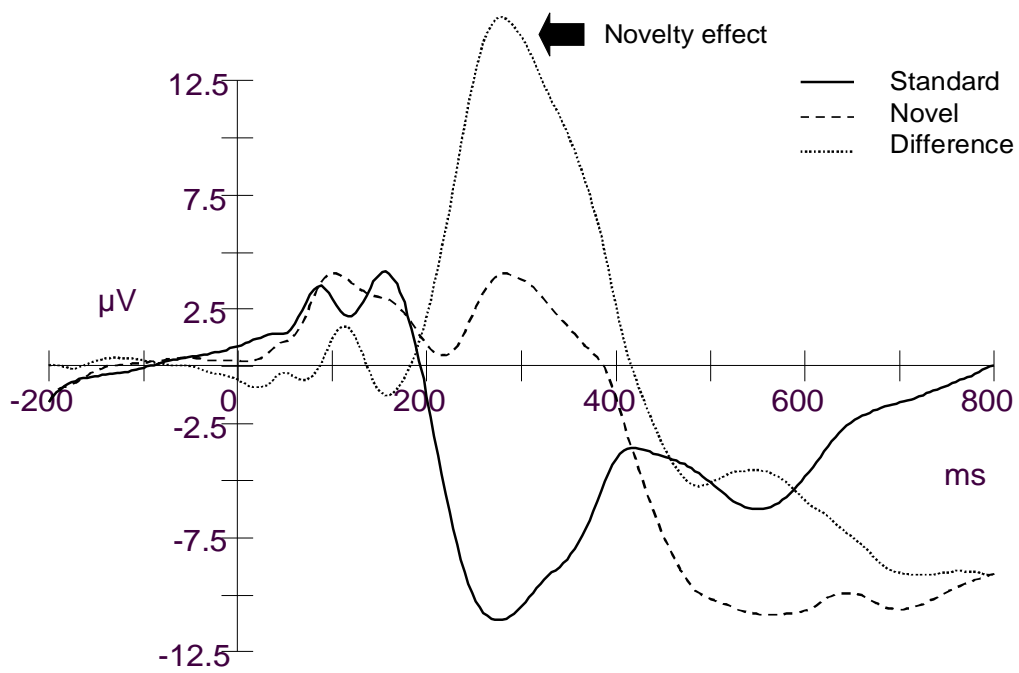

Fig. 3 displays the processing of auditory standard and novel stimuli in adults at electrode $\mathrm{Cz}$. The solid line represents the response to the standard stimuli; the dashed line the response to the novel stimuli and the dotted line the novelty difference wave, obtained by subtracting the response to the standard stimuli from the response to the novel stimuli. In the novelty difference wave the auditory novelty effect is visible and indicated by an arrow.

displays the visual novelty processing in 10-12 years olds at electrode Cz. Like Fig. 3, Fig. 4 represents the responses to the standard and novel stimuli and the novelty difference wave. As can be seen, the visual novelty component is negative, with a maximum peak of $-19 \mu \mathrm{V}$ at about $335 \mathrm{~ms}$ after stimulus presentation.

After calculating the z-scores of each child with PIM D individually, it showed that with regard to auditory novelty processing 7 out of 15 children with PIMD had zscores at or below the cut-off point of 4 . This means that the focusing of attention to the novel stimuli and the recognition that the template of the novel stimuli differed from the template of the standard stimuli present in working memory, was comparable to the functioning of these processes in control children. In addition, 2 of them showed a maturational delay. Furthermore, 6 out of 13 children with PIMD had normal visual novelty processing and 1 child displayed a maturational delay 
(Table 2). Despite the fact that none of the 6 children with visual disabilities had normal visual stimuli processing, it appeared that one of them had normal visual novelty processing and that another child showed a maturational delay. Please note that a deviant detection of auditory and/or visual stimuli does not always imply that the auditory and/or visual novelty processing is also deviant (see for example child number 02).

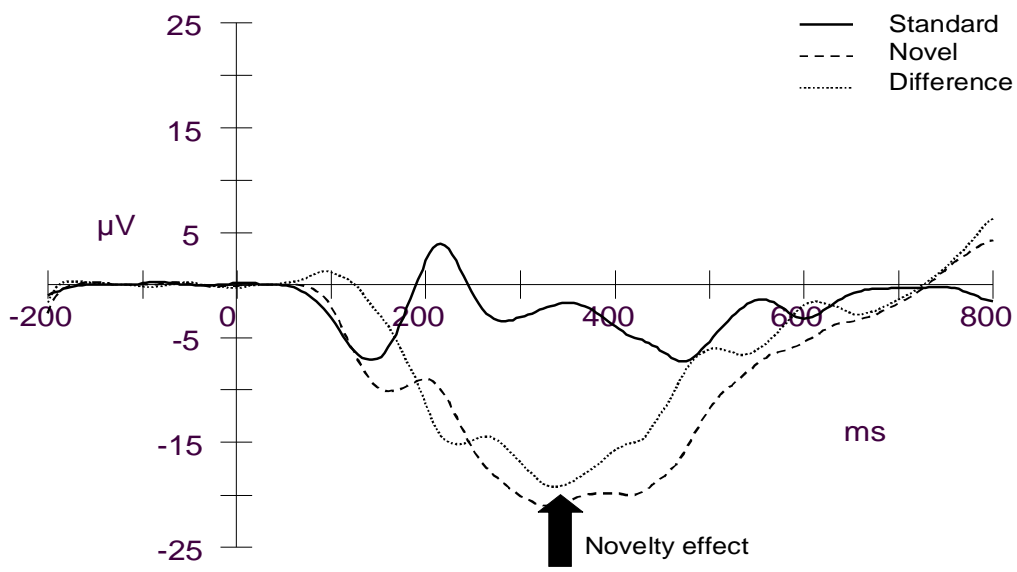

Fig. 4 displays the processing of visual standard and novel stimuli in 10-12 years olds at electrode $\mathrm{Cz}$. The solid line represents the response to the standard stimuli; the dashed line the response to the novel stimuli and the dotted line the novelty difference wave, obtained by subtracting the response to the standard stimuli from the response to the novel stimuli. In the novelty difference wave the visual novelty effect is visible and indicated by an arrow.

\section{Discussion}

In this study the detection of auditory and visual stimuli and the auditory and visual novelty processing in individual children with profound intellectual and 
multiple disabilities (PIM D) was examined. It appeared that all 15 children were able to hear, while 13 of them could see. When comparing the brain activity of children with PIMD to the brain activity of their age-matched control groups, it showed that the detection of auditory stimuli was normal in 12 out of 15 PIMD children, while only 3 out of 13 children had normal visual stimuli detection. Furthermore, 7 out of 15 children with PIMD had normal auditory novelty processing, while in 2 of them this processing was still immature. In addition, 6 out of 13 children with PIMD had normal visual novelty processing, while 1 child showed a maturational delay.

When brain activity is called aberrant in case of both deviant stimuli detection and deviant novelty processing, and in the absence of a maturational delay, $13 \%$ of all children with PIMD (2 out of 15) in this study has aberrant auditory and $46 \%$ of them ( 6 out of 13) has aberrant visual brain activity, These percentages deviate somewhat from earlier reports (e.g. M cCulloch, Sludden, McKeown, \& Kerr, 1996; Woodhouse, Griffiths, \& Gedling, 2000; Evenhuis, Theunissen, Denkers, Verschuure, \& Kemme, 2001; Aerts-Neggers, Schoonbrood-Lenssen, \& M aaskant, 2003; Van den Broek, Janssen, van Ramshorst, \& Deen, 2006; Van Splunder, Stilma, Bernsen, \& Evenhuis, 2006). According to these studies at least $19 \%$ has hearing problems and at least $59 \%$ displays visual impairments or is blind. Apart from the fact that the present study used a relatively small number of participants with PIMD, the research question in the present study differed from the other studies The earlier reports wanted to know whether hearing or vision was impaired, while the present study assessed stimuli detection and novelty processing in children with PIM D, not taking into account partial hearing or vision loss. Another reason may be that the participants in the present study were children aged 5-12 years, while the participants in most of the earlier reports were mainly adults.

The ERP referential data were not only used to determine whether the information processing in a child with PIMD was normal, they were also applied to assess whether the information processing in a PIMD child was maturational delayed. When the information processing in a PIMD child was deviant from the information processing in its age-matched control group, it was examined whether the child's information processing differed significantly from the information processing in younger control groups. If this was not the case, the child's information processing was called maturational delayed. In control children the auditory novelty component increases with age and is largest frontocentrally in 5-7 years olds and parietally in adults, while the visual novelty component becomes less negative with age. This means that the auditory novelty component in a 
maturational delayed PIMD child is smaller and more anteriorly focused, while the visual novelty component will be more negative compared to its age-matched control group.

In the present study the P1 component was used to assess the detection of both auditory and visual stimuli. Although the choice for the N1 component would have been more obvious with regard to auditory stimuli detection, this study preferred the $\mathrm{P} 1$ over the $\mathrm{N} 1$ for the following reason. Due to refractoriness the $\mathrm{N} 1$ is sensitive to the presentation rate of stimuli (Hari, Kaila, Katila, Tuomisto, \& Varpula, 1982). Especially in young children a N1 component is only visible with an Inter Stimulus Interval (ISI) of several seconds (Bruneau, Roux, Guerin, Barthelemy, \& Lelord, 1997; Čeponiene, Cheour, \& Näätänen, 1998; Wetzel, Widmann, Berti, \& Schröger, 2006). With regard to the limited abilities of children with PIMD the present study wanted to prevent long-lasting tasks, and opted for an ISI of 1 second, thus blocking the option of using the N1 when assessing auditory stimuli detection.

In order to assess the information processing in children with PIMD the brain activity across all electrodes of each PIMD child individually was compared to its age-matched control group. In order to do so a cut-off z-score was used, as was described in the Methods section. This procedure is comparable to the one used in IQ-tests. Their starting point is a normal distribution of intelligence. An accepted cut-off score of an IQ of 70 is commonly used for the diagnosis of intellectual disability, as it reflects two standard deviations below the mean score of 100 , and thus applies to about $2.5 \%$ of all children (O'Reilly \& Carr, 2007). According to their definition, normality is used for children that are able to attend regular schools. In the present study a stricter standard for normality was used, as children that attended regular schools but were having problems related to anxiety, depression, attention or school demands, were excluded from the study.

The ERP method has a number of advantages. First of all, it is non-invasive. This applies not only to the measurement itself but also to the total time involved. In this study the entire ERP measurement lasted 90 minutes, the application and removal of facial electrodes and electro-cap included. Furthermore, the present application of ERPs to assess information processing of individual children with PIMD is only a first step. For example, the ERP method is pre-eminently suited to establish an individual learning curve, by carrying out a second measurement after a certain period of time, and to assess therapy outcome. Another example is the fact that ERP research can help determine whether a child with PIMD can recognize the face or 
voice of a parent, can differentiate between emotions like happiness and anger, or is able to distinguish its favorite toy.

It appeared that 6 children with PIM D had visual abnormalities. Notwithstanding the fact that all of them had aberrant visual stimuli detection, one child showed normal visual novelty processing and one had a maturational delay. Reason for this discrepancy is the fact that ERPs can only indicate a child's strengths, not its weaknesses. The difference in outcome between visual stimuli detection and visual novelty processing suggests that these two children use alternative brain strategies to process visual stimuli information, as for novelty processing to be normal, some kind of effective sensory processing is necessary (Polich, 2007).

As stated before, it is very difficult, due to their cognitive and physical impairments, to estimate the developmental age (DA) of children with PIMD. Nonetheless, children, whose DA was estimated as very low by professionals, also had often deviant stimuli detection and novelty processing in the present study. However, in some cases a child was seriously underestimated. For example, child number 4 with an estimated DA of 9-10 months, had, based on its brain activity an information processing that was consistent with its chronological age. The underestimation of this child was probably due to his bilateral spasticity that hampered behavioral observations. In very young children with PIM D behavior is still pure, enabling professionals to give a rather accurate estimation of their developmental age. However, when these children grow older, their behavior loses its purity, and it becomes increasingly difficult to assess their cognitive level. This often leads to disagreements between parents and professionals about their child's DA. In contrast, ERP assessment is not troubled by a child's cognitive or motor impairments, and is thus able to resolve this disagreement.

The ERP tasks used in this study addressed operational processes like focusing of attention, recognition, and working memory. These processes are essential requirements for learning. However, they do not say anything about processes like (dis-) habituation or object permanence, as the research of these processes in children with PIMD demands the use of other passive ERP tasks. The results of the present tasks were gathered in a multimodal sensory and cognitive profile for each child with PIMD individually. This profile can help professionals attune educational, therapeutic or leisure activities more to the child's strengths and weaknesses, for example by in- or decreasing the stimulation of a certain modality during "snoezelen". "Snoezelen" is a multisensory stimulation program that is often applied to children with PIM D (e.g. Hogg, Cavet, Lambe, \& Smeddle, 2001). This will 
not only increase the benefit of a training or stimulation program for the child involved, but will also lead to lower costs in the long term.

At the end of this study the parents of each child with PIMD were informed about the results concerning their child's information processing. All parents, without exception, were very enthusiastic as this was the first time that they received behavior independent information about the multi-modal functioning of their child. Sometimes they were even confirmed in intuitive ideas about the functioning of their child that had been refuted by professionals up to now.

In conclusion, this was the first time that children with PIMD were individually assessed by event-related brain potentials (ERPs). The greatest merit of the ERP method is its ability to assess the information processing of a child, independent of its motor or cognitive impairments within a relatively short time. In addition, the ERP technique is non-invasive and behavior independent. Although the present ERP application only concerns the individual screening of multi-modal information processing, the range of practical and research possibilities is extensive, as ERPs can be perfectly used to tailor individual treatment programs and to evaluate treatment efficiency.

\section{Acknowledgements}

This research was supported by a grant of SWZ Zonhove, an institution for people with motor and multiple disabilities and by the Faculty of Psychology of the Maastricht University. We thank SWZ/Zonhove, the special primary school St. Emiliusschool in Son and Mariendael in Arnhem, the parents and the children for participating in our study. In addition, we are grateful to Esther Coenen, Aggie Bonten, Marinke Reubzaet, and Brechtje de Visser for their assistance in data acquisition. Finally, we thank the technical division of the faculty of Psychology and Neuroscience of Maastricht University, for their support in the ERP recordings and multimodal stimulus presentation. 

Chapter 6

General Discussion 
The research project described in this thesis examined whether it was possible to assess the sensory and cognitive information processing of children with profound intellectual and multiple disabilities (PIMD) by means of event-related brain potentials. The main reason for performing this research project was a request from SWZ/Zonhove, an institution for people with multiple disabilities. Due to very severe intellectual and motor disabilities, often combined with hearing and/or vision impairments it is extremely difficult to assess the sensory and cognitive abilities of children with PIMD. This poses a huge problem in practice, as the sensory and/or cognitive status and profile cannot be established. Without such a status and profile, the processing of sensory and cognitive information is unknown, leaving professionals in the dark of the best way to stimulate these children's development. In addition, professionals have no tools to assess the effectiveness of treatment, to decide among therapies, or to choose suitable daily activities. As the measurement of ERPs has the major advantage of assessing sensory and cognitive processing without requiring overt responses from its participants, much can be gained by applying the ERP method to children with PIMD. However, as this was the first time that brain activity of children with PIMD was assessed by means of ERPs, no relevant earlier studies were available. Before this research question could be addressed, norms or referential data concerning the sensory and cognitive information processing of normally developing children needed to be gathered. Therefore, this research project started with obtaining data regarding the auditory sensory gating (chapter 2) and auditory and visual novelty processing (chapter 3 and 4) in normally developing children aged 5-12 years and in adults.

All three studies described the development of passive information processing in children aged 5-12 years and in adults. It can be concluded that auditory sensory gating did not show as long a development as novelty processing, as intensity of processing and degree of sensory gating was already mature in 8 years olds (chapter 2). Intensity of processing and scalp distribution in auditory and visual novelty processing, on the other hand, was still not mature in 10-12 years olds (chapter 3 and 4). In all the studies on auditory sensory gating and on auditory and visual novelty processing the findings of earlier studies were replicated.

After finishing the three developmental studies the obtained referential data were used to assess the auditory and visual stimuli detection and novelty information processing in each child with PIMD individually (chapter 5). The results indicated that all children could hear and see. In addition, most children had normal auditory stimuli detection, while only a few had normal visual stimuli detection. 
Furthermore, about half of the children showed normal auditory and/or visual novelty processing, and some displayed a maturational delay.

In the next sections of this chapter technical and practical aspects arising from the use of ERPs in children with PIMD will be discussed. Furthermore, the yields of the ERP method for practice will be reported, where after this chapter will be ended by a general conclusion.

\section{Technical aspects concerning the use of ERPs in children with PIMD}

First, technical aspects with regard to the auditory P50 paradigm and novelty oddball paradigm will be addressed. Then, technical considerations concerning the use of the ERP method in children with PIM D will be listed.

\section{Auditory P50 paradigm}

The total auditory P50 paradigm lasts 10 minutes, interrupted halfway by a short break. This is rather long, especially when considering that the stimuli used were all clicks of $4 \mathrm{~ms}$. During the presentation of this paradigm children with PIMD could watch a silent movie. However, most of them were not very interested in the movie, and although the majority could be diverted by a favorite cuddle animal or other toy, some of them were not. These children had to be observed very carefully, as they often tried to pull off the head phones during the measurement.

Another drawback of the auditory P50 sensory gating paradigm is the size of the P50 component itself. Due to highly noisy EEG activity in children with PIMD, the P50 component is very difficult to detect. One possible solution to overcome this problem is the use of area measures in stead of peak scores. However, using area measures also involves the loss of latency information, so that subsequently the speed of auditory sensory gating cannot be assessed.

\section{Auditory and visual novelty oddball paradigm}

It seemed that the stimuli of the auditory novelty oddball task, especially the environmental sounds, were all well received by children with PIM D, as they often 
smiled when hearing the novel sounds. The stimuli of the visual novelty oddball task were presented on a 17 -inch LCD screen, before which the children were seated at a distance of 0.5 meter. This size and distance were chosen to maximize the chance that children with PIMD would notice the visual stimuli. Possibly, the impact of the stimuli, especially of the black-and-white gratings, was huge, as it was sometimes difficult for children with PIMD to keep looking at the screen. Two children even closed their eyes during the presentation of the visual stimuli. However, one of them had also his eyes closed during the auditory task, thus making it improbable that keeping the eyes shut had something to do with the visual stimulation. For future use in practice it is certainly worthwhile to decrease the intrusiveness of the black-and-white gratings by substituting the white background by a gray one. This adaptation will not have a significant effect on the novelty response, but will increase the pleasantness of the visual stimuli.

Another advantage of the novelty oddball paradigm is the fact that both the P1 and the novelty components are clearly visible in children with PIM D. Thus, it can be concluded that the novelty oddball task, be it auditory, or visual, is particularly well suited for the assessment of information processing in children with PIMD.

\section{The use of the ERP method}

One of the main assets for the use of the ERP method in children with PIMD is its ability to assess "passive" information processing. Although most ERP tasks include instructions and behavioral responses, the so-called "active" tasks, there are also tasks in which no instructions are given and no behavioral responses are required. These so-called "passive" tasks have the advantage that they can be applied to children and adults, and to responsive and non-responsive participants. In addition, passive tasks prevent that any brain activity will be added to the signal due to task demands or behavioral responses (DeBoer, Scott, \& Nelson, 2005). A disadvantage of passive paradigms is that no behavioral information is obtained.

The ERP method is an objective way to measure information processing. All data analyses can be done by computer, minimizing subjective influences. With this important characteristic the ERP technique distinguishes itself from other diagnostic tools for assessing information processing in children with PIM D.

Another aspect related to the ERP method is its high within-subject stability and test-retest reliability (e.g. Joutsiniemi, et al., 1998; Pekkonen, Rinne, \& Näätänen, 
1995; Räikkönen, Birkás, Horváth, Gervai, \& Winkler, 2003; Segalowitz \& Barnes, 1993). Developmental screening instruments like the Bayley Scales of Infant Development (BSID) are typically applied at least at two points in time in order to assess a child's cognitive development and to determine whether a child is growing into or out of deficit. However, the administration of intelligence tests like the BSID cannot be repeated shortly one after the other, as one has to account for practice effects (e.g. Barr, 2003; Bors \& Vigneau, 2003; Conway Greig, Nicholls, Wexler, \& Bell, 2004). The ERP paradigms used in this project provide information regarding a child's cognitive development, but are also so basic that no practice effects are to be expected.

Although many studies used ERPs to examine group effects, the individual assessment of sensory and cognitive information processing by means of cognitive ERPS is still extremely rare. The only other method that is commonly used to assess the sensory processing of an individual is the measurement of auditory and visual evoked potentials, also called brainstem potentials. Even though this technique can be used to detect hearing and vision impairments, this is surprisingly not a common screening procedure for people with PIMD, thus maintaining the uncertainty concerning their hearing and vision status. However, even if auditory and visual evoked potentials are used, their findings only relate to sensory processing, as during the measurement of evoked potentials no cognitive task manipulations are used, and analyses are limited to eyeballing. In addition to sensory processing, however, ERPs to cognitive paradigms also provide insight into cognitive information processing.

This is the first time that standard deviations were used to compare the individual brain activity patterns of children with PIM D to the brain activity patterns of age-matched control groups. Even though this is a totally new approach to assess stimuli detection and novelty processing in these children, it is evidence-based and based on widely accepted criteria used to determine, for example, IQ level. Although calculated separately, it was very interesting to notice that the standard deviation of all age groups, modalities, and components was the same, namely 4.0. Thus, when using this standard deviation measure of 4.0 , it is very easy to determine whether the stimuli detection and/or novelty processing of an individual is normal or deviant.

As this was the first time that children with PIMD were measured by means of ERPs, it was uncertain whether the ERP method could be successfully applied. This proved to be the case. It was also unknown, what kind of ERP data could be collected. Therefore, all 30 electrodes of the electro-cap were used during the ERP 
measurement in order to maximize the chance of obtaining useful data. Such a procedure requires that the resistance of all 30 electrodes will be lowered to an acceptable level. However, this is a rather laborious and time-consuming task. Now that more is known about the use of ERPs in children with PIMD, it is conceivable that in the future only those electrodes need to be used that provide the most relevant information. Thus, in the present battery of tests the total of 30 electrodes might be reduced to 10 or less electrodes, leading to a considerable shortening of the ERP measurement itself. The same line of reasoning applies to the facial electrodes that register the vertical eye movements. When the main effects have a central focus, a frontal electrode can be used for the correction of the vertical eye movements in the data analysis. This option also excludes the danger of pulling loose the cables of these facial electrodes. Another possible way to decrease the total ERP measuring time in the future is the improvement of existing technology. It is certainly imaginable that, for example, the development of active electrodes could make the lowering of the electrodes' impedance less stringent.

A final technical aspect regarding the use of ERPs in children with PIMD is the fact that ERPs can only deliver positive proof of existing sensory or cognitive processing abilities. This means that when a child is individually assessed, only its strengths can be positively identified, not its possible weaknesses. The reason for this is that a damaged brain, especially in young children, will try to compensate loss of brain function by finding alternative ways to process information. Thus, when information processing of a child is aberrant from age-matched control children, this may be due to either badly functioning brain structures, or to compensatory brain structures recruited by the brain, as both cases may result in a deviant ERP pattern.

\section{Practical aspects concerning the use of ERPs in children with PIMD}

The first practical aspect relates to the set-up for EEG measurements. The present set-up consisted of two laptops, namely one for EEG recording and one for stimulus presentation, an amplifier and a LCD-screen. As technical development and progress have provided increasingly smaller amplifiers, the total set-up for EEG measurement can be transported in two suitcases. This mobile set-up multiplied the possibilities for EEG measurement in some patient groups. Patients who until now 
had difficulties to go to fixed set-ups in, for example, universities and hospitals, are now measured at home, in their schools, or in the institutions wherein they reside.

During the EEG measurement it is preferable that a parent or a caregiver is present. One reason is that this person knows the child very well and recognizes when the child experiences any discomfort. A second reason is the fact that their presence will make the child more at ease, improving the quality of the EEG recording. The EEG measurement of a child with PIMD can be very laborious, as many of these children must be prevented from pulling off the electro-cap and/or facial electrodes before and during the measurement itself. At least one person is needed to handle the two laptops. Furthermore, periods of not-looking at the screen must be registered during the presentation of visual stimuli, so that these periods can be removed from the EEG signal afterwards. Therefore, an EEG measurement of a child with PIMD demands the presence of a minimum of two people, but preferably three.

Next, there are also some practical considerations concerning the presentation of the stimuli. When presenting auditory stimuli the present study used a headphone. Afterwards, this proved to be a suboptimal choice. Not only did some children pull this headphone off during the EEG recording, the headphone also appeared rather large for some children with microcephaly. However, the use of ear plugs is also not recommendable, as some children with PIMD have very sensitive ears. Furthermore, it is difficult to find ear plugs that are appropriate for young children. Speakers are an option, but due to head movements the stereo effect is not always as optimal as possible. However, this disadvantage can be overcome by placing the speakers further away from the participant. Unlike auditory stimuli the presentation of visual stimuli has the drawback that a child can very easily evade this stimulation by closing its eyes. In addition, as some children with vision impairments have peripheral looking or look out of the corner of their eyes, it is sometimes very difficult to see whether a child with PIMD is watching the screen or not. Thus, successful assessment of visual information processing is to a large extent dependent on a child's cooperation.

A huge advantage of the ERP method is the fact that in a relatively short period many data can be collected. The total ERP measurement in the present research project lasted about 90 minutes. During these 90 minutes not only four ERP tasks were offered to the participant, also the electro-cap and facial electrodes were applied and removed within this period. The ERP tasks consisted of the auditory P50 sensory gating paradigm, that lasted about 10 minutes, and of three novelty oddball tasks, namely an auditory, a visual, and a tactile one, that each lasted about 7.5 
minutes. The findings of the tactile novelty oddball are not dealt with in this thesis, but will be presented in another paper.

In order to assess the information processing of each child with PIMD individually, norm or referential data from normally developing children are necessary. Although the acquisition of reference data is a very time-consuming activity, it is certainly worthwhile as it also resulted in ideas to make the ERP paradigms more pleasant for children with PIMD. As the behavioral responses of children with PIMD are inconclusive, the input of normally developing children is sorely needed. An example of such an adaptation is the replacement of the white background by a gray one in the black-and-white gratings in order to reduce their intrusiveness.

Now that referential data have been collected, the battery of tests developed in this research project can be implemented in practice to serve as a diagnostic tool for children with PIM D. In order to do so equipment for the ERP measurement needs to be purchased. The ERP set-up used for the development of this battery consisted of two laptops, an amplifier, a headphone or speakers, a LCD-screen, a tactile stimulation device developed by the technical department of the faculty of Psychology and Neuroscience of Maastricht University, and software for the presentation of the stimuli and for the analysis of the data. Luckily, the costs for this kind of equipment reduced drastically during the last years, making such a purchase quite affordable. However, next to the purchase of an ERP set-up, a specialist needs to be involved, who will monitor the procedures about the EEG measurement like the quality of an EEG recording and the electrode and electro-cap application. In addition, this person must be able to select the appropriate ERP component, perform the data analyses and interpret its results.

In this research project a total of 17 children with PIMD were measured by means of the ERP method. Eventually, two children dropped out of the project, due to excessive movements. More participating children with PIMD moved excessively, but these movements could be controlled by the researchers and/or by the parent or caregiver. However, these two children moved so excessively, that it was not possible to apply the electro-cap and facial electrodes, and they actually needed to be measured for a second time. However, due to the limited amount of time available in this project, we refrained from doing so. Thus, it should be taken into account that some children with PIMD might need more than one attempt to ERP measurement. 


\section{Yields for practice when using the ERP method}

Although professionals make use of psychological test results and behavioral observations to assess the sensory and cognitive capabilities of children with PIMD, unlike ERPs, they do not have a clue what is going on inside the heads of these children. Very often there was a correspondence between the results obtained by ERPs and the developmental age that was indicated by professionals on the basis of psychological tests and behavioral observations. However, there were also children whose esteemed developmental age was below 24 months according to the professionals, but who, based on ERPs, had an auditory and/or visual stimuli detection and novelty processing like normally developing children of their own age. Most likely the disabilities of these children affect their behavior such that it is even more difficult to evaluate them with standard measurements. This discrepancy in outcome indicates the surplus value that the ERP method can have in practice. However, the ERP paradigms described in this thesis assessed very basic cognitive processes like stimuli detection and novelty processing. For higher cognitive processes more complex ERP paradigms are necessary.

According to the information processing theory, sensory processing precedes cognitive processing. However, some children with PIM D displayed abnormal brain activity patterns when processing sensory information, but normal patterns of brain activity when processing novelty (cognitive) information. Apparently, the brain disposes of an enormous flexibility with regard to information processing, as these children are fine examples of the compensatory abilities of the human brain.

Although not discussed in this thesis, the brain activity of all normally developing and PIMD children was measured a second time (after a year) using the same paradigms of the first ERP measurement. It was expected that children with PIMD would not develop more than normally developing children, however preliminary analyses showed a different picture. Children with PIMD displayed at least as much development over a year period as the control children did, notwithstanding the fact that most children with PIMD were 10 years or older. Thus, in contrast to the popular belief that 10 year old children with PIMD do not develop any further, the test-retest ERP data proof otherwise. An ERP test-retest as mentioned above can also be used for the assessment of treatment outcome. By performing a measurement before and after a therapy, it can be determined whether this treatment is favorable to the information processing of a person or not. In addition, it can also be established which therapy is most successful. 
The objective of this research project was to make a sensory and cognitive profile for each child with PIMD individually. Such an individual profile not only can be used to attune therapy and daily activities to a child's strengths and weaknesses, it can also assist in determining what other future research with ERPs would be beneficial for this child. An example of such research is the repeated measurement of a child during a certain period of time where after its progress will be mapped to an individual learning curve. At the end of the project a professional communicated the findings concerning the stimuli detection and novelty information processing to the parents of each participating child with PIMD in an individual session. The message brought was in most cases a positive one, as most participating children with PIMD did rather well on the tasks. Sometimes parents were even confirmed in intuitive ideas about the functioning of their child that had been refuted by professionals up to now.

Although all parents were very happy with the received ERP information, this first report was rather limited. More research and experience could extend the knowledge of a child's sensory and cognitive profile with insight into its learning abilities and its response to certain therapies. In addition, such a dossier could contain evaluations of additional ERP paradigms such as whether a child with PIMD can recognize the face or voice of a parent, can differentiate between emotions like happiness and anger, or is able to distinguish its favorite toy.

\section{General conclusion}

Stimuli detection and novelty processing in children with PIMD was evaluated, using referential data of age-matched control children. It appeared that all participating children with PIMD could hear and see. Most children with PIMD showed normal auditory stimuli detection, while only a few had normal visual stimuli detection. Half of the children displayed normal auditory and/or visual novelty processing, while in a few novelty processing was maturational delayed. The findings in this thesis proof that it is possible to assess information processing in children with PIM D by means of ERPs. The ERP technique is non-invasive, behaviorindependent, and many data can be gathered in a relatively short time. As reference data are now available, and the individual ERP evaluation in PIM D children has been established, the current ERP application is in principle ready for use in practice. 
Given that the ERPs in some children with PIMD suggest a much higher level of functioning as determined by professionals, it is to be recommended that the ERP method will be applied in a more standard fashion to these children, while at the same time the practical application can be further extended. 



\section{Summary}

Is it possible to assess sensory and cognitive information processing in children with profound intellectual and multiple disabilities (PIMD) by means of a noninvasive brain imaging technique like event-related brain potentials (ERPs)? This question was at the centre of the research project described in this thesis. Due to a very low intelligence level combined with motor disabilities and vision and/or hearing impairments, it is extremely difficult for children with PIM D to communicate with other people. This inability to communicate not only hampers their social life, but also thwarts professionals in their attempts to determine these children's sensory and cognitive capacities. As a result parents, caregivers and professionals are ignorant of the best way to approach them, have no means to assess developmental age and effects of therapy, and are unable to determine suitable training and daily activities.

An alternative to psychological tests and observational methods is the measurement of ERPs. A major advantage of this ERP method is its ability to assess information processing without additional communicative or behavioral requirements, thus enabling its applicability in children with PIM D. However, as this was the first time that the brain activity of children with PIMD was assessed by means of the ERP method, there were no earlier studies that could serve as startingpoint and thus, results to compare their brain activity to, were non-existent. Therefore, this research project started with obtaining data regarding the auditory sensory gating and auditory and visual novelty processing in normally developing children aged 5-12 years and in adults (chapter 2-4), where after these referential data were used to assess the auditory and visual stimuli detection and novelty processing in each child with PIM D individually (chapter 5).

The first ERP study of this research project examined the development of auditory sensory gating (chapter 2). Auditory sensory gating is the ability of the brain to suppress irrelevant/redundant stimulation in order to prevent the brain from being over flooded with information. It appeared that the processing speed of the two clicks and the distribution of brain activity over the skull were already adult like in 5 years olds. However, auditory sensory gating itself was not mature until the 
age of 8 years, as the difference in P50 response to the first and second click in 5-7 years olds was smaller compared to the elder children and adults.

The second ERP study of this research project focused on the development of auditory novelty processing (chapter 3 ). Although many ERP studies addressed the development of auditory novelty processing, all but one used active tasks requiring an overt response from their participants, thus rendering their results unsuitable for the assessment of auditory novelty processing in children with PIMD. The only passive study used a rather long and complicated paradigm. Therefore, the main goal of this study was to replicate the findings of this earlier passive study using a shorter and simplified paradigm. The adapted paradigm replicated the earlier findings regarding passive auditory novelty processing, as two auditory novelty components were found that were different in topography and development, and both novelty components were still not mature in 10-12 years olds. Thus, it appeared that the adapted paradigm is well suited to assess auditory novelty processing in children with PIM D.

By analogy with the chapter on auditory novelty processing chapter 4 described an ERP study regarding the development of visual novelty processing. Although earlier ERP studies examined the development of this processing, they used tasks that required overt responses. In order to obtain reference data the present study therefore used a passive visual novelty oddball paradigm. Overall, the findings of earlier studies on the development of active visual novelty processing were replicated. It appeared that passive visual novelty processing is still not mature in children aged 10-12 years, as children differ from adults in both speed and intensity of visual novelty processing.

The main goal of the last study was to assess the auditory and visual stimuli detection and novelty processing in children with PIM D individually by means of ERPs. To this purpose the same auditory and visual novelty oddball paradigm as used in the studies described in chapters 3 and 4, was presented to these children. Thus, the brain activity of each child with PIMD individually could be compared to the reference data of normally developing children. The main component of interest with regard to auditory and visual stimuli detection was the P1. When this component is visible in the auditory and/or visual brain activity of a child, it can be concluded that this child is able to detect the presented auditory and/or visual information. With regard to auditory and visual novelty processing the focus was on the novelty component. A novelty component will be present in the brain activity of a child, when the child's brain has focused its attention to the novel information and 
recognized that this new information is different from the old information kept in working memory. First, an auditory and/or visual P1 indicated that a child was able to hear and/or see. It appeared that all 15 children with PIM D could hear, and that 13 of them could see. In two children the visual stimuli detection could not be assessed as they closed their eyes during the EEG measurement. Next, the sensory P1 brain activity of an individual PIM D child was compared to the sensory P1 brain activity of aged-matched control children. When no significant differences were found, stimuli detection was called normal. In case of deviant sensory P1 brain activity, the sensory P1 brain activity was compared to the sensory P1 brain activity of younger control children, so that it could be determined whether the deviances in sensory P1 brain activity were due to a maturational delay. It appeared that 12 out of 15 children with PIMD had normal auditory stimuli detection, while only 3 of the 13 children with PIMD had normal visual stimuli detection. None of these children displayed an auditory or visual maturational delay. Finally, the novelty brain activity of each child with PIM D was compared to the novelty brain activity of age-matched control children, whereby the same procedure used for stimuli detection was followed. Seven out of 15 children with PIMD showed normal auditory novelty processing, while 6 out of 13 children had normal visual novelty processing. In addition, two of them had an auditory, and one of them had a visual maturational delay. When comparing these ERP results to the behavioral and observational data of professionals, there are many similarities, as most PIMD children with a very low developmental age (DA) also showed deviant information processing. However, some PIM D children were seriously underestimated, as they processed information similar to normally developing children of their own age. It can thus be concluded that the non-invasive measurement of ERPs is a very suitable and resourceful method to assess information processing in children with PIMD.

The general discussion addresses several aspects regarding the technical and practical application of the measurement of ERPs in children with PIMD. In addition, the profits that can be gained in practice by applying the ERP method to children with PIMD are discussed. 



\section{Samenvatting}

Is het mogelijk de sensorische en cognitieve informatieverwerking in ernstig meervoudig gehandicapte kinderen (EMG kinderen) te evalueren door middel van een non-invasieve brain-imaging techniek als taakgerelateerde hersenactiviteit (ERP)? Dit is de centrale vraag van dit proefschrift. Vanwege een zeer laag intelligentieniveau, motorische beperkingen en visie en/of gehoor problemen, is het zeer moeilijk voor EM G kinderen om te communiceren met andere mensen. Dit onvermogen om te communiceren heeft niet alleen een negatieve invloed op hun sociaal leven, het hindert ook professionals in hun pogingen de sensorische en cognitieve capaciteiten van deze kinderen vast te stellen. Dit leidt ertoe dat ouders, zorgverleners, en professionals niet weten hoe ze hen het beste kunnen benaderen, niet kunnen inschatten wat hun ontwikkelingsleeftijd is, en niet in staat zijn om te evalueren of een therapie effect heeft gehad. Ook het bepalen van de meest geschikte training en/of dagactiviteit is zo zeer moeilijk.

Een alternatief voor psychologische tests en observaties vormt het meten van taakgerelateerde hersenactiviteit (ERP). Deze methode is uitermate geschikt voor EMG kinderen, omdat het ook informatieverwerking kan evalueren zonder dat een kind communiceert of bepaalde gedragingen laat zien. Vandaar dat in dit onderzoeksproject voor het eerst de hersenactiviteit van EMG kinderen werd geëvalueerd met behulp van ERP's. Vanwege het ontbreken van eerdere studies waren er geen resultaten beschikbaar waarmee de hersenactiviteit van EMG kinderen vergeleken kon worden. Daarom is dit onderzoeksproject begonnen met het verzamelen van referentiedata voor de auditieve "sensory gating", en auditieve en visuele "novelty" verwerking in normaal ontwikkelende kinderen (5-12 jaar) en in volwassenen (hoofdstukken 2-4). Vervolgens zijn deze referentiedata gebruikt om de auditieve en visuele stimuli detectie en "novelty" verwerking in elk EMG kind afzonderlijk te evalueren.

De eerste ERP studie van dit onderzoeksproject heeft de ontwikkeling van auditieve "sensory gating" onderzocht (hoofdstuk 2). Auditieve "sensory gating" is het vermogen van het brein om irrelevante of overbodige stimulatie te blokkeren, zodat voorkomen wordt dat het brein wordt overspoeld met informatie. De 
resultaten lieten zien dat de verwerkingssnelheid van de twee klikken en het P50 patroon van hersenactiviteit reeds volwassen was in 5-jarigen. Auditieve "sensory gating" was daarentegen pas uitontwikkeld in kinderen van 8 jaar, omdat het verschil tussen de P50 respons op de eerste klik en op de tweede klik in 5-7 jarigen kleiner was dan in oudere kinderen en in volwassenen.

De tweede ERP studie van dit onderzoeksproject hield zich bezig met de ontwikkeling van auditieve "novelty" verwerking (hoofdstuk 3). Hoewel de ontwikkeling van auditieve "novelty" verwerking al vaker onderzocht is, hebben al deze eerdere studies, op één na, actieve ERP taken gebruikt. Doordat deze taken een gedragrespons van hun deelnemers vragen, zijn hun data ongeschikt om de auditieve "novelty" verwerking in EMG kinderen te evalueren. De enige passieve studie heeft een nogal lang en gecompliceerd ERP paradigma gebruikt. Vandaar dat dit onderzoek erop was gericht de bevindingen van deze eerdere passieve studie te repliceren door gebruik te maken van een korter en vereenvoudigd paradigma. Dit aangepaste paradigma bleek inderdaad in staat de eerdere resultaten betreffende passieve auditieve "novelty" verwerking te repliceren. Zo werden er twee auditieve "novelty" componenten gevonden, die allebei een verschillende topografie en ontwikkeling lieten zien, en die beide nog niet uitontwikkeld waren in 10-12 jarigen. Aldus blijkt dat het aangepaste paradigma zeer geschikt is om de auditieve "novelty" verwerking in EM G kinderen te evalueren.

Naar analogie van het hoofdstuk over auditieve "novelty" verwerking, wordt in hoofdstuk 4 een ERP studie naar de ontwikkeling van visuele "novelty" verwerking beschreven. Hoewel eerdere ERP studies ook al de ontwikkeling van visuele "novelty" verwerking hebben onderzocht, werd hierbij altijd gebruik gemaakt van taken die een gedragsrespons vereisen. Om over passieve referentie data te kunnen beschikken heeft de huidige studie daarom een passief visueel "novelty oddball" paradigma gebruikt. Over het algemeen werden de bevindingen van eerdere studies naar de ontwikkeling van actieve visuele "novelty" verwerking gerepliceerd. De data lieten zien dat passieve visuele "novelty" verwerking nog niet is uitontwikkeld in 1012 jarigen, aangezien zowel de snelheid als de intensiteit van visuele "novelty" verwerking in kinderen verschilt van die in volwassenen.

De laatste studie was gericht op het evalueren van de auditieve en visuele stimuli detectie en "novelty" verwerking in elk individueel EM G kind met behulp van taakgerelateerde hersenactiviteit (hoofdstuk 5). Hiertoe werd hetzelfde auditieve en visuele "novelty oddball" paradigma gebruikt zoals beschreven in de hoofdstukken 3 en 4 . De hersenactiviteit van elk EMG kind afzonderlijk werd 
vergeleken met referentie data afkomstig van normaal ontwikkelende kinderen. De P1 component werd gebruikt voor de evaluatie van auditieve en visuele stimuli detectie. Als deze component zichtbaar is in de auditieve en/of visuele hersenactiviteit van een kind, dan betekent dit dat het kind in staat is de aangeboden auditieve en/of visuele informatie te detecteren. De "novelty" component is van belang bij de auditieve en visuele "novelty" verwerking. De aanwezigheid van een "novelty" component in de hersenactiviteit van een kind, geeft aan dat dit kind in staat is zijn aandacht te focussen op de nieuwe informatie en te herkennen dat deze nieuwe informatie anders is dan de oude informatie die aanwezig is in het werkgeheugen. De aanwezigheid van een auditieve en/of visuele P1 is een indicatie voor het horen en/ of zien van dit kind. Het bleek dat alle 15 EMG kinderen konden horen, en dat 13 van hen konden zien. De visuele stimuli detectie van twee kinderen kon niet worden geëvalueerd omdat ze de ogen sloten tijdens de EEG meting. Vervolgens werd het patroon van de P1 hersenactiviteit van een individueel EM G kind vergeleken met het patroon van de P1 hersenactiviteit van controle kinderen van dezelfde leeftijd. Indien er geen significante verschillen werden gevonden, werd de stimuli detectie normaal genoemd. Indien er wel significante afwijkingen te zien waren, werd de P1 hersenactiviteit van het betreffende EMG kind vergeleken met de P1 hersenactiviteit van jongere controle kinderen. Zo kon worden vastgesteld of de afwijkingen in de P1 hersenactiviteit het gevolg waren van een ontwikkelingsachterstand. De resultaten lieten zien dat 12 van de 15 EMG kinderen een normale auditieve stimuli detectie hadden, terwijl slechts 3 van de 13 EM G kinderen een normale visuele stimuli detectie vertoonden. Geen van deze kinderen liet met betrekking tot stimuli detectie een ontwikkelingsachterstand zien. Tenslotte werd de "novelty" hersenactiviteit van elk EMG kind vergeleken met de "novelty" hersenactiviteit van controle kinderen van zijn eigen leeftijd, waarbij dezelfde procedure zoals gebruikt voor stimuli detectie werd gevolgd. Zeven van de $15 \mathrm{EMG}$ kinderen vertoonden een normale auditieve "novelty" verwerking, 6 van de 13 EMG kinderen een normale visuele "novelty" verwerking. Tevens hadden 2 kinderen een auditieve en 1 kind een visuele ontwikkelingsachterstand in de "novelty" verwerking. Het vergelijken van deze ERP resultaten met de gedragsdata en observaties van professionals laat veel overeenkomsten zien, aangezien de meeste EMG kinderen met een zeer lage ontwikkelingsleeftijd ook een afwijkende informatieverwerking vertoonden. Een aantal EM G kinderen werd echter ernstig onderschat, aangezien zij op een zelfde manier informatie bleken te verwerken als normaal ontwikkelende kinderen van 
hun eigen leeftijd. Aldus kan worden geconcludeerd dat de non-invasieve meting van taakgerelateerde hersenactiviteit een zeer geschikte en vindingrijke methode is om de informatieverwerking in EM G kinderen te evalueren.

In de algemene discussie worden een aantal aspecten behandeld van de technische en praktische toepassing van het meten van taakgerelateerde hersenactiviteit in EM G kinderen. Tevens wordt aangegeven wat de voordelen zijn voor de praktijk als de ERP methode wordt toegepast op EM G kinderen. 


\section{References}

Adler, L.E., Pachtman, E., Franks, R.D., Pecevich, M., Waldo, M.C., \& Freedman, R. (1982). Neurophysiological evidence for a defect in neuronal mechanisms involved in sensory gating in schizophrenia. Biological Psychiatry, 17, 639-654.

Adler, L.E., Rose, G., \& Freedman, R. (1986). Neurophysiological studies of sensory gating in rats: Effects of amphetamine, phencyclidine, and haloperidol. Biological Psychiatry, 21, 787-798.

Aerts-Neggers, T.R.B., Schoonbrood-Lenssen, A.M .J., \& M aaskant, M .A. (2003). Gehoorverlies bij mensen met een verstandelijke handicap. Resultaten van een screeningsonderzoek in drie activiteitencentra. Nederlands Tijdschrift voor Zwakzinnigenzorg, 4, 238-250.

Aylward, G.P., Pfeiffer, S.I., Wright, A., \& Verhulst, S.J. (1989). Outcome studies of low birth weight infants published in the last decade: A meta-analysis. Journal of Pediatrics, 115, 515-520.

Barr, B.B. (2003). Neuropsychological testing of high school athletes. Preliminary norms and test-retest indices. Archives of Clinical Neuropsychology, 18, 91-101.

Barrett, S.E., \& Rugg, M.D. (1990). Event-related potentials and the semantic matching of pictures. Brain and Cognition, 14, 201-212.

Bax, M., Goldstein, M., Rosenbaum, P., Leviton, A., \& Paneth, N. (2005). Proposed definition and classification of cerebral palsy. Developmental Medicine \& Child Neurology, 47, 571-576.

Bayley, N. (1993). Bayley Scales of Infant Development (BSID-II)-Second Edition. San Antonio, TX, Psychological Corporation.

Berger, H. (1929). Über das Elektrenkephalogramm das M enschen. Archiv für Psychiatrie, 87, 527-570.

Bickford-Wimer, P.C., Nagamoto, H., Johnson, R., Adler, L.E., Egan, M., Rose, G.M., \& Freedman, R. (1990). Auditory sensory gating in hippocampal neurons: A model system in the rat. Biological Psychiatry, 27, 183-192.

Bors, D.A., \& Vigneau, F. (2003). The effect of practice on Raven's Advanced Progressive Matrices. Learning and Individual Differences, 13, 291-312.

Boutros, N.N., \& Belger, A. (1999). Midlatency evoked potentials attenuation and augmentation reflect different aspects of sensory gating. Biological Psychiatry, 45, 917-922.

Boutros, N.N., Bonnet, K.A., Millana, R., \& Liu, J. (1997). A parametric study of the N40 auditory evoked response in rats. Biological Psychiatry, 42, 1051-1059.

Boutros, N.N., \& Kwan, S.W. (1998). Test-retest reliability of the rat N40 auditory evoked response: Preliminary data. Psychiatry Research, 81, 269-276.

Brinkman, M.J.R., \& Stauder, J.E.A. (2007). Development and gender in the P50 paradigm. Clinical Neurophysiology, 118, 1517-1524.

Brinkman, M.J.R., \& Stauder, J.E.A. (2008). The development of passive auditory novelty processing. International Journal of Psychophysiology, 70, 33-39.

Brinkman, M.J.R., Stauder, J.E.A. The development of passive visual novelty processing. (in preparation).

Bruneau, N., Roux, S., Guerin, P., Barthelemy, C., \& Lelord, G. (1997). Temporal prominence of auditory evoked potentials (N1 wave) in 4- to 8-year-old children. Psychophysiology, 34, 32-38. 


\section{REFERENCES}

Bunge, S.A., Dudukovic, N.M., Thomason, M.E., Vaidya, C.J., \& Gabrieli, J.D. (2002). Immature frontal lobe contributions to cognitive control in children: Evidence from fM RI. Neuron, 33, 301-311.

Carr, A., \& O'Reilly, G. (2007). In A. Carr, G. O'Reilly, P. Noonan Walsh, \& J. M cevoy (Eds.), The handbook of intellectual disability and clinical psychology practice. New-York, Routledge, pp. 3-49.

Čeponiene, R., Cheour, M., \& Näätänen, R. (1998). Interstimulus interval and auditory event-related potentials in children: Evidence for multiple generators. Electroencephalography and Clinical Neurophysiology, 108, 345-354.

Čeponiene, R., Lepistö, T., Soininen, M., Aronen, E., Alku, P., Näätänen, R. (2004). Event-related potentials associated with sound discrimination versus novelty detection in children. Psychophysiology, 41, 130 141.

Coch, D., Skendzel, W., \& Neville, H.J. (2005). Auditory and visual refractory period effects in children and adults: An ERP study. Clinical Neurophysiology, 116, 2184-2203.

Coles, M.G.H., \& Rugg, M.D. (1995). Event-related brain potentials: An introduction. In M.D. Rugg, \& M.G.H. Coles (Eds.), Electrophysiology of mind: Event-related brain potentials and cognition. New York, Oxford University Press, pp. 1-26.

Conway Greig, T., Nicholls, S.S., Wexler, B.E., \& Bell M.D. (2004). Test-retest stability of neuropsychological testing and individual differences in variability in schizophrenia outpatients. Psychiatry Research, 129, 241-247.

Courchesne, E. (1977). Event-related brain potentials: Comparison between children and adults. Science, 197, 589-592.

Courchesne, E. (1978a). Neurophysiological correlates of cognitive development: Changes in long-latency event-related potentials from childhood to adulthood. Electroencephalogr.Clinical Neurophysiology, 45, 468-482.

Courchesne, E. (1978b). Changes in P3 waves with event repetition: Long term effects on scalp distribution and amplitudes. Electroencephalography and Clinical Neurophysiology, 45, 754-766.

Courchesne, E., Hillyard, S.A., \& Galambos, R. (1975). Stimulus novelty, task relevance and the visual evoked potential in man. Electroencephalography and Clinical Neurophysiology, 39, 131-143.

Cycowicz, Y.M ., \& Friedman, D. (1997). A developmental study of the effect of temporal order on the ERPs elicited by novel environmental sounds. Electroencephalography and Clinical Neurophysiology, 103, 304-318.

Cycowicz, Y.M., \& Friedman, D. (1998). Effect of sound familiarity on the event-related potentials elicited by novel environmental sounds. Brain and Cognition, 36, 30-51.

Cycowicz, Y.M., Friedman, D., \& Rothstein, M. (1996). An ERP developmental study of repetition priming by auditory novel stimuli. Psychophysiology, 33, 680-690.

Daffner, K.R., Scinto, L.F.M., Weitzman, A.M., Faust, R., Rentz, D., Budson, A.E. (2003). Frontal and parietal components of a cerebral network mediating voluntary attention to novel events. Journal of Cognitive Neuroscience, 15, 294-313.

DeBoer, T., Scott, L.S., \& Nelson, Ch.A. (2005). ERPs in developmental populations. In: T.C. Handy (Ed.), Event-related potentials. A methods handbook. Cambridge, M IT press, pp.263-298.

De Moor, J.M.H., Mulders, A.H.M., \& Didden, R. (2003). Meervoudig gehandicapt. Het kind met een motorische én cognitieve beperking. In M.J. Meihuizen-de Regt, J.M.H. de Moor, A.H.M. Mulders (Eds.), Kinderrevalidatie. Assen, Van Gorcum, pp.512-544.

Escera, C., Alho, K., Winkler, I., \& Näätänen, R. (1998). Neural mechanisms of involuntary attention to acoustic novelty and change. Journal of Cognitive Neuroscience, 10, 590-604. 
Evenhuis, H.M., Theunissen, M., Denkers, I., Verschuure, H., \& Kemme, H. (2001). Prevalence of visual and hearing impairment in a Dutch institutionalized population with intellectual disability. Journal of Intellectual Disability Research, 45, 457-464.

Fabiani, M., \& Friedman, D. (1995). Changes in brain activity patterns in aging: the novelty oddball. Psychophysiology, 32, 579-594.

Fabiani, M., Gratton, G., \& Coles, M.G.H. (2000). Event-related brain potentials. Methods, Theory and Applications. In: J.T. Cacioppo, L.G. Tassinary, \& G.G. Brantson (Eds.), Handbook of Psychophysiology. Cambridge, University Press, pp. 53-77.

Fabiani, M., Kazmerski, V.A., Cycowicz, Y.M ., \& Friedman, D. (1996). Naming norms for brief environmental sounds: effects of age and dementia. Psychophysiology, 33, 462-475.

Fagan, J.F. (1990). The paired-comparison paradigm and infant intelligence. Annuals of the New York Academy of Science, 608, 337-363.

Fagan, J., \& Shepherd, P.A. (1985). The Fagan Test of Infant Intelligence. Cleveland, Ohio, Infanttest Corporation.

Flach, K.A., Adler, L.E., Gerhardt, G.A., Miller, C., Bickford, P., M acGregor, R.J. (1996). Sensory gating in a computer model of the CA3 neural network of the hippocampus. Biological Psychiatry, 40, 1230-1245.

Frankenburg, W.K., \& Dodds, J.B. (1990). Denver II Screening M anual. Denver, CO, Denver Developmental Materials.

Freedman, R., Adler, L.E., \& Waldo, M. (1987). Gating of the auditory evoked potential in children and adults. Psychophysiology, 24, 223-227.

Freedman, R., Adler, L.E., Waldo, M.C., Pachtman, E., \& Franks, R.D. (1983). Neurophysiological evidence for a defect in inhibitory pathways in schizophrenia: Comparison of medicated and drug-free patients. Biological Psychiatry, 18, 537-551.

Freedman, R., Waldo, M., Bickford-Wimer, P., \& Nagamoto, H. (1991). Elementary neuronal dysfunctions in schizophrenia. Schizophrenia Research, 4, 233-243.

Friedman, D., Cycowicz, Y.M., \& Gaeta, H. (2001). The novelty P3: An event-related brain potential (ERP) sign of the brain's evaluation of novelty. Neuroscience and Biobehavioral Reviews, 25, 355-373.

Friedman, D., Kazmerski, A., \& Cycowicz, Y.M. (1998). Effects of aging on the novelty P3 during attend and ignore oddball tasks. Psychophysiology, 35, 508-520.

Fröhlich, A. (1995). Basale stimulatie. In A. Fröhlich (Ed.), Basale stimulatie. Leuven-Apeldoorn.

Grunwald, T., Boutros, N.N., Pezer, N., von Oertzen, J., Fernandez, G., Schaller, C., \& Elger, C.E. (2003). Neuronal substrates of sensory gating within the human brain. Biological Psychiatry, 53, 511-519.

Gumenyuk, V., Korzyukov, O., Alho, K., Escera, C., \& Näätänen, R. (2004). Effects of auditory distraction on electrophysiological brain activity and performance in children aged 8-13 years. Psychophysiology, 41, 30-36.

Gumenyuk, V., Korzyukov, O., Alho, K., Escera, C., Schröger, E., Ilmoniemi, R.J., \& Näätänen R. (2001). Brain activity index of distractibility in normal school-age children. Neuroscience Letters, 314, 147-150.

Hamm, J.P., Johnson, B.W., \& Kirk, I.J. (2002). Comparison of the N300 and N400 ERPs to picture stimuli in congruent and incongruent contexts. Clinical Neurophysiology, 113, 1339-1350.

Hari, R., Kaila, K., Katila, T., Tuomisto, T., \& Varpula, T. (1982). Interstimulus interval dependence of the auditory vertex response and its magnetic counterpart: Implications for their neural generation. Electroencephalography and Clinical Neurophysiology, 54, 561-569.

Hetrick, W.P., Sandman, C.A., Bunney, W.E., Jin, Y., Potkin, S.G. \& White, M.H. (1996). Gender differences in gating of the auditory evoked potential in normal subjects. Biological Psychiatry, 39, 51-58. 
Hogg, J., Cavet, J., Lambe, L., \& Smeddle, M. (2001). The use of 'Snoezelen' as multisensory stimulation with people with intellectual disabilities: A review of the research. Research in Developmental Disabilities, 22, 353-372.

Hogg, J., Juhlberg, K., \& Lambe, L. (2007). Policy, service pathways and mortality: A 10-year longitudinal study of people with profound intellectual and multiple disabilities. Journal of Intellectual disability Research, 51, 366-376.

Holcomb, P.J., \& M cPherson, W.B. (1994). Event-related brain potentials reflect semantic priming in object decision task. Brain and Cognition, 24, 259-276.

Jeon, Y.W., \& Polich, J. (2001). P3a from a passive visual stimulus task. Clinical Neurophysiology, 112, $2202-$ 2208.

Johnson, M.R., Wilhelm, C., Eisert, D., \& Halperin-Philips, D.L. (2001). Assessment of children with motor impairments. In: R.J. Simeonsson \& S.L. Rosenthal (Eds.), Psychological and developmental assessment. New-York, Guilford Press, pp. 205-224.

Johnstone, S.J., Barry, R.J., Anderson, J.W., \& Coyle, S.F. (1996). Age-related changes in child and adolescent event-related potential component morphology, amplitude and latency to standard and target stimuli in an auditory oddball task. International J ournal of Psychophysiology, 24, 223-238.

Jonkman, L.M., Lansbergen, M., \& Stauder, J.E.A. (2003). Developmental differences in behavioral and event-related brain responses associated with response preparation and inhibition in a go/nogo task. Psychophysiology, 40, 752-761.

Joutsiniemi, S.L., Ilvonen, T., Sinkkonen, J., Huotilainen, M., Tervaniemi, M., Lehtokoski, A., Rinne, T., \& Näätänen, R. (1998). The mismatch negativity for duration decrement of auditory stimuli in healthy subjects. Electroencephalography and Clinical Neurophysiology, 108, 154-159.

Judd, L.L., M cAdams, L., Budnick, B., \& Braff, D.L. (1992). Sensory gating deficits in schizophrenia: New results. American Journal of Psychiatry., 149, 488-493.

Kane, N.M., Curry, S.H., Butler, S.R. \& Cummins, B.H. (1993). Electroencephalogical indicators of awakening from coma. Lancet, 341, 13.

Katoff, L.S., Reuter, J., \& Dunn, V. (1980). The Kent Infant Development Scale manual. Kent, OH, Kent Developmental M etrics.

Kemner, C., Verbaten, M.N., Cuperus, J.M., Camfferman, G., \& van Engeland, H. (1995). Auditory eventrelated brain potentials in autistic children and three different control groups. Biological Psychiatry, 38, 150-165.

Kisley, M.A., Polk, S.D., Ross, R.G., Levisohn, P.M ., \& Freedman, R. (2003). Early postnatal development of sensory gating. Neuroreport, 14, 693-697.

Klingberg, T., Forssberg, H., \& Westerberg, H. (2001). Increased brain activity in frontal and parietal cortex underlies the development of visuospatial working memory capacity during childhood. Journal of Cognitive Neuroscience, 14, 1-10.

Knight, R.T. (1984). Decreased response to novel stimuli after prefrontal lesions in man. Electroencephalography and Clinical Neurophysiology, 59, 9-20.

Knight, R.T., Grabowecky, M.F., \& Scabini, D. (1995). Role of human prefrontal cortex in attentional control. In: H.H. Jasper, S. Goldman-Rakic, S, Riggio (Eds.), Epilepsy and the functional anatomy of the frontal lobe. Raven Press, New-York, pp. 21-36.

Knight, R.T., \& Nakada, T. (1998). Cortico-limbic circuits and novelty: A review of EEG and blood flow data. Reviews in the Neurosciences, 9, 57-70.

Knight, R.T., Staines, W.R., Swick, D., \& Chao, L.L. (1999). Prefrontal cortex regulates inhibition and excitation in distributed neural networks. Acta Psychologia (Amsterdam), 101, 159-178. 
Kok, A. (1986). Effects of degradation of visual stimulation on components of the event-related potential (ERP) in go/nogo reaction tasks. Biological Psychology, 2, 21-38.

Kurtzberg, D., Vaughan, H.G., Kreuzer, J.A., \& Fliegler, K.Z. (1995). Developmental studies and clinical application of mismatch negativity: problems and prospects. Ear Hear, 16,105-117.

Kutas, M., \& Dale, A. (1997). Electrical and magnetic readings of mental functions. In M.D. Rugg (Ed.), Cognitive Neuroscience. Hove, East Sussex, Psychology press, pp.197-242.

Lang, P.J., Bradley, M .M ., \& Cuthbert, B.N. (1999). International affective picture system (IAPS): Instruction manual and affective ratings. The centre for research in psychophysiology, University of Florida.

Määttä, S., Saavalainen, P., Könönen, M., Pääkkönen, A., Muraja-Murro, A., \& Partanen, J. (2005). Processing of highly novel auditory events in children and adults: An event-related potential study. Neuroreport, 16, 1443-1446.

Maes, B., Lambrechts, G., Hostyn, I., \& Petry, K. (2007). Quality-enhancing interventions for people with profound intellectual and multiple disabilities: A review of the empirical research literature. Journal of Intellectual Developmental Disability, 32, 163-178.

Marshall, P.J., Bar-Haim, Y., \& Fox, N.A. (2004). The development of P50 suppression in the auditory eventrelated potential. International J ournal of Psychophysiology, 51, 135-141.

M cCarthy, G., \& Wood, C.C. (1985). Scalp distributions of event-related potentials: Unambiguity associated with analysis of variance models. Electroencephalography and Clinical Neurophysiology, 62, 203-208.

McCulloch, D.L., Sludden, P.A., McKeown, K., \& Kerr, A (1996). Vision care requirements among intellectually disabled adults: A residence-based pilot study. Journal of Intellectual Disability Research, 40, 140-150.

M euwese-Jongejeugd, A., Vink, M., Zanten, van, B., Verschuure, H., Eichhorn, E., Koopman, D., Bernsen, R., \& Evenhuis, H. (2006). Prevalence of hearing loss in 1598 adults with an intellectual disability: Crosssectional population based study. International journal of Audiology, 45, 660-669.

Moxon, K.A., Gerhardt, G.A., Gulinello, M., \& Adler, L.E. (2003). Inhibitory control of sensory gating in a computer model of the CA3 region of the hippocampus. Biological Cybernetics, 88, 247-264.

M yles-Worsley, M., Coon, H., Byerley, W., Waldo, M., Young, D., \& Freedman, R. (1996). Developmental and genetic influences on the P50 sensory gating phenotype. Biological Psychiatry, 39, 289-295.

Nelson, C.A., Thomas, K.M., Haan, de, M., \& Wewerka, S.S. (1998). Delayed recognition memory in infants and adults as revealed by event-related potentials. International Journal of Psychophysiology, 29, 145165.

Oades, R.D., Dittmann-Balcar, A., \& Zerbin, D. (1997). Development and topography of auditory eventrelated potentials (ERPs): Mismatch and processing negativity in individuals 8-22 years of age. Psychophysiology, 34, 677-693.

O'Reilly, G., \& Carr, A. (2007). Evaluating intelligence across the life-span: Integrating theory, research and measurement. In A. Carr, G. O'Reilly, P. Noonan Walsh, \& J. McEvoy (Eds.), The handbook of intellectual disability and clinical psychology practice. Hove: Routledge.

Paetau, R., Ahonen, A., Salonen, O., \& Sams, M. (1995). Auditory evoked magnetic fields to tones and pseudowords in healthy children and adults. Journal of Clinical Neurophysiology, 12, 177-185.

Pekkonen, E., Rinne, T., \& Näätänen, R. (1995). Variability and replicability of the mismatch negativity. Electroencephalography and Clinical Neurophysiology, 96, 546-554.

Pfefferbaum, A., Ford, J.M., Weller, B.J., \& Kopell, B.S. (1985). ERPs to response production and inhibition. Electroencephalography and Clinical Neurophysiology, 60, 423-434.

Polich, J. (1989). P300 from a passive auditory paradigm. Electroencephalography and Clinical Neurophysiology, 7, 312-320. 
Polich, J. (2007). Updating P300: An integrative theory of P3a and P3b. Clinical Neurophysiology, 118, 2128-2148.

Polich, J., \& Starr, A. (1984). Evoked potentials in aging. In: M.L. Albert (Ed.), Clinical Neurology of Aging. Oxford University Press, pp. 149-176.

Räikkönen, K., Birkás, E., Horváth, J., Gervai, J., \& Winkler, I. (2003). Test-retest reliability of auditory ERP components in healthy 6-year-old children. NeuroReport, 14, 2121-2124.

Rasco, L., Skinner, R.D., \& Garcia-Rill, E. (2000). Effect of age on sensory gating of the sleep statedependent P1/P50 midlatency auditory evoked potential. Sleep Research Online, 3, 97-105.

Raven, J.C., Court, J.H., \& Raven, J. (1983). M anual for Raven's progressive matrices and vocabulary scales. H.K. Lewis \& Co. LTD, London.

Russell, D.J., Rosenbaum, P.L., Gowland, C., Hardy, S., Lane, M., \& Plews, N., M cGavin, H., Cadman, D., \& Jarvis, S. (1993). Gross Motor Function Measure: A Measure of Gross Motor Function in Cerebral Palsy. Hamilton, Ontario, Canada, M cM aster University.

Schendan, H.E., \& Kutas, M. (2002). Neurophysiological evidence of two processing times for visual object identification. Neuropsychologia, 40, 931-945.

Segalowitz, S.J., \& Barnes, K.L. (1993). The reliability of ERP components in the auditory oddball paradigm. Psychophysiology, 30, 451-459.

Sitnikova, T., West, W.C., Kuperberg, G.R., \& Holcomb, P.J. (2006). The neural organization of semantic memory: electrophysiological activity suggests feature-based segregation. Biologial Psychology, 71, 326-340.

Smith, D.A., Boutros, N.N., \& Schwarzkopf, S.B. (1994). Reliability of P50 auditory event-related potential indices of sensory gating. Psychophysiology, 31, 495-502.

Smulders, F.T., Kenemans, J.L., \& Kok, A. (1994). A comparison of different methods for estimating singletrial P300 latencies. Electroencephalography and Clinical Neurophysiology, 92,107-114.

Sokolov, E.N. (1963). Higher nervous functions: The orienting reflex. Annual Review of Physiology, 25, 545580.

Solot, C.B. (1998). Promoting function: Communication and feeding. In: J.P. Dormans, \& L. Pellegrino (Eds.), Caring for children with cerebral palsy. Baltimore, Paul H. Brookes, pp. 347-370.

Squires, N.K., Squires, K.C., \& Hillyard, S.A. (1975). Two varieties of long-latency positive waves evoked by unpredictable auditory stimuli in man. Electroencephalography and Clinical Neurophysiology, 38, 387401.

Stauder, J.E.A., Brinkman, M.J.R., \& Curfs, L.M.G. (2002). M ulti-modal P300 deflation of event-related brain activity in Prader-Willi syndrome. Neuroscience Letters, 327, 99-102

Stauder, J.E.A., van der Molen, M.W., \& Molenaar, P.C.M. (2003). Age, intelligence and event-reltated brain potentials during late childhood: A longitudinal study. Intelligence, 31, 257-274.

Stauder, J.E.A., Smeets, E.E.J., van Mil, S.G.M., \& Curfs, L.G.M. (2006). The development of visual and auditory processing in Rett syndrome: An ERP study. Brain \& Development, 28, 487-494.

Thomas, K.M., \& Nelson, C.A. (1996). Age-related changes in the electrophysiological response to visual stimulus novelty: A topographical approach. Electroencephalography and Clinical Neurophysiology, 98, 294-308.

Van den Broek, E.G.C., Janssen, C.G.C., van Ramshorst, T., \& Deen, L. (2006). Visual impairments in people with severe and profound multiple disabilities: An inventory of visual functioning. Journal of Intellectual Disability Research, 50, 470-475.

Van der Stelt, O., Geesken, R., Gunning, W.B., Snel, J., \& Kok, A. (1998). P3 scalp topography to target and novel visual stimuli in children of alcoholics. Alcohol, 15, 119-136. 
Van Splunder, J., Stilma, J.S., Bernsen, R.M .D., \& Evenhuis, H.M. (2006). Prevalence of visual impairment in adults with intellectual disabilities in the Netherlands: Cross-sectional study. Eye, 20, 1004-1010.

Verhulst, C., van der Ende, J., \& Koot, H.M . (1996). Handleiding voor de CBCL/4-18. Erasmus Universiteit Rotterdam, Rotterdam.

Vlaskamp, C. (2006). Interdisciplinary assessment of people with profound intellectual and multiple disabilities. In: J. Hogg, \& A. Langa (Eds.), Assessing adults with intellectual disability: A service provider's guide. Oxford, Blackwell publishers, pp.39-51.

Weate, S.J., Moore, J.L., \& Drake, M.E.(1995). Effect of frontal and temporal seizure foci on P50 auditory evoked potentials. Clinical Electroencephalography, 26, 214-218.

Weisser, R., Weisbrod, M., Roehrig, M., Rupp, A., Schroeder, J., \& Scherg, M. (2001). Is frontal lobe involved in the generation of auditory evoked P50? Neuroreport, 12, 3303-3307.

Wetzel, N., \& Schröger, E. (2007). M odulation of involuntary attention by the duration of novel and pitch deviant sounds in children and adolescents. Biological Psychology, 75, 24-31.

Wetzel, N., Widmann, A., Berti, S., \& Schröger, E. (2006). The development of involuntary and voluntary attention from childhood to adulthood: A combined behavioral and event-related potential study. Clinical Neurophysiology, 117, 2191-2203.

White, P.M., Kanazawa, A., \& Yee, C.M. (2005). Gender and suppression of mid-latency ERP components during stress. Psychophysiology, 42, 720-725.

Wijnen, V.J.M., van Boxtel, G.J.M., Eilander, H.J., \& de Gelder, B. (2007). Mismatch negativity predicts recovery from the vegetative state. Clinical Neurophysiology, 118, 597-605.

Woodhouse, J.M., Griffiths, C., \& Gedling, A. (2000). The prevalence of ocular defects and the provision of eye care in adults with learning disabilities living in the community. Opthalmic and Physiological Optics, 20, 79-89.

World Health Organization (1980). The international classification of impairments, disabilities, and handicaps (ICIDH). Geneva, WHO.

World Health Organization (1992). The ICD-10 classification of mental and behavioural disorders: Clinical descriptions and diagnostic guidelines. Geneva, WHO.

World Health Organization (1993).The ICD-10 classification of mental and behavioural disorders. Diagnostic criteria for research. Geneva, WHO.

World Health Organization (1996). Multiaxal classification of child and adolescent psychiatric disorders: The ICD 10 classification of mental and behavioural disorders in children and adolescents. Cambridge, Cambridge University Press.

World Health Organization (2001). The International Classification of Functioning, Disability and Health (ICF). Geneva, WHO.

Zenker, F., \& Barajas, J.J. (1999). Auditory P300 development from an active, passive and single-tone paradigms. International Journal of Psychophysiology, 33, 99-111.

Zijlstra, H.P., \& Vlaskamp, C. (2005). Leisure provision for persons with profound intellectual and multiple disabilities: Quality time or killing time? Journal of Intellectual Disability Research, 49, 434-438.

Zouridakis, G., \& Boutros, N.N. (1992). Stimulus parameter effects on the P50 evoked response. Biological Psychiatry, 32, 839-841. 



\section{Dankwoord}

Promoveren doe je niet alleen. Met het einde van het promotietraject in zicht wil ik graag een aantal mensen bedanken voor alle steun, hulp en adviezen die ik de afgelopen jaren van hen heb mogen ontvangen.

In eerste instantie ben ik zeer veel dank verschuldigd aan Chris Zaad, nu met de vut, maar indertijd als eindverantwoordelijk behandelaar verbonden aan SWZ Zonhove, een zorginstelling voor meervoudig gehandicapten te Son. Vanuit gedrevenheid en visie heeft hij de uitzonderlijke stap genomen om vanuit de praktijk de universiteit te benaderen met het verzoek onderzoek te verrichten bij ernstig meervoudig gehandicapte kinderen. Vervolgens heeft Chris er niet alleen voor gezorgd dat SWZ Zonhove de helft van mijn promotieonderzoek heeft gefinancierd, hij heeft ook een belangrijke rol gespeeld bij de uiteindelijke onderzoeksopzet.

Verder heb ik natuurlijk ook veel te danken aan SWZ Zonhove zelf, zonder hun financiële steun zou dit hele onderzoek niet mogelijk zijn geweest. Andere werknemers van SWZ Zonhove die ik zeer erkentelijk ben, zijn Evelyne Schuivens, GZ-psycholoog. Zj is nauw betrokken geweest bij het werven van de proefkinderen, en de hele organisatie rondom de EEG-metingen. Daarnaast heeft zij door de wijze waarop ze de individuele onderzoeksresultaten van elk gemeten ernstig meervoudig gehandicapt kind heeft overgebracht aan de ouders, bij hen veel draagkracht gecreëerd voor mogelijk toekomstig vervolgonderzoek. Vervolgens John van Dijen, directeur van de Emiliusschool, een mytyl-, en tyltylschool op het terrein van SWZ Zonhove, voor het regelen van onderzoeksruimten in zijn school. Dan Minette van der Pas en haar collega's voor hun hulp bij het samenstellen van de onderzoeksgroep. En tenslotte de mensen van de Vroegbegeleiding, de activiteitenbegeleiders, en de woonbegeleiders voor al hun praktische ondersteuning en flexibiliteit tijdens de metingen.

Ook aan de Universiteit Maastricht (UM ) zijn er een aantal mensen aan wie ik veel te danken heb. Op de allereerste plaats is dat Hans Stauder, copromotor en universitair hoofddocent aan de UM. Hij was mijn rots in de branding. Een betere begeleider en copromotor is volgens mij niet denkbaar. Hans was er altijd als ik hem 
nodig had. Met zijn grote kennis, creativiteit, en kalmte heeft hij mij door heel wat moeilijke perioden geloodst, en mij weer vlot getrokken als ik was vastgelopen. Typerend is zijn grenzeloos optimistische ("Het glas is halfvol") levenshouding. Zonder Hans had ik de eindstreep nooit gehaald. Dan Paul Curfs, hoogleraar aan de UM en eerste promotor. Zijn bemoedigende telefoontjes en mailtjes hebben mij net dat duwtje in de rug gegeven om, ondanks een zeer drukke nieuwe baan, toch te blijven werken aan de losse eindjes van mijn proefschrift. Vervolgens de stagiaires Esther Coenen, Aggie Bonten, Marinke Reubzaet, en Brechje de Visser. Zonder hun tomeloze inzet was het onmogelijk geweest om ruim 100 basisschoolleerlingen en 15 ernstig meervoudig gehandicapte kinderen twee keer te meten. De Technische dienst van de UM voor alle technische ondersteuning en geduld bij het uitleggen van de procedures. Hierbij mag Ron Hellebrands niet onvermeld blijven. Ron heeft een grote bijdrage geleverd aan het ontwikkelen van het "trilapparaat", en vervolgens uitgepuzzeld hoe de somatosensorische taak in ERTS geprogrammeerd diende te worden. Dan Annemie Jeukens voor de altijd perfecte administratieve ondersteuning en al haar goede zorgen. Tenslotte mijn kamergenote Milene Bonte voor al haar praktische adviezen, morele ondersteuning en onze gezellige onderonsjes als nieuwbakken moeders.

Ook ben ik veel verschuldigd aan Jan de Moor, tweede promotor en hoogleraar Kinderrevalidatie aan de Radboud Universiteit te Nijmegen. Als niet-ERP specialist heeft Jan mij vanuit een andere invalshoek laten kijken naar mijn onderzoek. Ook heeft hij woord voor woord mijn teksten gelezen. M et zijn concrete aanwijzingen heeft hij er niet alleen voor gezorgd dat de teksten een stuk duidelijker zijn geworden, hij is er ook in geslaagd mij bewuster te laten schrijven. Ik vind het heel jammer dat hij pas in een zeer laat stadium bij het onderzoek betrokken is geworden.

Dit promotieonderzoek was ook niet mogelijk geweest zonder de hulp van de basisscholen St. Jozef te Elsloo, Don Bosco te Stein, en Dionysius te Schinnen, en van Mariendael te Arnhem, een school voor leerlingen met een lichamelijke, verstandelijke of meervoudige handicap. Ook ben ik de ouders en leerlingen zeer erkentelijk voor hun medewerking aan de EEG-metingen.

Tenslotte het thuisfront, Jan, Wiesje en Léonce. Aan hen is dit proefschrift opgedragen. Zonder hun steun en begrip had ik het nooit volgehouden. In de eerste plaats Jan die nooit heeft getwijfeld aan het slagen van deze onderneming, en mij altijd wist te motiveren toch de draad weer op te pakken. Ik ben mij ervan bewust dat hij de laatste maanden onevenredig veel is belast. Dan Wiesje, mijn oudste 
dochter en 7 jaar oud. Vooral zij heeft veel te lijden gehad van alle drukte rondom het promotietraject, de komst van een zusje en mijn nieuwe baan. Ondanks alles blijft ze onvoorstelbaar lief. En tenslotte Léonce, 21 maanden en mijn jongste dochter. Zij weet niet beter dan dat haar mama altijd heel erg druk is, en nooit tijd heeft om te spelen. Maar, betere tijden zijn in aantocht! 



\section{Curriculum Vitae}

Marjo Brinkman was born on December 9th, 1965, in Heerlen, the Netherlands. In 1984 she graduated at the Gymnasium of the Coriovallum College in Heerlen. From 1984 she studied to be a translator in Brussels, until she graduated in 1988. Hereafter she worked as an insurance sales representative. In 1997 she started studying Psychology at M aastricht University. During this study she also worked as a teaching assistant. In 2002 she graduated with a specialization in Biological Psychology. Her Master's thesis described an ERP study of attention and inhibition in people with Prader-Willi Syndrome. In 2003 she started her PhD-project at the department of Cognitive Neuroscience, section Biological Developmental Psychology, also at M aastricht University, that resulted in this PhD-thesis. Currently, she is supervising professionals specialized in coaching children with behavioural and/or psychiatric problems. 